CENTRO UNIVERSITÁRIO FEI

RENATA VIEIRA MUSOLINO

ANÁLISE DAS PRÁTICAS DE LOGÍSTICA REVERSA NA CADEIA DE SUPRIMENTOS DE MEDICAMENTOS NO ESTADO DE SÃO PAULO 
RENATA VIEIRA MUSOLINO

\begin{abstract}
ANÁLISE DAS PRÁTICAS DE LOGÍSTICA REVERSA NA CADEIA DE SUPRIMENTOS DE MEDICAMENTOS NO ESTADO DE SÃO PAULO
\end{abstract}

Dissertação de Mestrado apresentada ao Centro Universitário FEI para obtenção do título de Mestre em Engenharia Mecânica. Orientador: Prof. Dr. Wilson de Castro Hilsdorf 
Musolino, Renata Vieira.

ANÁLISE DAS PRÁTICAS DE LOGÍSTICA REVERSA NA CADEIA DE SUPRIMENTOS DE MEDICAMENTOS NO ESTADO

DE SÃO PAULO / Renata Vieira Musolino. São Bernardo do Campo, 2021.

$128 \mathrm{f}$. : il.

Dissertação - Centro Universitário FEl.

Orientador: Prof. Dr. Wilson de Castro Hilsdorf.

1. Sustentabilidade. 2. Logística reversa. 3. Green Supply Chain. 4. Industria farmacêutica. I. Hilsdorf, Wilson de Castro, orient. II. Título.

Elaborada pelo sistema de geração automática de ficha catalográfica da FEI com os dados fornecidos pelo(a) autor(a). 
centro

\section{APRESENTAÇÃO DE DISSERTAÇÃO}

Mestrado ATA DA BANCA EXAMINADORA

Aluno: Renata Vieira Musolino

Matrícula: 217318-5

Título do Trabalho: Análise das práticas de logística reversa na cadeia de suprimentos de medicamentos no estado de São Paulo.

Área de Concentração: Produção

Orientador: Prof. Dr. Wilson de Castro Hilsdorf

Data da realização da defesa: 08/04/2021

ORIGINAL ASSINADA

Avaliação da Banca Examinadora:

A candidata foi aprovada por unanimidade da banca, devendo proceder às correções solicitadas no prazo regimental.

São Bernardo do Campo, 08 / 04 / 2021

MEMBROS DA BANCA EXAMINADORA

Prof. Dr. Wilson de Castro Hilsdorf

Ass.:

Prof.a Dr.a Fernanda Cristina Vianna

Ass.:

Prof. Dr. Alexandre de Oliveira Aguiar

Ass::

A Banca Julgadora acima-assinada atribuiu ao aluno o seguinte resultado: APROVADO $\square$

REPROVADO $\square$

\section{YERSÃO EINAL DA DISSERTACÃO}

APROVO A VERSÃO FINAL DA DISSERTAČ̃̃ EM QUE FORAM INCLUUIDAS AS RECOMENDACÓES DA BANCA EXAMTNADORA
Aprovaçäo do Coordenador do Programa de Pós-graduaçăo

Prof. Dr. Rodrigo Magnabosco 


\section{AGRADECIMENTOS}

Esta pesquisa se concretizou graças ao apoio e suporte de inúmeras pessoas, entre elas meus familiares, amigos, professores e as empresas que abriram as portas para realização das entrevistas.

Agradecimento especial à minha família que é a base do que sou e principalmente ao meu marido Massafumi Kato, minha irmã Carla Musolino e sobrinhas pelo apoio e compreensão durante esses anos em que, muitas vezes, tive que abdicar do convívio familiar.

Meus sinceros agradecimentos ao meu orientador professor Dr. Wilson de Castro Hilsdorf que transmitiu seu conhecimento para a realização desta pesquisa. Estendendo também a valorosa contribuição das professoras Dra. Fernanda Cristina Vianna e Dra. Claudia Aparecida de Mattos no período da qualificação.

Aos meus colegas do curso de mestrado que compartilharam seus conhecimentos e tornaram esta jornada mais acessível. 


\section{RESUMO}

O tema sustentabilidade vem ganhando interesse entre a população, pesquisadores e as indústrias nas últimas décadas. O aumento desordenado da população, o aumento dos índices de poluição e a escassez de recursos naturais, bem como o seu mau uso, despertam para urgência do tema sustentabilidade, visando um melhor aproveitamento e preservação de recursos naturais. A Logística Reversa (LR) ganha destaque com intuito de diminuir a geração de resíduos e maximizar o reaproveitamento dos recursos. Para tal finalidade é necessário gerenciar os resíduos em consonância com a legislação vigente e preservação do meio ambiente. O avanço da medicina trouxe grandes benefícios à população com consequente aumento na produção de medicamentos e na quantidade disponível para comercialização, porém, os medicamentos, quando descartados incorretamente, podem contaminar a natureza, representando risco à vida humana, à fauna e à flora. O objetivo desta pesquisa é identificar as práticas da LR adotadas em diferentes segmentos da cadeia farmacêutica e compará-las aos artigos estudados e à legislação brasileira, destacando o papel dos atores da cadeia farmacêutica em relação ao consumidor final. A pesquisa foi realizada através de um estudo de caso único incorporado, baseado na cadeia farmacêutica e seus atores participantes, concentrando-se no Estado de São Paulo. Apesar de todos os atores da cadeia de suprimentos reconhecerem a importância da $L R$, é imprescindível a implementação do sistema de LR em um sentido mais amplo, visando o descarte adequado de medicamentos com ampla conscientização de todos os elos da cadeia e adequação às regulamentações governamentais que ainda é ambígua e complexa.

Palavras-chave: Sustentabilidade. Green supply chain. Closed-loop supply chain. Logística Reversa. Indústria farmacêutica. 


\begin{abstract}
In recent years, sustainability is gaining increasing interest among the population, researchers and industries. The diminishing of raw material, the disorganized increasing of population and the increasing levels of pollution drive sustainability as urgent, where the Reverse Logistic is part of it to diminish the waste generation and to improve the reuse of the resources. It is necessary to manage waste to be complied with government regulation and preserve the environment. The medical research has brought great benefits to the population with consequent increase in the medicines production and in the amount available for commercialization, but the medicines when discarded inappropriately may contaminate the nature, causing damages of human health and aquatic organisms. Thus, the aim of this research is to identify the reverse logistics practices adopted by pharmaceutical supply chain and compare to the articles and to Brazilian government regulation, emphasizing the pharmaceutical supply chain stakeholders role in post consumption with the consumers. The research will be carried out through an embedded single case study with stakeholders of pharmaceutical supply chain from São Paulo State. Although all stakeholders in pharmaceutical supply chain recognize the importance of reverse logistic, it is essential to implement the reverse logistic in a broader sense, aiming at the proper disposal of medicines with wide awareness of supply chain, being compliance with government regulations that are still ambiguous and complex
\end{abstract}

Key words: Sustainability. Green supply chain. Closed-loop supply chain. Reverse logistic. Pharmaceutical industry. 


\section{LISTA DE FIGURAS}

Figura 1 - Cadeia de suprimentos do setor de medicamentos .............................17

Figura 2 - CLSC dentro da sustentabilidade ...................................................... 19

Figura 3 - Fluxo genérico da cadeia direta e reversa ..........................................20

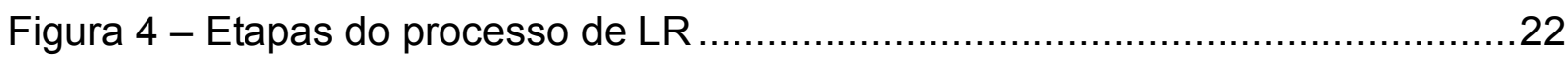

Figura 5 - Classificação de Resíduos Sólidos de Serviço de Saúde (RSS) …..........34

Figura 6 - Normas e legislações estudadas na linha do tempo ................................37

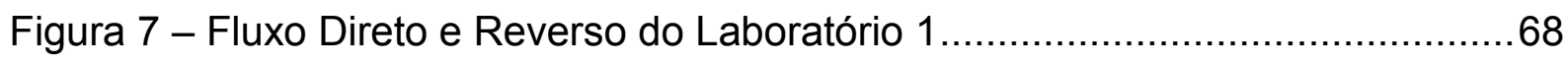

Figura 8 - Fluxo Direto e Reverso Laboratório 2 .................................................. 69

Figura 9 - Fluxo Direto e Reverso Laboratório 3 ………..................................... 70

Figura 10 - Fluxo Direto e Reverso do Distribuidor 1 .......................................... 71

Figura 11 - Fluxo Direto e Reverso do Distribuidor 2 …...................................... 72

Figura 12 - Fluxo direto e reverso da Farmácia 1 .................................................73

Figura 13 - Fluxo direto e reverso da Farmácia 2 .............................................. 74

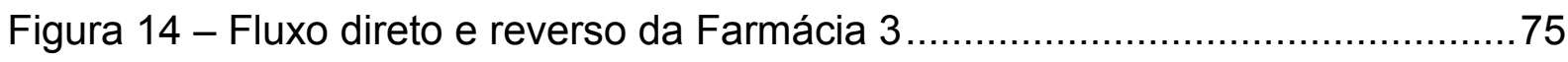

Figura 15 - Fluxo direto e reverso do Hospital 1 ................................................. 76

Figura 16 - Fluxo direto e reverso do Hospital 2 …...............................................77 


\section{LISTA DE TABELAS}

Tabela 1 - Artigos LR na indústria farmacêutica e/ou sobre descarte de

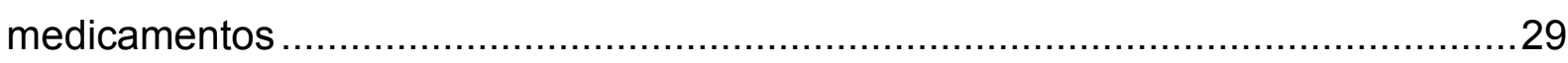

Tabela 2 - Resumo da legislação sobre disposição de medicamentos ....................36

Tabela 3 - Categorias da LR com base nos artigos e normas .................................38

Tabela 4 - Protocolo para levantamento de dados ..................................................4 43

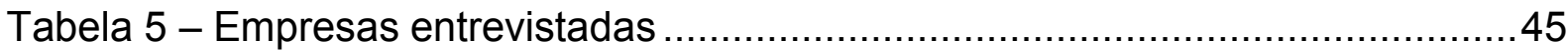

Tabela 6 - Tabela resumo da pesquisa em campo.............................................53 


\section{LISTA DE ABREVIATURAS E SIGLAS}

3PL

Third-party logistic / fornecedores terceiros

ABNT

Associação Brasileira de Normas Técnicas

ABRAFARMA Associação Brasileira das Redes de Farmácias e Drogarias

AMLURB $\quad$ Autoridade Municipal de Limpeza Urbana

ANVISA Agência Nacional de Vigilância Sanitária

BHS Brasil Health Service

BSI

British Standard Institution

CADRI Certificado de Movimentação de Resíduos de Interesse Ambiental

CBPF Certificado de Boas Práticas Farmacêuticas

CD Centro de Distribuição

CETESB Companhia Ambiental do Estado de São Paulo

CLSC Closed-Loop Supply Chain / Cadeia de Suprimentos de Circuito Fechado

CONAMA Conselho Nacional de Meio Ambiente

CRF Conselho Regional de Farmácia

CVS Centro de Vigilância Sanitária

EHS Environment, Health and Safety / Segurança, Saúde e Meio Ambiente

EOL $\quad$ End of life / Fim de vida

FDSR Ficha com Dados de Segurança de Resíduos Químicos

FEFO First expired, first Out / Primeiro a vencer, primeiro a sair

FISPQ Ficha de Informação de Segurança dos Produtos Químicos

GSCM Green Supply Chain Management / Gestão da Cadeia de Suprimentos Verde 
IBAMA Instituto Brasileiro do Meio Ambiente e dos Recursos Naturais Renováveis

INTERFARMA Associação da Indústria Farmacêutica de Pesquisa

ISO International Organization for Standardization

LCM Life Cycle Management / Gerenciamento do Ciclo de Vida

LR Logística Reversa

MTR Manifesto de Transporte de Resíduos

NBR Normas Brasileiras

NF Nota Fiscal

PGRSS Plano de Gerenciamento de Resíduos de Serviços de Saúde.

PNRS Política Nacional de Resíduos Sólidos

PROADI Programa de Apoio ao Desenvolvimento Institucional

PSC Pharmaceutical Supply Chain / Cadeia de Suprimentos Farmacêutica

RDC Resolução da Diretoria Colegiada

RFID Radio Frequency Identification / Identificação de rádio frequência

RSS Resíduos Sólidos de Serviços de Saúde

SABESP Companhia de Saneamento Básico do Estado de São Paulo

SAC Serviço de Atendimento ao Consumidor

SINDUSFARMA Sindicato da Indústria de Produtos Farmacêuticos

SUS Sistema Único de Saúde

TBL Triple Bottom Line / Tripé da sustentabilidade

TCLR Termo de Compromisso de LR

TI Tecnologia da informação

UBS Unidade Básica de Saúde

UTR Unidade de tratamento de resíduos 
1 INTRODUÇÃO

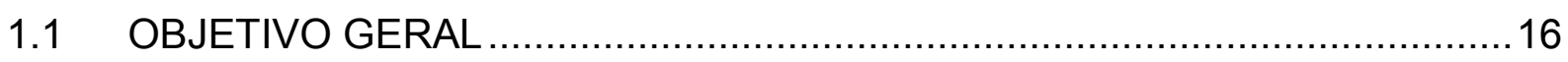

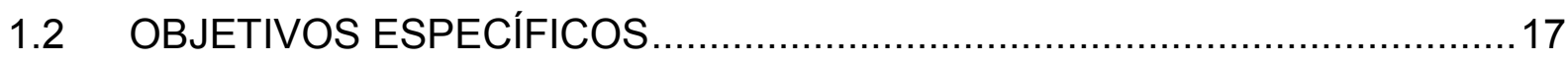

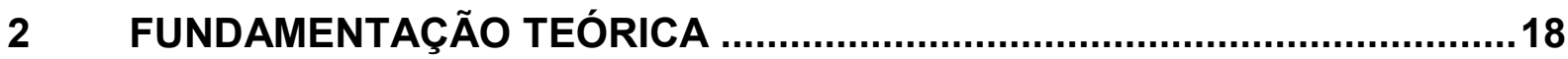

2.1 LOGÍSTICA REVERSA - INTRODUÇÃO

2.2 LOGÍSTICA REVERSA NA INDÚSTRIA FARMACÊUTICA ..........................24

2.3 LOGÍSTICA REVERSA NA INDÚSTRIA FARMACÊUTICA NO BRASIL .....30

2.4 NORMAS E REGULAMENTOS SOBRE GESTÃO DE RESÍDUOS DE MEDICAMENTOS NO BRASIL..............................................................33

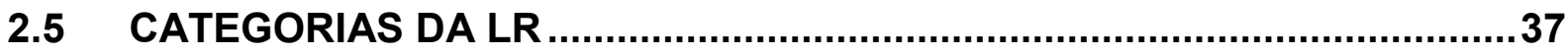

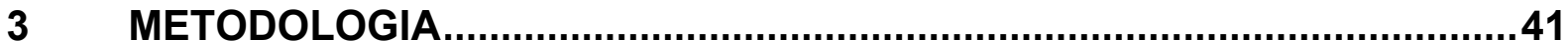

4 APRESENTAÇÃO DAS EMPRESAS ANALISADAS ..................................

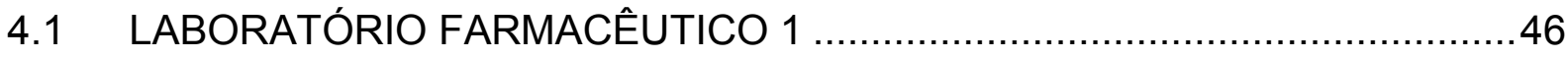

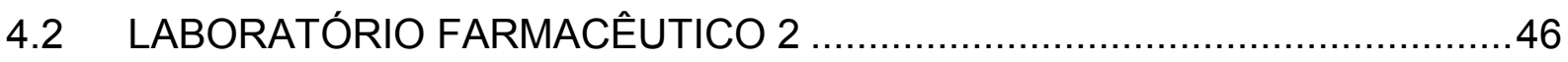

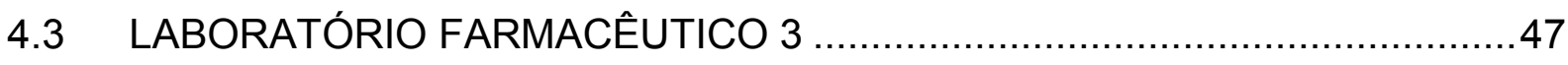

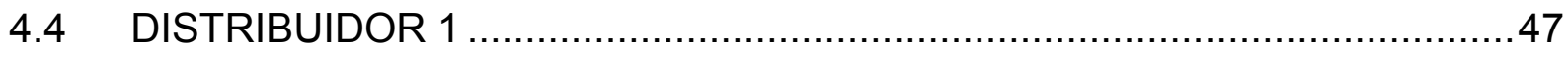

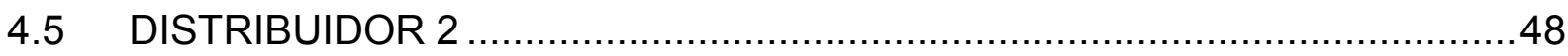

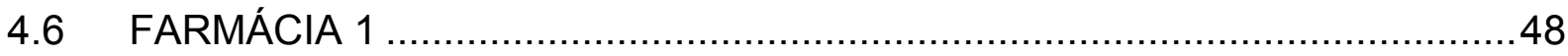

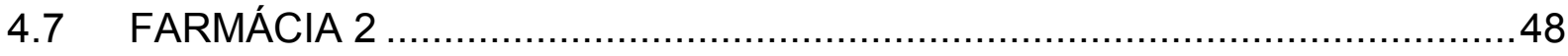

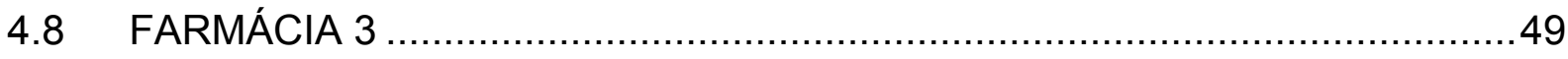

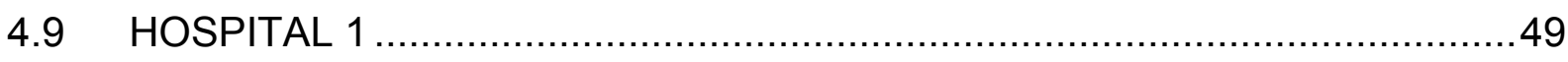

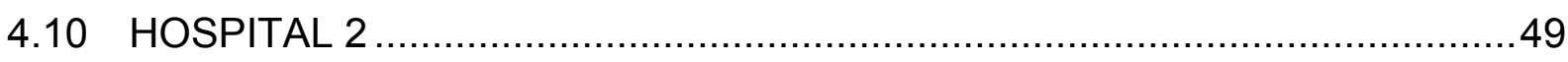

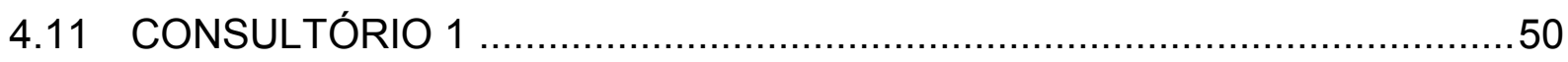

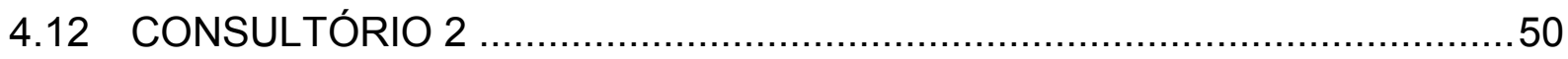

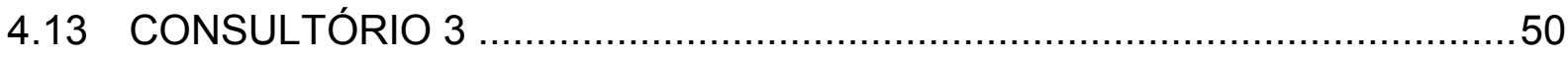

4.14 BHS - BRASIL HEALTH SERVICE (INTERFARMA) …...........................5

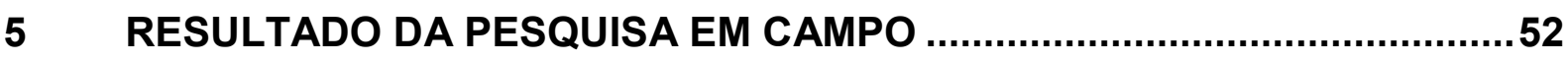

5.1 SUSTENTABILIDADE: IMPACTOS SOCIAIS E AMBIENTAIS (BLOCO A) ...54

5.2 REGULAMENTOS GOVERNAMENTAIS (BLOCO B)................................57

5.3 LR DE MEDICAMENTOS DOMICILIARES (BLOCO C) ….........................59

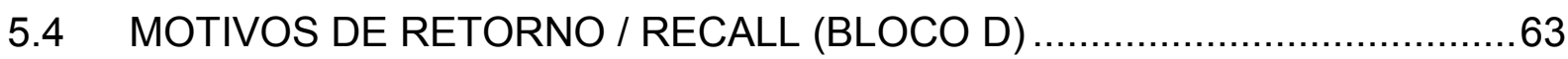

5.5 GESTÃO DO FLUXO DE DEVOLUÇÕES (BLOCO E) ................................67 
5.6 DEFINIÇÃO DE RESPONSABILIDADES / CUSTO DA LR (BLOCO F) ........78

5.7 3PL: UTILIZAÇÃO DE PRESTAÇÃO DE SERVIÇOS TERCEIRIZADOS NA LR (BLOCO G)

5.8 COLABORAÇÃO / COMPARTILHAMENTO DE INFORMAÇÕES $(\mathrm{BLOCO} \mathrm{H})$ 83

5.9 RASTREABILIDADE DE MEDICAMENTOS (BLOCO I) ............................ 86

5.10 CLASSIFICAÇÃO DE MEDICAMENTOS PARA DESCARTE (BLOCO J) .....87

5.11 MÉTODOS DE DESCARTE / DISPOSIÇÃO FINAL (BLOCO K) ...................90

5.12 REUTILIZAÇÃO DE MEDICAMENTOS DEVOLVIDOS NO PRAZO DE VALIDADE (BLOCO L) . 91

5.13 DEVOLUÇÃO DE MEDICAMENTOS / PONTOS DE COLETA (BLOCO M) ..93

5.14 CONSCIENTIZAÇÃO / CAMPANHA DE DIVULGAÇÃO (BLOCO N) ...........99

5.15 INCERTEZA: QUANTIDADE E QUALIDADE DE PRODUTOS RETORNADOS

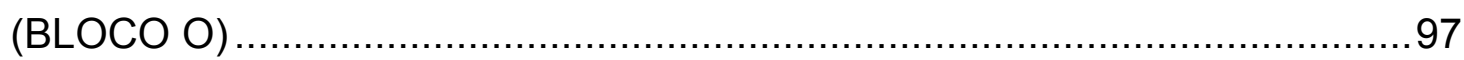

5.16 PRÁTICA LR: COMPLEXIDADE E DESAFIO (BLOCO P) .........................99

5.17 INDICADORES DE LR (BLOCO Q) ............................................ 101

6 ANÁLISE E DISCUSSÃO DOS RESULTADOS ........................................104

6.1 SUSTENTABILIDADE: IMPACTOS SOCIAIS E AMBIENTAIS ...................104

6.2 REGULAMENTOS GOVERNAMENTAIS ......................................... 105

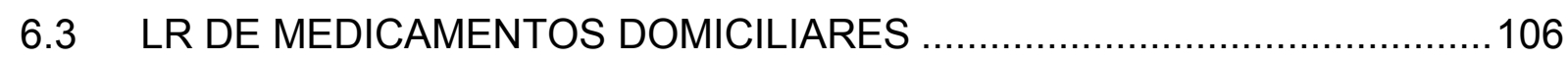

6.4 LR: MOTIVOS DE RETORNO / RECALL ........................................... 107

6.5 GESTÃO DO FLUXO DE DEVOLUÇÕES ........................................ 108

6.6 DEFINIÇÃO DE RESPONSABILIDADES / CUSTO DA LR ......................109

6.7 3PL: UTILIZAÇÃO DE FORNECEDORES TERCEIROS NA LR ................110

6.8 COMPARTILHAMENTO DE INFORMAÇÕES .....................................111

6.9 RASTREABILIDADE DOS MEDICAMENTOS .......................................111

6.10 CLASSIFICAÇÃO DE MEDICAMENTOS PARA DESCARTE ....................112

6.11 MÉTODOS DE DESCARTE / DISPOSIÇÃO FINAL .................................113

6.12 REUTILIZAÇÃO DE MEDICAMENTOS DEVOLVIDOS NO PRAZO DE

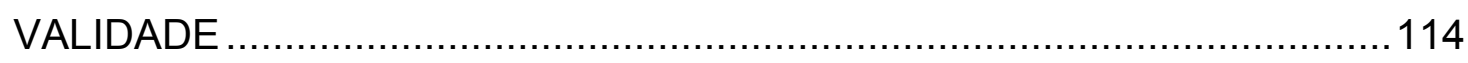

6.13 DEVOLUÇÃO DE MEDICAMENTOS / PONTOS DE COLETA ...................114

6.14 CONSCIENTIZAÇÃO / CAMPANHAS DE DIVULGAÇÃO .........................116

6.15 INCERTEZA: QUANTIDADE E QUALIDADE DOS PRODUTOS RETORNADOS 
6.16 PRÁTICA LR: COMPLEXIDADE E DESAFIO …...............................117

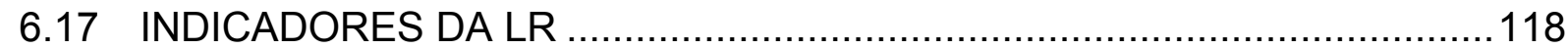

7 CONCLUSÃO E PESQUISAS FUTURAS ……........................................119

REFERÊNCIAS ............................................................................122 


\section{INTRODUÇÃO}

Nos últimos anos, a sustentabilidade tem sido um tema de grande importância na área acadêmica e nas indústrias. A escassez de recursos naturais bem como o seu mau uso e o aumento desordenado da população despertam para a urgência do tema sustentabilidade na perspectiva do tripé da sustentabilidade (TBL - Triple Bottom Line), ou seja, na integração dos aspectos ambientais, sociais e econômicos. A Gestão da Cadeia de Suprimentos Verde (GSCM - Green Supply Chain Management) vem ganhando uma importância crescente entre pesquisadores, principalmente pelo aumento da deterioração do meio ambiente, pela diminuição dos recursos naturais, pelo aumento da geração de resíduos e pelos altos índices de poluição mundial (FLEISCHMANN et al., 2001; SRIVASTAVA, 2007).

Srivastava (2007) destaca que uma das preocupações do GSCM é a logística reversa (LR), nela os produtos retornam do ponto de consumo para possíveis reciclagem, remanufatura ou disposição adequada (DOWTATSHAHI, 2000).

A LR, juntamente com a cadeia de suprimentos direta, formam a cadeia de suprimentos em circuito fechado (CLSC - Closed-Loop Supply Chain) (YE; ZHENHUA, 2014).

Planejar a cadeia de suprimentos pensando não somente na logística direta, mas englobando também a LR, pode ser uma vantagem competitiva em muitas áreas e demonstra uma preocupação com questões ambientais (GUIDE; WASSENHOVE, 2009).

As atividades da LR incluem a tomada de decisão sobre a disposição de cada peça do produto, podendo gerar etapas de desmontagem, remanufatura, reparo, reciclagem ou o descarte apropriado (GUIDE; WASSENHOVE, 2009; SOUZA, 2013). Em muitos casos, a remanufatura pode contribuir no aproveitamento de resíduos, reduzindo o espaço no aterro sanitário, podendo até mesmo ser mais rentável do que produzir a partir de matéria-prima (LEE; LAM, 2012).

$\mathrm{Na}$ indústria farmacêutica, os medicamentos não são como alguns produtos que, quando retornados, podem ser reparados, remanufaturados, reciclados ou doados; ao contrário, precisam ser destruídos, dando a correta disposição (KABIR, 2013). Existe a dificuldade de monitoramento para assegurar que os produtos farmacêuticos foram manipulados corretamente depois de expedidos e entregues aos clientes, o que inviabiliza o reaproveitamento dos medicamentos mesmo dentro 
da validade. Kabir (2013) observou que muitos medicamentos são altamente sensíveis à temperatura e uma temperatura de armazenagem incorreta pode alterar as propriedades do medicamento ou reduzir seu prazo de validade, tornando-o ineficaz ou prejudicial.

Os principais fatores que contribuem para a sobra de medicamentos são interrupção do tratamento do paciente, quantidade de medicamento na embalagem maior do que a prescrita pelo médico, amostras grátis distribuídas pelos laboratórios farmacêuticos como publicidade e a gestão inadequada do inventário de medicamentos pelas farmácias e outros estabelecimentos de saúde públicos ou privados (BELLAN et al., 2012).

Quando descartados incorretamente, os medicamentos causam inúmeros problemas na natureza, tais como: toxicidade e contaminação por substâncias químicas, fatores estes que representam um risco para a vida humana e organismos aquáticos (PEREIRA et al., 2017).

Luna e Viana (2017) salientaram que vários segmentos na indústria brasileira não desenvolveram um planejamento adequado na LR e identificaram como os laboratórios farmacêuticos estão posicionados em relação à Política Nacional dos Resíduos Sólidos (PNRS), Lei federal n 12.305/2010. Os mesmos autores em 2019 ampliaram a pesquisa para os representantes da indústria farmacêutica, redes de farmácias e o órgão regulador do setor e identificaram uma extensa cadeia de suprimentos não ativa no processo de LR, tendo apenas a preocupação com medicamentos vencidos nos pontos de vendas.

A cadeia de suprimentos farmacêutica - Pharmaceutical Supply Chain (PSC) é composta por diversas empresas, tais como, laboratórios farmacêuticos, distribuidores, farmácias, hospitais, postos de saúde e consumidor final. Luna e Viana (2017) recomendaram a necessidade de envolvimento de todos os elos da PSC, especialmente com as redes de farmácias e o poder público, a fim de que se aumente o escopo da pesquisa e sejam incluídas as visões de diversos componentes da cadeia de suprimentos. Existe também a necessidade de estudar $o$ envolvimento do consumidor final na cadeia, destacando o seu papel na redução de medicação desnecessária e descarte de medicamentos sem uso ou vencidos de modo adequado (XIE; BREEN, 2012). Campos et al. (2017) destacaram a necessidade de aprofundar a pesquisa para melhor entender o papel dos profissionais de hospitais e farmácias nos medicamentos não utilizados e salientam 
a importância da conscientização dos profissionais do PSC, bem como a ampliação dos estudos não só em países desenvolvidos, mas em nível global.

Narayana, Elias e Pati (2014) sugeriram que em futuras pesquisas sejam avaliados como os requisitos regulatórios podem melhorar as práticas da LR. Estudos comparando legislações e políticas restritivas que afetam o segmento farmacêutico sobre retornos de produtos seriam extremamente relevantes (CAMPOS et al., 2017).

Para que as indústrias de qualquer segmento se tornem mais sustentáveis, a responsabilidade de suas atividades deve ser expandida por toda a cadeia de suprimentos, integrando-as. Apenas poucas organizações se preocupam em desenvolver produtos que agridam menos o meio ambiente por sua própria iniciativa; em muitos casos, incorporam-se os requisitos ambientais por pressão social ou governamental (GLOVER et al., 2014; JORGENSEN, 2008; SOUZA, 2013).

Os requisitos regulatórios e pressões dos consumidores estão impulsionando as cadeias de suprimentos a pensarem mais no processo produtivo em relação a reduzir, reutilizar, retrabalhar, recondicionar, recuperar, reciclar, remanufatura, ou seja, na importância da LR (SRIVASTAVA, 2007).

Em vista da necessidade de se preservar os recursos naturais, é fundamental elaborar estratégias que impactem positivamente no meio ambiente, economia e sociedade. Dentro deste contexto, a pesquisa tem sua contribuição porque a geração de resíduos é uma realidade na cadeia produtiva na indústria farmacêutica, onde o descarte inadequado de medicamentos impõe riscos para a saúde humana e para o meio ambiente (CAMPOS et al., 2017; KONGAR et al., 2015; LUNA; VIANA, 2017; PEREIRA et al., 2017), e se propõe a contribuir com a prática da LR na cadeia de medicamentos, avaliando a legislação que está em constante mudança e o papel dos atores em relação ao consumidor final.

\subsection{OBJETIVO GERAL}

O objetivo desta pesquisa é analisar as práticas da logística reversa adotadas na cadeia de suprimentos de medicamentos, identificando as atuações e responsabilidades de cada ator da cadeia farmacêutica. 


\subsection{OBJETIVOS ESPECÍFICOS}

Os objetivos específicos desta pesquisa foram:

1. Identificar a participação dos laboratórios farmacêuticos, distribuidores, hospitais, farmácias, consultórios médicos nas práticas de LR e na conscientização do consumidor final.

2. Avaliar o conhecimento e o cumprimento das regulamentações sobre descarte de medicamentos na cadeia de suprimentos farmacêuticos.

A Figura 1 ilustra a cadeia de suprimentos do setor de medicamentos com os principais atores envolvidos, e os quadros em destaque mostram os atores que foram o foco da pesquisa.

Figura 1 - Cadeia de suprimentos do setor de medicamentos

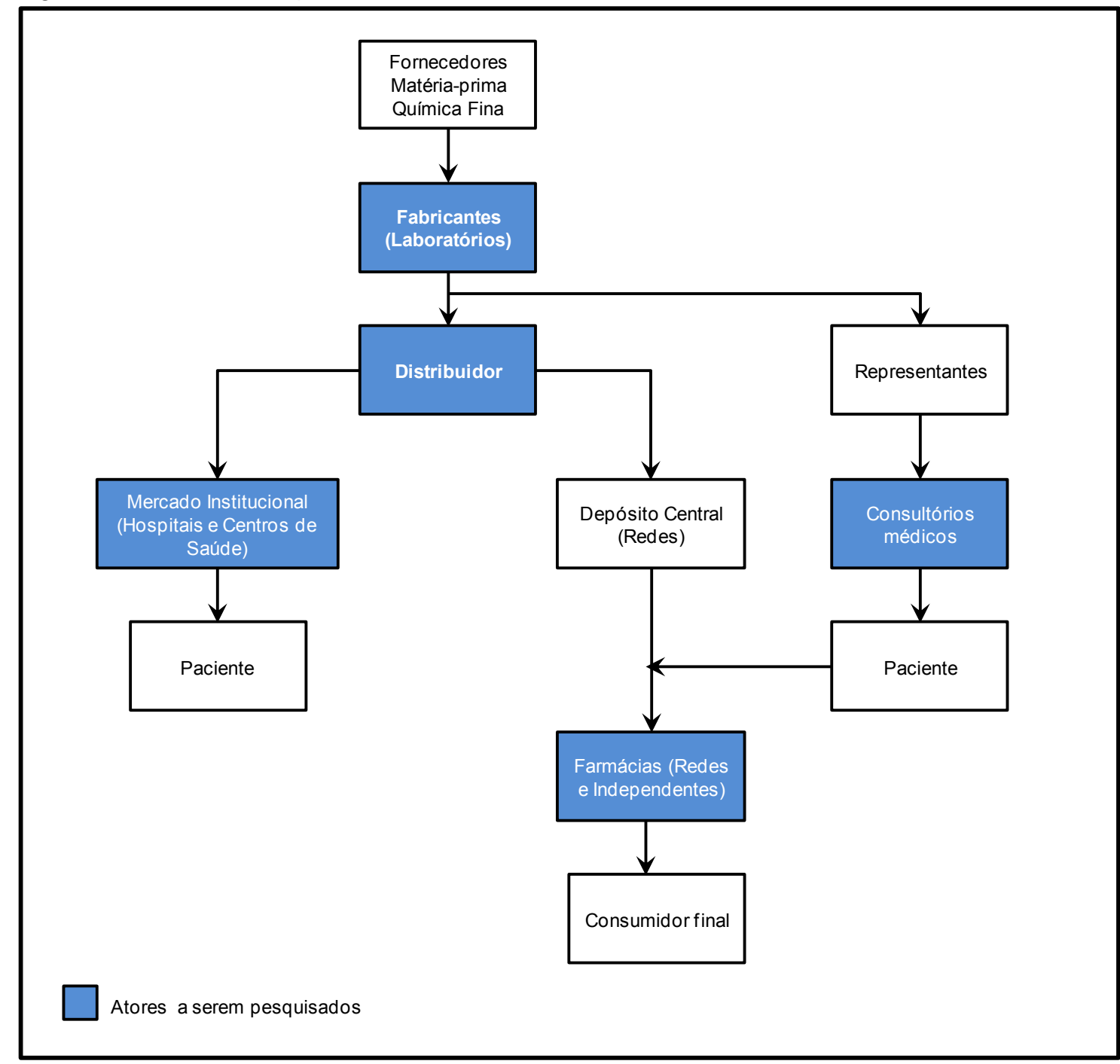

Fonte: Autor, baseado em Moori et al. (2005). 


\section{FUNDAMENTAÇÃO TEÓRICA}

A sustentabilidade se propõe a resolver questões complexas que envolvem fatores sociais, técnicos e legislativos, a fim de evitar a deterioração ambiental causada pela geração de resíduos, bem como minimizar sua geração ou até mesmo, potencializar o seu reaproveitamento (FLEISCHMANN et al., 2001; YE; ZHENHUA, 2014).

Na década de 90, iniciou-se uma mudança na cadeia de suprimentos, através da integração da gestão ambiental com as operações (SRIVASTAVA, 2007), surgindo o conceito do sistema de gerenciamento ambiental pela British Standard Institution (BSI) que foi o precursor para as normativas ISO 14000 - International Organization for Standardization. Neste contexto, o GSCM vem ganhando cada vez mais interesse entre os pesquisadores e gestores das operações (SRIVASTAVA, 2007). Dentro do conceito de sustentabilidade, GSCM é definido como:

Integração do pensamento ambiental no gerenciamento da cadeia de suprimentos, incluindo o design do produto, fornecimento e seleção de materiais, processos de fabricação, entrega do produto final aos consumidores, bem como o gerenciamento de fim de vida útil do produto (SRIVASTAVA, 2007, p. 54).

O foco principal do GSCM é melhorar a qualidade das estratégias de gerenciamento da cadeia de suprimentos aliado ao desempenho ambiental (SHOHAN et al., 2019).

A primeira menção de "circuito fechado" dentro do GSCM que surgiu com Clendenin (1997) demonstrou preocupação com a integração da cadeia de suprimentos e a reengenharia na LR como oportunidade de negócio. O conceito de "Closed-Loop Supply Chain" (CLSC) surgiu em 2001 (FLEISCHMANN et al., 2001), sendo que a LR representa o retorno neste circuito. Segundo Guide e Wassenhove (2009, p. 10) "CLSC é definida como o projeto, controle e operação de um sistema para maximizar a criação de valor ao longo de todo o ciclo de vida de um produto com recuperação dinâmica de volumes retornados ao longo do tempo".

\subsection{LOGÍSTICA REVERSA - INTRODUÇÃO}

Rogers e Tibben-Lembke (1999, p. 2) definiram Logística Reversa como: 
Um processo de planejamento, implementação e controle de fluxo eficiente e econômico de matérias-primas, inventário em processo, produtos acabados e informações relacionadas, desde o ponto de consumo até o ponto de origem, que tem o propósito de recuperar o seu valor ou efetuar o descarte adequado.

Uma gestão da cadeia de suprimentos com preocupações ambientais (GSCM) engloba tanto a cadeia direta de fornecedores quanto à $L R$, as quais formam o CLSC (NARAYANA; ELIAS; PATI, 2014) e a gestão dos resíduos gerados deve ser realizada de forma sustentável e de acordo com a legislação vigente. Toda esta rede está sob o guarda-chuva da sustentabilidade, conforme ilustrado na Figura 2.

Figura 2 - CLSC dentro da sustentabilidade

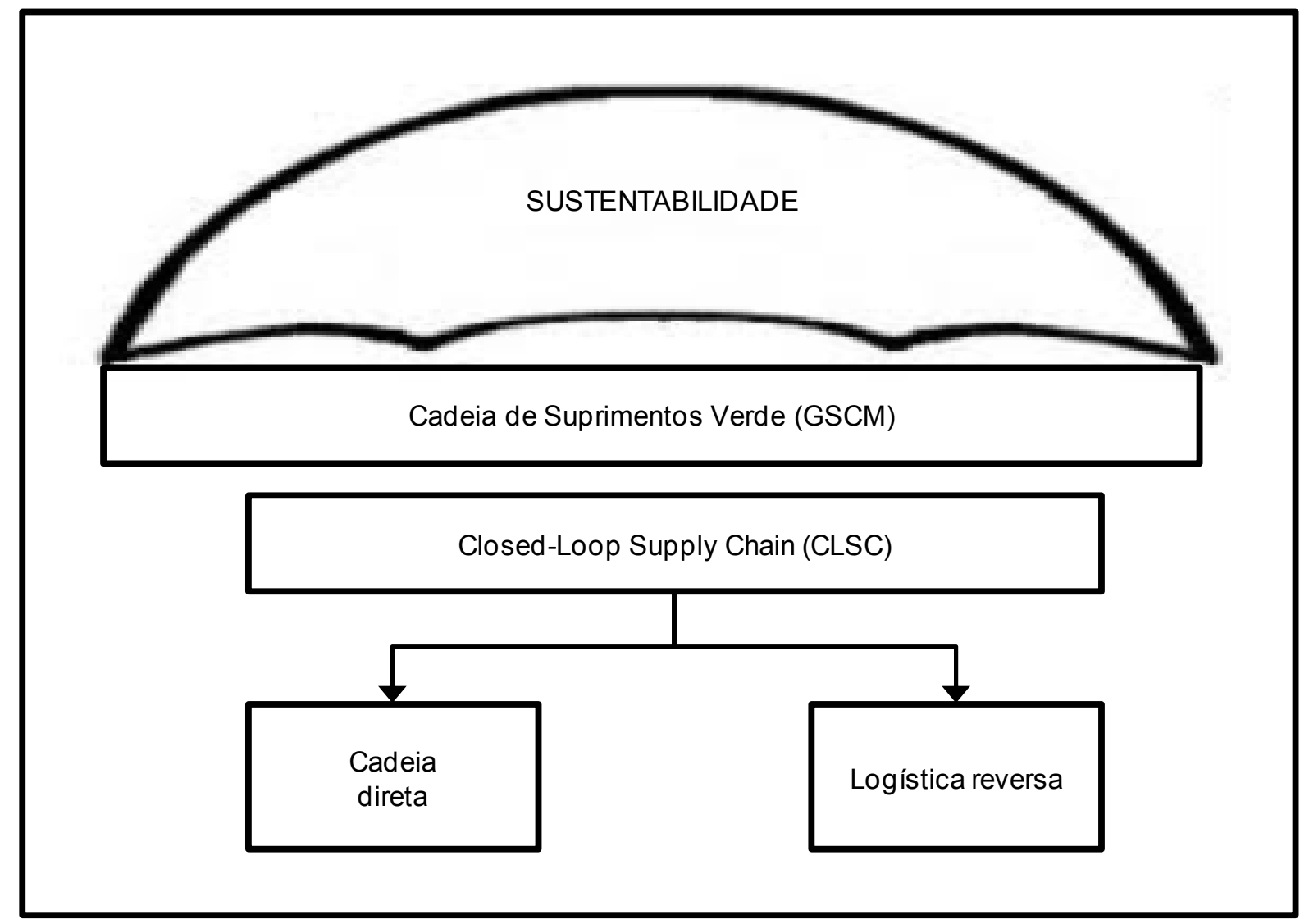

Fonte: Autor.

No detalhe, a Figura 3 mostra um fluxo genérico da cadeia direta e reversa elaborado por Tonanont et al. (2008). 
Figura 3 - Fluxo genérico da cadeia direta e reversa

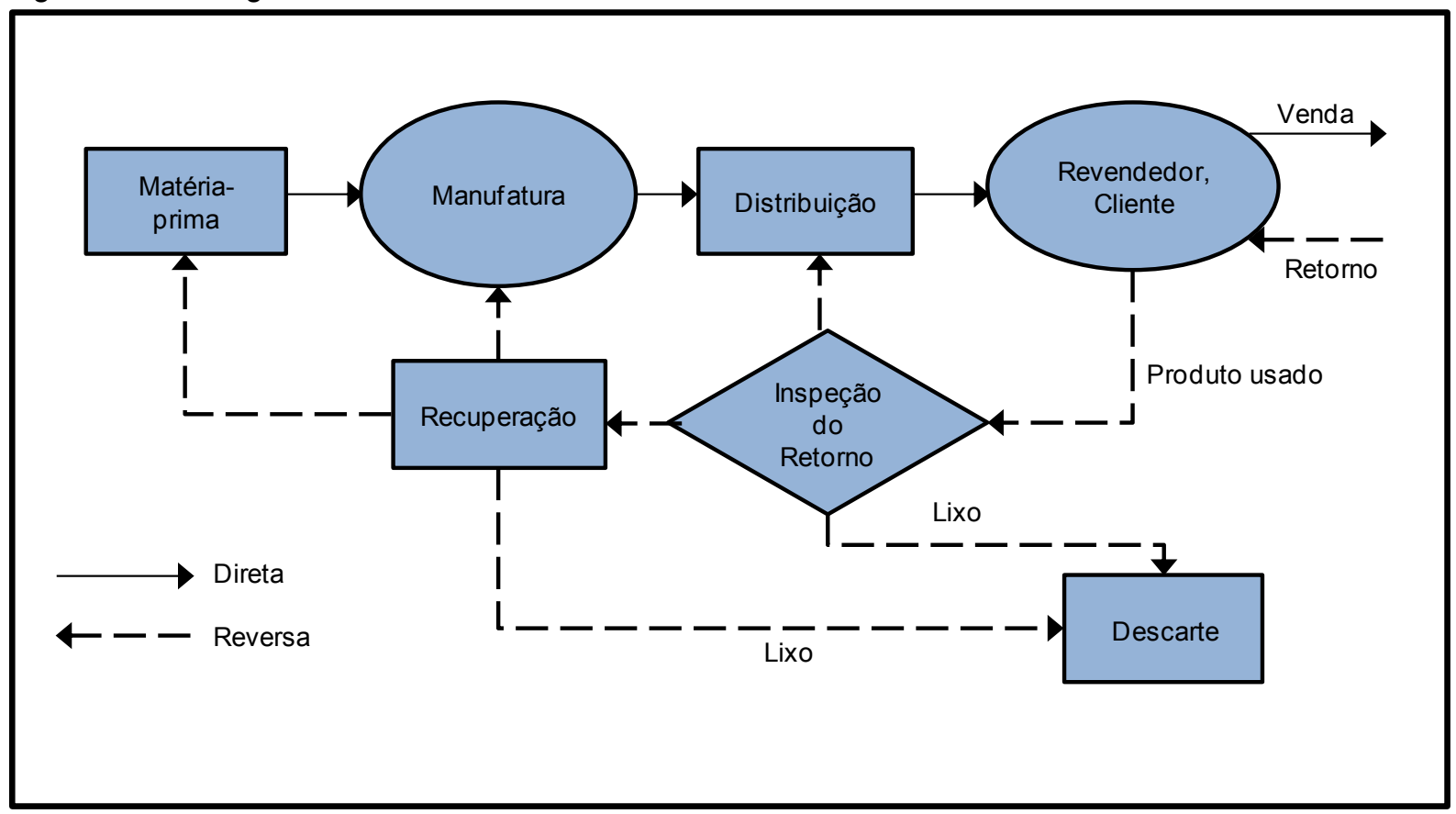

Fonte: Tonanont et al. (2008).

Já Govindan, Soleimani e Kannan (2015) apresentaram uma revisão abrangente da literatura, identificando as pesquisas realizadas em LR, CLSC, GSCM e sustentabilidade. Foram revisados 382 artigos publicados entre janeiro de 2007 a março de 2013 procurando identificar lacunas na literatura e identificar novas oportunidades de pesquisas na área.

Kainuma e Tawara (2006) incluíram reutilização e reciclagem ao longo do ciclo de vida de produtos e serviços, e propuseram uma abordagem "lean e verde" para avaliar o desempenho da cadeia de suprimentos do ponto de vista ambiental, demonstrando que o compartilhamento de informações ao longo da cadeia de suprimentos pode melhorar a gestão do estoque.

Jorgensen (2008) e Glover et al. (2014) consideraram que as empresas adotam iniciativas de gestão da cadeia de suprimentos verde em resposta aos regulamentos governamentais e pressões dos clientes. Já estudos de Shohan et al. (2019) mostraram que os fatores mais significativos para implementação do GSCM são a pressão e a vontade do fornecedor, mas o custo seria a principal barreira. Jayaram e Avittathur (2015) exemplificaram casos na Índia, onde empresas exigem que seus fornecedores cumpram normas ambientais. Kabir (2013) acrescentou que além das preocupações com o meio ambiente, a concorrência e o marketing, também impulsionam a LR. 
O retorno dos produtos manufaturados está muito ligado à estratégia do fabricante e a legislação vigente no país em um determinado setor produtivo (SOUZA, 2013). Dowlatshahi (2000) mencionou que a legislação mais vigorosa força as empresas a se tornarem mais responsáveis pela geração de resíduos e produto final, mesmo após a venda do produto.

A pesquisa de Farradia, Bon e Muharam (2019) destacou uma preocupação no desempenho econômico ligado às práticas do GSCM na indústria petroquímica da Indonésia, assim como Ismail et al. (2019) evidenciaram em sua pesquisa com fabricantes de produtos farmacêuticos na Jordânia, que as condutas do GSCM afetam o desempenho organizacional.

O desenvolvimento do produto com o foco no Gerenciamento do Ciclo de Vida (Life Cicle Management - LCM) deve ser pensado com objetivo de implementar um sistema de gestão ambiental que seja integrado com toda cadeia de fornecimento utilizando uma estratégia na indústria a fim de diminuir os impactos ambientais. Assim, muitas empresas incorporaram requisitos de sustentabilidade aos seus processos, selecionando fornecedores que estejam alinhados com essa política. Sob a perspectiva de ciclo de vida, isso resultaria em uma otimização da utilização de matérias-primas, menos transporte de materiais, menor consumo de energia com consequente diminuição na produção de material para descarte ou reutilização (JORGENSEN, 2008).

Muitos produtos industriais em fim de vida (EOL - End of life) apresentam risco ambiental potencial, como por exemplo, resíduos médicos, pesticidas, tintas, detergentes, etc (TSAI; HUNG, 2009). O que salienta a importância da LR deve ser considerada no desenvolvimento do produto aliado ao seu ciclo de vida, (CLSC) potencializando sua viabilidade econômica e reduzindo impactos ambientais (CAMPOS et al., 2017).

A LR envolve o manuseio e disposição de bens devolvidos do cliente, específico de cada tipo de produto (SKINNER; BRYANT; RICHEY, 2008). Geralmente, os processos LR incluem: autorização de retornos, transporte, auditoria, disposição do produto e criação de informações sobre os tipos de produtos que estão sendo retornados e de onde eles vieram (TREBILCOCK, 2001).

A LR é responsável pelo fluxo inverso de materiais com o objetivo de reutilizar, recondicionar, reciclar componentes que podem retornar ao mercado mais 
uma vez, através da sua transformação em novos produtos e também o descarte, dando a correta disposição (MISHRA; NAPIER, 2014).

A LR engloba as práticas de recuperação do produto que podem ser divididas em: reparar, renovar, remanufaturar, canibalizar, reciclar (THIERRY, 1995) e desmontar (TALEB; GUPTA, 1997). Todos os processos de disposição do produto retornado citados estão resumidos na Figura 4, incluindo incineração e aterro sanitário.

Figura 4 - Etapas do processo de LR

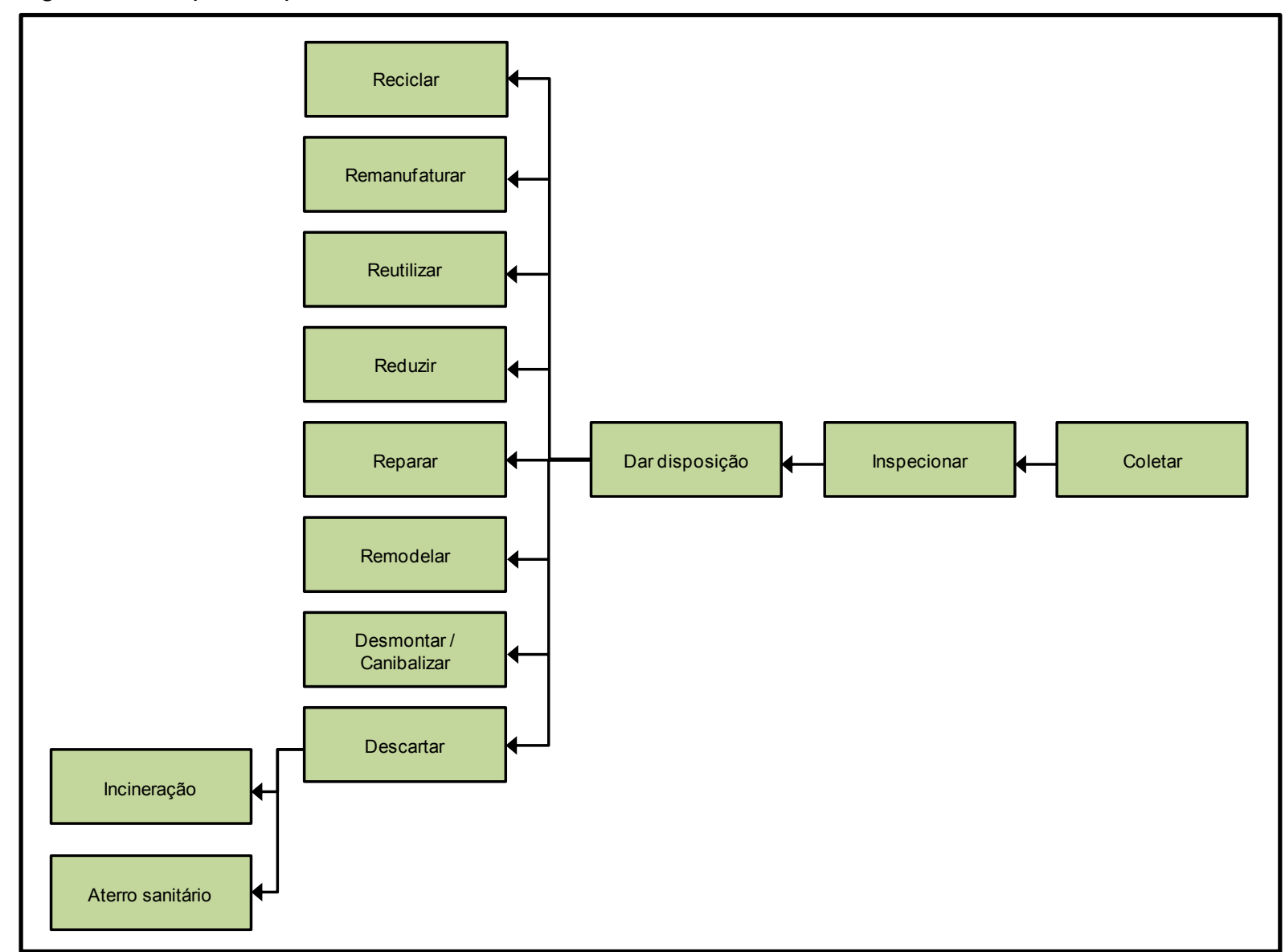

Fonte: Autor, baseado na compilação dos artigos lidos sobre o tema.

As opções de disposição são, muitas vezes, específicas da indústria, dependendo das características do produto, como preço, valor, custo de transporte, vida útil do produto e padrões de demanda do mercado (SKINNER; BRYANT; RICHEY, 2008). Quando os produtos são de valor suficientemente alto e podem ser remanufaturados para revenda, a LR eficiente pode trazer lucro (STOCK; SPEH; SHEAR, 2002). 
Embora sejam reconhecidos os benefícios de programas de $L R$, a realidade de muitas indústrias mostra que, às vezes, é difícil aceitar suas vantagens, porque existe a ideia de que o fluxo reverso somente representa custos não sendo priorizados pelas empresas que geralmente resistem a fazer o que é favorável para o meio ambiente só porque não é rentável (TSAl; HUNG, 2009).

O custo logístico indica o valor consumido por todo o trabalho na operação, incluindo o custo de transporte, o custo de embalagem, o custo de armazenamento, o custo de entrega, o custo de reciclagem e/ou descarte (ZHOU; ZHANG, 2011).

Um dos principais custos associados à coleta de um produto retornado é o custo do transporte, devido ao fato do volume de produto retornado tende a ser menor (RAJAGOPAL; SUNDRAM; NAIDU, 2015). É possível reduzir os custos de transporte de materiais devolvidos, otimizando a coleta de produtos dos mesmos na mesma carga da entrega de produtos fabricados, ou consolidando cargas de outros clientes (BRAVO; CARVALHO, 2015). Uma maior integração da logística direta e reversa pode gerar também oportunidades de redução de custos para a empresa. Uma avaliação econômica é um importante indicador do desempenho logístico reverso de uma empresa (SKINNER; BRYANT; RICHEY, 2008).

Outra característica importante é a incerteza da recuperação do produto dado que a quantidade e a qualidade de uso dos produtos retornados são mais difíceis de controlar (YE; ZHENHUA, 2014), gerando a dificuldade de medir seu desempenho e criar vantagens competitivas. Tibben-Lembke e Rogers (2002) compararam as diferenças entre a logística direta e a LR dentro de um cenário do mercado varejista, salientando a falta de uniformidade em vários aspectos da cadeia reversa, principalmente na incerteza da quantidade e qualidade dos produtos retornados.

Ao contrário da logística direta, produtos retornados pela LR não são rastreados amplamente devido ao elevado custo de tecnologia de informação (TI) que estabelece um sistema integrado e às incertezas no retorno (KUMAR; DIEVENEY; DIEVENEY, 2009). Chouinard, D'Amours e Ait-Kadi (2005) demonstraram problemas relacionados à integração das atividades de LR dentro de um sistema de informação da cadeia de suprimentos.

Olorunniwo e Li (2010) investigaram como o uso de tecnologia da informação (TI) e iniciativas de gerenciamento de cadeia de suprimentos (informações, compartilhamento e colaboração) impactam no desempenho de uma empresa em LR. Os mesmos ressaltaram que as empresas deveriam ser capazes de gerenciar 
todas as atividades de LR, do ponto de consumo para o ponto de origem, sendo que, TI representa um papel importante neste cenário para armazenar dados e compartilhar informações. Os autores concluíram que a colaboração baseada em compartilhamento de informações de alta qualidade é fundamental para um melhor desempenho da LR e também para a integração das atividades envolvidas no CLSC.

A LR é um processo complexo e dinâmico, que requer um planejamento, e não meramente uma inversão da direção da cadeia de suprimentos (RAJAGOPAL; SUNDRAM; NAIDU, 2015).

Campos et al. (2017) agruparam a falta de coordenação e colaboração com a logística de fornecedores terceiros, percepção do cliente sobre LR, falta de um sistema para monitorar os retornos e falta de consciência sobre os benefícios de LR como sendo importantes barreiras para implementação da LR.

Segundo Kumar, Dieveney e Dieveney (2009) para uma gestão eficiente da LR faz necessário um processo bem definido e consistente, garantindo que cada pessoa na cadeia de suprimentos esteja ciente de seus papéis e responsabilidades.

No Brasil, em 2010, foi criada a Política Nacional de Resíduos Sólidos (PNRS), definindo o princípio da responsabilidade sobre o produto, a qual exigiu mudanças no comportamento corporativo em relação ao produto retornado, incentivando a prática e pesquisa de LR (BOUZON; MIGUEL; RODRIGUEZ, 2014).

\subsection{LOGÍSTICA REVERSA NA INDÚSTRIA FARMACÊUTICA}

A indústria farmacêutica está focada na descoberta, desenvolvimento e fabricação de medicamentos para diagnóstico, tratamento ou prevenção de doenças (CAMPOS et al., 2017; SHAH, 2004).

A cadeia de suprimentos farmacêuticos (PSC) é definida como uma "combinação de processos, organizações e operações envolvidas no desenvolvimento, projeto e fabricação de medicamentos" (SINGH et al., 2016, p. 1 apud VIEGAS et al., 2019).

$\mathrm{Na}$ indústria farmacêutica, a LR é extremamente importante não apenas do ponto de vista econômico, mas também do ponto de vista do meio ambiente e regulatório, a fim de minimizar a geração de resíduos prejudiciais ao meio ambiente (KABIR, 2013). 
O retorno dos produtos na indústria farmacêutica ocorre principalmente quando estes estão com a data de validade próxima ao vencimento ou vencidos, produtos ou embalagens danificados, recall, entrega incorreta ou atualização de produto (BRAVO; CARVALHO, 2015; KABIR, 2013; LUNA; VIANA, 2017; LUNA; VIANA, 2019; NARAYANA; ELIAS; PATI, 2014). Sendo alguns produtos químicos de alto valor, o gerenciamento de devoluções de medicamentos, estoque vencido e recalls é necessário através da implementação de sistemas eficientes de LR para evitar roubo de carga e falsificação de medicamentos (KONGAR et al., 2015; NARAYANA; ELIAS; PATI, 2014).

Em relação ao consumidor final, um dos motivos que contribuem para o acúmulo de medicamentos EOL é que vários pacientes interrompem o tratamento prescrito e passam para outros medicamentos. As sobras de produtos farmacêuticos ou com validade vencida podem prejudicar o meio ambiente e a saúde da população se não forem descartados adequadamente. O potencial perigo dos produtos EOL requer um sistema LR bem estabelecido de como coletar, reutilizar, reciclar e principalmente, descartar adequadamente esses produtos. Com essas motivações, a estrutura LR tem que incorporar preocupações ambientais, econômicas e sociais para produtos farmacêuticos (KONGAR et al., 2015).

Daughton (2003) salientou que muitas farmácias nos EUA recebem medicamentos vencidos, sendo que alguns estados dos EUA permitem a reutilização de medicamentos. Segundo sua pesquisa, existem diferenças de opinião quanto à reutilização de medicamentos por não se saber as condições de temperatura e umidade em que o produto foi armazenado.

Narayana, Pati e Padhi (2019) recomendaram mudanças na PSC e nos processos de LR na Índia a fim de permitir a realocação de medicamentos sem uso dentro do prazo de validade para mercados carentes. Ainda reforçaram que essa estratégia, se implementada com sucesso, pode reduzir danos ambientais e perdas econômicas, ajudando assim a PSC a se alinhar com os objetivos de sustentabilidade favoráveis a uma política de compartilhamento de riscos e das informações para minimizar as devoluções.

Ainda há limitações em vários estados dos EUA em relação ao reaproveitamento de medicamentos devido à confiabilidade e integridade dos medicamentos redistribuídos e às questões de responsabilidade (KONGAR et al., 2015). 
Países como Canadá, Itália, França e Espanha conduziram programas sobre a LR de medicamentos para o correto descarte de produtos farmacêuticos. Também na Austrália, em 1998, foi lançado um programa de coleta de medicamentos em parceria com o Governo e indústrias farmacêuticas com o objetivo de diminuir o descarte de medicamentos no meio ambiente, reduzir as intoxicações infantis por medicamentos armazenados em casa e minimizar o compartilhamento impróprio de medicamentos (DAUGHTON, 2003).

Segundo Vollmer (2010), a maioria dos países da Europa criaram programas que utilizam as redes de farmácias e drogarias como pontos centrais de coleta de medicamentos vencidos, o que facilita o descarte destes produtos pelo consumidor final. Sendo assim, em 2011, a União Europeia estabeleceu uma campanha para conscientizar a população sobre impactos ambientais e de saúde no descarte inadequado de produtos farmacêuticos, orientando sobre métodos de eliminação segura de medicamentos vencidos ou sobras (KONGAR et al., 2015).

As campanhas de conscientização são extremamente importantes, pois minimizam a possibilidade de envenenamento acidental de crianças por ingestão de medicamentos, reduzem os custos com medicamentos, evitam a automedicação inadequada e o dano potencial ao meio ambiente (DAUGHTON, 2003).

De modo geral, os produtos farmacêuticos retornados devem ser incinerados ou dispostos em aterros, após inspecionados e classificados (BLANKENSTEIN; JUNIOR, 2018; CAMPOS et al., 2017; DAUGHTON, 2003; LUNA; VIANA, 2017; LUNA; VIANA, 2019; NARAYANA; ELIAS; PATI, 2014; NARAYANA; PATI; PADHI, 2019; STOCHER et al., 2018). Os principais métodos de descarte dos resíduos químicos, incluindo os medicamentos adotados pela PSC são: retornar à indústria; disposição em aterros, sempre que o resíduo for encapsulado ou desativado; em aterros com proteção ao sistema aquífero e de esgoto; incineração em contentores fechados; incineração a temperaturas médias; e decomposição química (BELLAN et al., 2012). A incineração, por exemplo, ainda gera gastos de energia e poluentes, resultado da queima de resíduos (AQUINO et al., 2018). Kongar et al. (2015) recomendaram a utilização da energia gerada através do processo de incineração. Os resíduos da incineração podem ser vendidos à indústria cimenteira para o abastecimento de seus fornos, desde que este material não seja um psicotrópico (LUNA, VIANA, 2019). 
Grande parte dos consumidores, por falta de informação adequada, descartam os medicamentos diretamente no lixo doméstico, na pia e no vaso sanitário ou estocam em casa com risco de consumo após data de vencimento e raramente, levam de volta à farmácia ou pontos de coleta (JONES; VOULVOULIS; LESTER, 2003; TONG; PEAKE; BRAUND, 2011). Musson et al. (2007) desenvolveram uma pesquisa com participantes que indicaram que o descarte de produtos farmacêuticos que excederem a data de validade em esgoto é uma prática comum.

Em muitos casos, o processo de tratamento de água não consegue eliminar completamente alguns medicamentos, como antibióticos e hormônios (LUO et al., 2014). Há teorias de que bactérias cada vez mais resistentes são consequência de antibióticos descartados inadequadamente nas águas (JONES; VOULVOULIS; LESTER, 2003).

Os medicamentos vencidos ou em desuso, quando descartados inadequadamente por um consumidor final, trazem muitos desafios do ponto de vista ambiental, social e saúde pública (PEREIRA et al., 2017). É necessário aumentar a conscientização sobre o impacto da medicação no meio ambiente e métodos de disposição eficientes, como por exemplo, trazendo a medicação para um local de coleta (XIE; BREEN, 2012). Guirguis (2010) sugeriu que os profissionais do ramo farmacêutico são a melhor opção para coletar medicamentos não utilizados e educar os clientes.

A rastreabilidade é uma das dificuldades mencionadas por Kumar, Dieveney e Dieveney (2009) que citam a implementação de etiquetas de identificação de rádio frequência - RFID (Radio Frequency Identification) que permitem rastrear os produtos ao longo do cadeia de suprimentos, reduzindo a possibilidade do ingresso de medicamentos falsos e reagindo rapidamente no caso de um recall. Devido à gravidade potencial do uso de medicamentos vencidos ou ineficazes, os autores recomendaram que as empresas farmacêuticas fizessem a gestão da LR.

A etiqueta RFID também pode monitorar medicamentos vencidos ou próximos da data de vencimento, auxiliando no controle de inventário e gestão de produtos devolvidos em toda cadeia de suprimentos, monitorando em tempo real a quantidade exata de medicamentos em fim de vida útil (KONGAR et al., 2015; KUMAR; DIEVENEY; DIEVENEY, 2009). 
Kumar, Dieveney e Dieveney (2009) salientaram que se todos os parceiros dentro da cadeia de suprimentos trabalharem de forma colaborativa e utilizarem o mesmo sistema RFID, a rastreabilidade se torna mais eficiente e confiável, porém, o alto custo ainda é um grande limitador. Segundo os autores, devido ao retorno de produtos farmacêuticos ser predominantemente realizado por prestadores de serviço (3PL - Third-party logistic), falta uma melhor compreensão do processo como um todo.

Segundo Bravo e Carvalho (2015), o retorno dos medicamentos é uma tarefa muito complexa, principalmente em empresas multinacionais que operam em diversos países devido a vários fatores, entre eles à diferença de legislação e aos processos logísticos. Eles analisaram os impactos sociais e ambientais dos retornos e recalls de medicamentos da cadeia farmacêutica, especialmente das farmácias hospitalares. Com o aumento do número de empresas envolvidas na PSC, muitas empresas introduziram avaliação de fornecedores no quesito ambiental e social.

Para muitos autores, a LR ainda é considerada um desafio e uma prática inovadora em países em desenvolvimento, como o Brasil.

A Tabela 1 mostra os artigos selecionados sobre o tema, pesquisados nas plataformas Scopus e Web of Science. Foram utililizadas combinações entre as seguintes palavras-chave: "Sustainability". "Green supply chain", "Closed-loop supply chain". "Reverse logistic" e "Pharmaceutical industry". Em uma primeira avaliação, foram considerados área de interesse, títulos, abstract e os journals para catalogálos e selecioná-los, sendo na sequencia realizada a leitura completa dos artigos selecionados a fim de identificar sua relevância ao tema da dissertação. Nota-se que o Brasil é o país com maior número de artigos publicados, os quais serão explorados no item 2.3. 
Tabela 1 - Artigos LR na indústria farmacêutica e/ou sobre descarte de medicamentos

\begin{tabular}{|c|c|c|c|}
\hline Ano & Autores & Título do artigo & País \\
\hline 2019 & Luna, R.A.; Viana, F.L.E. & $\begin{array}{l}\text { O papel da Política Nacional dos Resíduos Sólidos na Logística } \\
\text { Reversa em empresas farmacêuticas }\end{array}$ & Brasil \\
\hline 2019 & $\begin{array}{l}\text { Narayana, S. A.; Pati, R. } \\
\text { K.; Padhi, S. S. }\end{array}$ & $\begin{array}{l}\text { Market dynamics and reverse logistics for sustainability in the } \\
\text { Indian Pharmaceuticals industry }\end{array}$ & India \\
\hline 2019 & $\begin{array}{l}\text { Viegas, C. V.; Bond, A.; } \\
\text { Vaz, C. R.; Bertolo, R. J. }\end{array}$ & $\begin{array}{l}\text { Reverse flows within the pharmaceutical supply chain: A } \\
\text { classificatory review from the perspective of end-of-use and end- } \\
\text { of-life medicines }\end{array}$ & Brasil \\
\hline 2018 & $\begin{array}{l}\text { Aquino, S. Spina, G.A. } \\
\text { Zajac, M.A.L. Lopes, E.L }\end{array}$ & $\begin{array}{l}\text { Reverse logistics of postconsumer medicines: The roles and } \\
\text { knowledge of pharmacists in the municipality of São Paulo, Brazil }\end{array}$ & Brasil \\
\hline 2018 & $\begin{array}{l}\text { Stocher, F. M; Silva, M.L.; } \\
\text { Cappellari, G.; } \\
\text { Cassanego Junior, P.V. }\end{array}$ & $\begin{array}{l}\text { A logística reversa no setor farmacêutico: um estudo em Santana } \\
\text { do Livramento }\end{array}$ & Brasil \\
\hline 2018 & $\begin{array}{l}\text { Blankenstein, G.M.P.; } \\
\text { Junior, A.P. }\end{array}$ & $\begin{array}{l}\text { O descarte de medicamentos e a Política Nacional de Resíduos } \\
\text { Sólidos: uma motivação para a revisão das normas sanitárias }\end{array}$ & Brasil \\
\hline 2017 & $\begin{array}{l}\text { Pereira, A. L.; Barros, R. } \\
\text { T. V.; Pereira, S. R. }\end{array}$ & $\begin{array}{l}\text { Pharmacopollution and Household Waste Medicine (HWM): how } \\
\text { reverse logistics is environmentally important to Brazil }\end{array}$ & Brasil \\
\hline 2017 & Luna, R.A.; Viana, F.L.E. & $\begin{array}{l}\text { The challenges of pharmaceutical industry in the wake of the } \\
\text { brazilian policy for solid wastes | [Os desafios da indústria } \\
\text { farmacêutica brasileira diante da política nacional de resíduos } \\
\text { sólidos] }\end{array}$ & Brasil \\
\hline 2017 & $\begin{array}{l}\text { de Campos, E.A.R., de } \\
\text { Paula, I.C., Pagani, R.N., } \\
\text { Guarnieri, P. }\end{array}$ & $\begin{array}{l}\text { Reverse logistics for the end-of-life and end-of-use products in the } \\
\text { pharmaceutical industry: a systematic literature review }\end{array}$ & Brasil \\
\hline 2015 & $\begin{array}{l}\text { Kongar, E., } \\
\text { Haznedaroglu, E., } \\
\text { Abdelghany, O., Bahtiyar, } \\
\text { M.O. }\end{array}$ & $\begin{array}{l}\text { A novel IT infrastructure for reverse logistics operations of end-of- } \\
\text { life pharmaceutical products }\end{array}$ & $\begin{array}{l}\text { Turquia/ } \\
\text { EUA }\end{array}$ \\
\hline 2015 & $\begin{array}{l}\text { Bravo, A.M.S., De } \\
\text { Carvalho, J.C. } \\
\end{array}$ & $\begin{array}{l}\text { Challenging times to pharmaceutical supply chains towards } \\
\text { sustainability: A case study application }\end{array}$ & Portugal \\
\hline 2014 & $\begin{array}{l}\text { Medeiros M. S. G; } \\
\text { Moreira L. M. F.; Lopes } \\
\text { C. C. G. O. }\end{array}$ & $\begin{array}{l}\text { Descarte de medicamentos: programas de recolhimento e novos } \\
\text { desafios }\end{array}$ & Brasil \\
\hline 2014 & $\begin{array}{l}\text { Luo, Y.; Guo, W.; Ngo, H. } \\
\text { H.; Nghiem, L. D.; Hai, F. } \\
\text { I.; Zhang, J.; Liang S.; } \\
\text { Wang, X. C }\end{array}$ & $\begin{array}{l}\text { A review on the occurrence of micropollutants in the aquatic } \\
\text { environment and their fate and removal during wastewater } \\
\text { treatment }\end{array}$ & China \\
\hline 2014 & $\begin{array}{l}\text { Narayana, S.A. Elias, } \\
\text { A.A. Pati, R.K. }\end{array}$ & $\begin{array}{l}\text { Reverse logistics in the pharmaceuticals } \\
\text { industry: a systemic analysis }\end{array}$ & Índia \\
\hline 2013 & Kabir, M.I. & Reverse logistics in pharmaceutical industry & Bangladesh \\
\hline 2012 & Xie, Y.; Breen, L. & $\begin{array}{l}\text { Greening community pharmaceutical supply chain in UK: a cross } \\
\text { boundary approach }\end{array}$ & U.K. \\
\hline 2012 & $\begin{array}{l}\text { Bellan, N., Pinto, T. D. J. } \\
\text { A., Kaneko, T. M., } \\
\text { Moretto, L. D., Santos } \\
\text { Junior, N. D }\end{array}$ & $\begin{array}{l}\text { Critical analysis of the regulations regarding the disposal of } \\
\text { medication waste }\end{array}$ & Brasil \\
\hline 2011 & $\begin{array}{l}\text { Tong A. Y.; Peake, B. M.; } \\
\text { Braund, R. }\end{array}$ & Disposal practices for unused medications around the world & $\begin{array}{c}\text { Nova } \\
\text { Zelandia } \\
\end{array}$ \\
\hline 2010 & Vollmer, G. & $\begin{array}{l}\text { Disposal of pharmaceutical waste in households-a European } \\
\text { survey. In: Green and Sustainable pharmacy }\end{array}$ & Europa \\
\hline 2010 & Guirguis, K. & $\begin{array}{l}\text { Medications collected for disposal by outreach pharmacists in } \\
\text { Australia }\end{array}$ & Austrália \\
\hline 2009 & $\begin{array}{l}\text { Kumar, S., Dieveney, E., } \\
\text { Dieveney, A. }\end{array}$ & $\begin{array}{l}\text { Reverse logistic process control measures for the pharmaceutical } \\
\text { industry supply chain }\end{array}$ & EUA \\
\hline 2007 & $\begin{array}{l}\text { Musson, S. E.; } \\
\text { Townsend, T.; Seaburg, } \\
\text { K.; Mousa, J. }\end{array}$ & $\begin{array}{l}\text { A continuous collection system for household pharmaceutical } \\
\text { wastes: a pilot project }\end{array}$ & EUA \\
\hline 2004 & Shah, N. & $\begin{array}{l}\text { Pharmaceutical supply chains: key issues and strategies for } \\
\text { optimization }\end{array}$ & U.K. \\
\hline 2003 & Daughton, C. G. & $\begin{array}{l}\text { Cradle-to-cradle stewardship of drugs for minimizing their } \\
\text { environmental disposition while promoting human health. II. Drug } \\
\text { Disposal, Waste Reduction, and Future Directions }\end{array}$ & EUA \\
\hline 2003 & $\begin{array}{l}\text { Jones, O. A.; Voulvoulis, } \\
\text { N.; Lester, J. N. }\end{array}$ & Potential impact of pharmaceuticals on environmental health. & U.K. \\
\hline
\end{tabular}

Fonte: Autor, baseado no Scopus e Web of Science. 


\subsection{LOGÍSTICA REVERSA NA INDÚSTRIA FARMACÊUTICA NO BRASIL}

No Brasil, produtos farmacêuticos são amplamente utilizados pela população, porém, não havendo a devida atenção ao processo de retorno dos resíduos gerados, há espaço para que ocorram impactos ambientais (LUNA; VIANA, 2017). Em sua entrevista, Luna e Viana (2017) detectaram equívocos no conceito de LR em membros da cadeia, dizendo que para cadeia farmacêutica não se aplica LR por se descartar os produtos, não tendo reaproveitamento e eles também evidenciaram que há desinformação sobre se há possibilidade de descartar algum medicamento na pia ou lixo comum, como por exemplo, uma vitamina.

Aquino et al. (2018), bem como outros autores estrangeiros, ressaltaram que sobras de medicamentos são descartadas diretamente no lixo comum ou na rede de esgoto, além da própria excreção urinária contribuir para geração de resíduos de medicamentos na rede de esgoto. A falta de consciência da população sobre o descarte correto de medicamentos não é um problema somente no Brasil. Daughton (2003) e Vollmer (2010) enfatizaram que em alguns países desenvolvidos da Europa e em alguns estados dos EUA, a entrega de medicamentos vencidos e utilizados pelos consumidores no ponto de venda já é uma prática. Já no Brasil, o descarte correto de medicamentos ainda é um grande desafio (CAMPOS et al., 2017; LUNA; VIANA, 2017).

Luna e Viana (2017) analisaram a influência da Política Nacional dos Resíduos Sólidos (PNRS), Lei federal $n^{\circ}$ 12.305/2010, na LR da indústria farmacêutica brasileira com uso domiciliar. Conforme a portaria do Centro de Vigilância Sanitária (CVS) $n^{\circ} 21$ de 10/09/2008, uma parcela significativa de medicamentos, inclusive os perigosos, são descartadas em aterros inadequados, expondo trabalhadores da limpeza urbana e recicladores ao contato direto com agentes tóxicos e contaminando o meio ambiente (SÃO PAULO, 2008).

A PNRS tem como diretriz a gestão de resíduos sólidos, porém não aborda com clareza o descarte de medicamentos de uso domiciliar especificamente (LUNA; VIANA, 2017; LUNA; VIANA, 2019). Bellan et al. (2012), Aquino et al. (2018) e Stocher et al. (2018) também afirmaram que não há uma legislação brasileira específica para o descarte de medicamentos pelo consumidor final e salientaram a necessidade de uma LR de medicamentos pós-consumo. Em 5 de setembro de 2016, Associação Brasileira de Normas Técnicas (ABNT) publicou uma norma 
específica ABNT NBR 16457:2016 - referente a LR de medicamentos de uso humano vencidos e/ou em desuso descartados pelo consumidor. A norma traz diretrizes para atender à PNRS, visando boas práticas pela população nas etapas de coleta, armazenamento temporário e coleta externa dos medicamentos vencidos (ABNT, 2016).

Medeiros, Moreira e Lopes (2014) citaram que o Hospital das Clínicas tem um programa chamado de Devolução Segura de Medicamentos, onde há o recebimento e avaliação de medicamentos que estando em perfeitas condições podem ser direcionados a outros pacientes.

Luna e Viana (2017) levantaram a questão sobre as possíveis soluções e pontos de coletas para os medicamentos vencidos ou em desuso, de modo que a indústria farmacêutica possa ter um canal reverso específico para a coleta, que poderia ser nas farmácias, facilitando ao consumidor final a entrega do medicamento. Os autores mencionaram a importância da informatização e a rastreabilidade durante o processo de distribuição dos medicamentos, podendo auxiliar na implantação de um processo de LR mais robusto e coerente com as demandas da PNRS. Aquino et al. (2018) realizaram uma pesquisa diretamente em farmácias no município de São Paulo, com o objetivo de compreender o papel dos farmacêuticos na LR de medicamentos, visando a conscientização da população no descarte adequado dos medicamentos expirados. Stocher et al. (2018) observaram em sua pesquisa realizada no Rio Grande do Sul, que coletores de medicamentos vencidos ou em desuso em farmácias proporcionam uma imagem de sustentabilidade à organização, podendo gerar uma vantagem competitiva sobre as demais concorrentes, mas ainda salientaram que há pouca divulgação sobre o serviço de coleta oferecido pela rede Panvel.

Luna e Viana (2019) observaram em pesquisa na rede farmacêutica que existe uma predisposição para o retorno dos medicamentos que chegam com problemas para a comercialização, mas não existe ainda um foco em receber medicamentos dos consumidores finais, pois não há uma legislação nacional que obrigue a farmácia a receber o medicamento vencido ou não utilizado pelo consumidor final, sendo esta uma iniciativa individual de algumas farmácias.

Programas de conscientização destinados aos consumidores devem ser desenvolvidos a fim de educá-los para o uso racional dos medicamentos conforme a quantidade prescrita e, em caso de sobras, descartá-los corretamente nas farmácias 
ou pontos de coleta (AQUINO et al., 2018; CAMPOS et al., 2017; LUNA; VIANA, 2017). Em entrevista com representantes da Associação Brasileira das Redes de Farmácias e Drogarias (ABRAFARMA), Aquino et al. (2018) declararam que não está estabelecido um acordo setorial entre as farmácias e os fabricantes sobre as responsabilidades pelos custos da LR e seleção dos destinos adequados. Os principais custos são o transporte e a disposição final em aterros ou incineração, que estão diretamente ligados ao volume de produto retornado, o que no caso, é uma incerteza neste setor. Segundo Demajorovic, Augusto e Souza (2016), existem muitos conflitos sobre a divisão de custos e responsabilidades na $L R$, sendo que 0 setor privado acusa o governo de não estabelecer papéis bem definidos na LR e reclamam da falta de políticas de incentivo para a implantação. No Brasil, estes custos ainda são mais críticos, devido à dimensão e características distintas das regiões, dificultando a implantação de um sistema unificado de LR (BELLAN et al., 2012; MEDEIROS; MOREIRA; LOPES, 2014). Luna e Viana (2019) evidenciaram em suas entrevistas com os fabricantes farmacêuticos e as redes de farmácias, 0 mesmo conflito sobre a definição de responsabilidades pela LR e principalmente, sobre os custos. Campos et al. (2017) salientaram a oportunidade de reduzir os custos relacionados ao transporte de baixos volumes no processo de $L R$, através de iniciativas conjuntas entre as empresas, onde poder-se-ia compartilhar os custos com os membros da cadeia de suprimentos. Ainda recomendaram a inclusão de fornecedores de logística terceirizados (3PLs) em termos dos critérios para selecioná-los e as certificações exigidas.

Campos et al. (2017) também recomendaram o papel das universidades na preparação dos profissionais de saúde para educar a população nas práticas de LR na indústria farmacêutica.

Tanto os fabricantes de medicamentos quanto as farmácias atribuem ao Governo a responsabilidade de conscientização sobre os riscos do descarte incorreto, mas Luna e Viana (2019) reforçaram a importância da conscientização ser assumida por todos integrantes da PSC. Pereira et al. (2017) citaram em sua pesquisa programas de conscientização no Brasil como: Programa Destino Certo; Programa Descarte Consciente; Programa Descarte Correto de Medicamentos, mas relatam a falta de um programa nacional vigente. 


\subsection{NORMAS E REGULAMENTOS SOBRE GESTÃO DE RESÍDUOS DE MEDICAMENTOS NO BRASIL}

A legislação pode ser considerada como a principal ferramenta para combater o descarte incorreto de medicamentos (BLANKENSTEIN; JUNIOR, 2018). A falta de orientação ou regulamentos conflitantes sobre o descarte de medicamentos em relação à sua disposição ambiental existe em outros países, além do Brasil (DAUGHTON, 2003).

Apesar das várias normas publicadas no Brasil com preocupações ambientais, ainda não há uma legislação específica que regulamenta a manipulação e destinação correta dos medicamentos em desuso ou vencidos nos domicílios da população, induzindo a sociedade ao descarte indevido de medicamentos, o que acarreta danos ao meio ambiente e afeta a saúde pública. Já sobre os Resíduos Sólidos de Serviço de Saúde (RSS), a regulamentação está mais bem definida (BELLAN et al., 2012; LUNA; VIANNA, 2017; STOCHER et al., 2018).

No âmbito federal, em fevereiro de 1989 , pela Lei $n^{0} 7.735$ foi criado o Instituto Brasileiro do Meio Ambiente e dos Recursos Naturais Renováveis, mais conhecido pelo acrônimo IBAMA, responsável por gerir os planos de gerenciamento dos resíduos sólidos (BRASIL, 1989). Todas as empresas geradoras de RSS devem seguir as diretrizes impostas pelo IBAMA, pelo Conselho Nacional de Meio Ambiente (CONAMA) no 358 e Resolução da Diretoria Colegiada (RDC) no 222 da Agência Nacional de Vigilância Sanitária (ANVISA).

Em abril de 2005, foi estabelecida a resolução CONAMA no 358 que dispõe sobre o tratamento e a disposição final dos resíduos dos serviços de saúde (BRASIL, 2005). Em março de 2018, adotou-se a RDC no 222 que regulamenta as Boas Práticas de Gerenciamento dos Resíduos de Serviços de Saúde (BRASIL, 2018).

De acordo com a CONAMA $n^{\circ} 358$ e RDC $n^{\circ} 222$, os geradores de RSS devem elaborar e implantar o Plano de Gerenciamento de Resíduos de Serviços de Saúde - PGRSS (BRASIL, 2005; BRASIL, 2018).

Além disso, a CONAMA n ${ }^{\circ} 358$ e a RDC n 222 classificam os resíduos da seguinte forma: Grupo A - Resíduos Biológicos; Grupo B - Resíduos Químicos; Grupo C - Resíduos Radioativos; Grupo D - Resíduos Comuns Recicláveis e Não Recicláveis; Grupo E - Resíduos Perfurocortantes (ver Figura 5). Os produtos 
farmacêuticos se enquadram no Grupo B - Químicos (BRASIL, 2005; BRASIL, 2018).

Figura 5 - Classificação de Resíduos Sólidos de Serviço de Saúde (RSS)

\begin{tabular}{|c|c|c|}
\hline síMBOLO & GRUPO & CLASSIFICAÇÃO \\
\hline & A & Infectantes \\
\hline & B & Químicos (Tóxicos) \\
\hline & C & Radioativos \\
\hline & \multirow{2}{*}{ D } & Não Reciclável \\
\hline & & Reciclável \\
\hline & $\mathrm{E}$ & Perfurocortantes \\
\hline
\end{tabular}

Fonte: RDC n² 222/2018 e CONAMA n 358/2005.

O lixo deve ser separado de acordo com a categoria e para cada tipo de resíduo deve ser dado um tratamento diferente (BELLAN et al., 2012).

Em relação às farmácias e drogarias, em agosto de 2009 , foi publicada a $R D C$ n 44 que dispõe sobre Boas Práticas Farmacêuticas para o controle sanitário do funcionamento, da dispensação e da comercialização de produtos e da prestação de serviços farmacêuticos em farmácias e drogarias. Pelo Artigo 93, "fica permitido às farmácias e drogarias participar de programa de coleta de medicamentos a serem descartados pela comunidade, com vistas a preservar a saúde pública e a qualidade do meio ambiente" e pelo Artigo 97, "as farmácias e drogarias devem possuir PGRSS, conforme legislação específica" (BRASIL, 2009).

A PNRS foi sancionada em agosto de 2010 pela Lei Federal $n^{\circ} 12305$ e regulamentada pelo Decreto $\mathrm{n}^{\circ}$ 7404. A PNRS reúne as diretrizes relativas ao gerenciamento dos RSS, as responsabilidades dos geradores e do poder público. Os geradores de resíduos são responsáveis pelas atividades que abrangem a coleta seletiva, recuperação e reciclagem, tratamento e destinação final dos resíduos (BRASIL, 2010). Já em relação ao consumidor final, o artigo 33 da PNRS obriga os fabricantes, importadores, distribuidores e comerciantes de agrotóxicos, pilhas, 
baterias, pneus, óleos lubrificantes, lâmpadas fluorescentes e produtos eletrônicos a estruturar e implementar sistemas de LR, mediante retorno dos produtos após o uso pelo consumidor. No parágrafo $\S 4^{\circ}$ também cita que os consumidores deverão efetuar a devolução dos produtos e das embalagens após o uso, aos comerciantes ou distribuidores, entretanto, não se faz referências aos produtos farmacêuticos de uso doméstico (BRASIL, 2010). Em setembro de 2016, a ABNT publicou a NBR 16.457 sobre a LR de medicamentos de uso humano e/ou em desuso (ABNT, 2016).

Em 5 de junho de 2020, entrou em vigor o Decreto Federal $n^{\circ} 10.388$ que oficializa a LR de medicamentos, que institui o sistema de LR de medicamentos domiciliares vencidos ou em desuso, de uso humano, industrializados e manipulados, e de suas embalagens após o descarte pelos consumidores.

As regras de descarte de medicamentos vencidos ou em desuso podem variar conforme os estados (BLANKENSTEIN; JUNIOR, 2018). No Estado de São Paulo, há especificamente a Portaria CVS n²1 (Centro de Vigilância Sanitária), de 10/09/2008, onde se estabelecem os critérios técnicos de segurança para o gerenciamento de resíduos perigosos de medicamentos em serviços de saúde. A Decisão de Diretoria N ${ }^{\circ}$ 076/2018 de 03 de abril de 2018 da Companhia Ambiental do Estado de São Paulo - CETESB estabeleceu procedimento para incorporação da LR no âmbito do licenciamento ambiental em atendimento à Resolução SMA 45 de 23 de junho de 2015, onde empreendimentos que fabriquem ou sejam responsáveis pela importação, distribuição ou comercialização de medicamentos domiciliares, desde que licenciados pela CETESB por meio do licenciamento ordinário, devem apresentar um plano de LR para medicamentos domiciliares (SÃO PAULO, 2018). Com o início da aplicação do plano de LR gerou-se um aprendizado e a necessidade de adequação, acarretando uma nova revisão do procedimento em 23 de outubro de 2019, passando para No 114/2019/P/C (SÃO PAULO, 2019).

A norma da CETESB No 114/2019/P/C diz que o cumprimento das obrigações referentes à estruturação e implantação de sistemas de LR poderá ser feito por adesão das empresas a um dos Termos de Compromisso de LR (TCLR). Em relação aos medicamentos domiciliares, de uso humano, vencidos ou em desuso, não existe, até o momento, Acordo Setorial ou TCLR firmado. O TCLR tem como objetivo o acompanhamento, por parte do poder público estadual, da estruturação, implementação e operacionalização de Sistemas de LR no Estado de São Paulo (SÃO PAULO, 2019). O Plano de LR no estado de São Paulo é uma 
iniciativa da CETESB, regulamentada pela Decisão de Diretoria da CETESB $N^{\circ}$ 114/2019/P/C A INTERFARMA - Associação da Indústria Farmacêutica de Pesquisa atua como articuladora desse Plano de LR junto a CETESB, estruturando a adesão dos seus associados. A empresa BHS Brasil Health Service é a Entidade Gestora que criou o Sistema de LR de medicamentos e operacionaliza, com a participação dos pontos de coleta, dentro do Estado de São Paulo (INTERFARMA, 2020). Percebe-se uma preocupação com a LR de medicamentos domiciliares, mas ainda não está claro como será dado um direcionamento para viabilizá-la.

Abaixo, segue uma tabela resumo (Tabela 2) com as normas e regulamentos vigentes sobre resíduos de serviços de saúde no Brasil.

Tabela 2 - Resumo da legislação sobre disposição de medicamentos

\begin{tabular}{|c|c|c|c|}
\hline & Ano & Lei & Descrição \\
\hline \multirow{11}{*}{$\begin{array}{l}\text { B } \\
\text { R } \\
\text { A } \\
\text { S } \\
\text { I } \\
\text { L }\end{array}$} & 1989 & IBAMA & $\begin{array}{l}\text { Controlar e fiscalizar os sistemas de logística reversa já implantados pelas } \\
\text { Resoluções Conama; } \\
\text { Gerir os Planos de Gerenciamento de Resíduos Sólidos das atividades }\end{array}$ \\
\hline & 1989 & Portaria $\mathrm{n}^{\circ} 344$ & Medicamentos controlados \\
\hline & 2004 & $\begin{array}{l}\mathrm{RDC} \mathrm{n}^{\circ} 306- \\
\text { ANVISA } \\
\text { revogada }\end{array}$ & Revogada e substituida pela RDC $n^{\circ} 222$ \\
\hline & 2005 & CONAMA n 358 & $\begin{array}{l}\text { Dispõe sobre o tratamento e a disposição final dos resíduos dos serviços } \\
\text { de saúde. }\end{array}$ \\
\hline & 2009 & $\begin{array}{l}\text { RDC n } n^{\circ} 44- \\
\text { ANVISA }\end{array}$ & $\begin{array}{l}\text { Dispõe sobre Boas Práticas Farmacêuticas para o controle sanitário do } \\
\text { funcionamento, da dispensação e da comercialização de produtos e da } \\
\text { prestação de serviços farmacêuticos em farmácias e drogarias. }\end{array}$ \\
\hline & 2010 & $\begin{array}{l}\text { PNRS - Política } \\
\text { Nacional } \\
\text { dos Resíduos } \\
\text { Sólidos }\end{array}$ & $\begin{array}{l}\text { Dispõe sobre os princípios, objetivos e instrumentos, bem como sobre as } \\
\text { diretrizes relativas à gestão integrada e ao gerenciamento de resíduos } \\
\text { sólidos, incluídos os perigosos, às responsabilidades dos geradores e do } \\
\text { poder público e aos instrumentos econômicos aplicáveis }\end{array}$ \\
\hline & 2016 & $\begin{array}{l}\text { ABNT:NBR } \\
16457\end{array}$ & $\begin{array}{l}\text { Logística reversa de medicamentos de uso humano vencidos e/ou em } \\
\text { desuso. }\end{array}$ \\
\hline & 2018 & $\begin{array}{l}\text { RDC nं } 222- \\
\text { ANVISA }\end{array}$ & $\begin{array}{l}\text { Regulamenta as Boas Práticas de Gerenciamento dos Resíduos de } \\
\text { Serviços de Saúde. }\end{array}$ \\
\hline & 2019 & $\begin{array}{l}\text { RDC n०301- } \\
\text { ANVISA }\end{array}$ & $\begin{array}{l}\text { Dispõe sobre as Diretrizes Gerais de Boas Práticas de Fabricação de } \\
\text { Medicamentos }\end{array}$ \\
\hline & 2019 & $\begin{array}{l}\text { RDC n³04 - } \\
\text { ANVISA }\end{array}$ & $\begin{array}{l}\text { Dispõe sobre as Boas Práticas de Distribuição, Armazenagem e de } \\
\text { Transporte de Medicamentos }\end{array}$ \\
\hline & 2020 & $\begin{array}{l}\text { Decreto Federal } \\
n^{\circ} 10388\end{array}$ & $\begin{array}{l}\text { Regulamenta o } \S 1^{\circ} \text { do caput do art. } 33 \text { da Lei } n^{\circ} 12.305 \text {, de } 2 \text { de agosto } \\
\text { de } 2010 \text {, e institui o sistema de logística reversa de medicamentos } \\
\text { domiciliares vencidos ou em desuso, de uso humano, industrializados e } \\
\text { manipulados, e de suas embalagens após o descarte pelos consumidores. }\end{array}$ \\
\hline $\begin{array}{l}\mathbf{S} \\
\mathbf{P}\end{array}$ & 2008 & $\begin{array}{l}\text { Portaria CVS no } \\
\text { 21, de } \\
10 / 09 / 2008\end{array}$ & $\begin{array}{l}\text { Estabelecer critérios técnicos de segurança para o gerenciamento } \\
\text { de resíduos perigosos de medicamentos em serviços de saúde }\end{array}$ \\
\hline & 2018 & $\begin{array}{l}\text { CETESB - } \mathrm{N}^{\circ} \\
076 / 2018 / \mathrm{C} \\
\text { revogada }\end{array}$ & Revogada e substituida pela CETESB No 114/2019/P/C \\
\hline & 2019 & $\begin{array}{l}\text { CETESB - No } \\
114 / 2019 / P / C\end{array}$ & Incorporação da Logística Reversa no âmbito do licenciamento ambiental. \\
\hline
\end{tabular}

Fonte: Autor. 
A figura 6 abaixo ilustra as normas e legislações estudadas em uma linha do tempo.

Figura 6 - Normas e legislações estudadas na linha do tempo

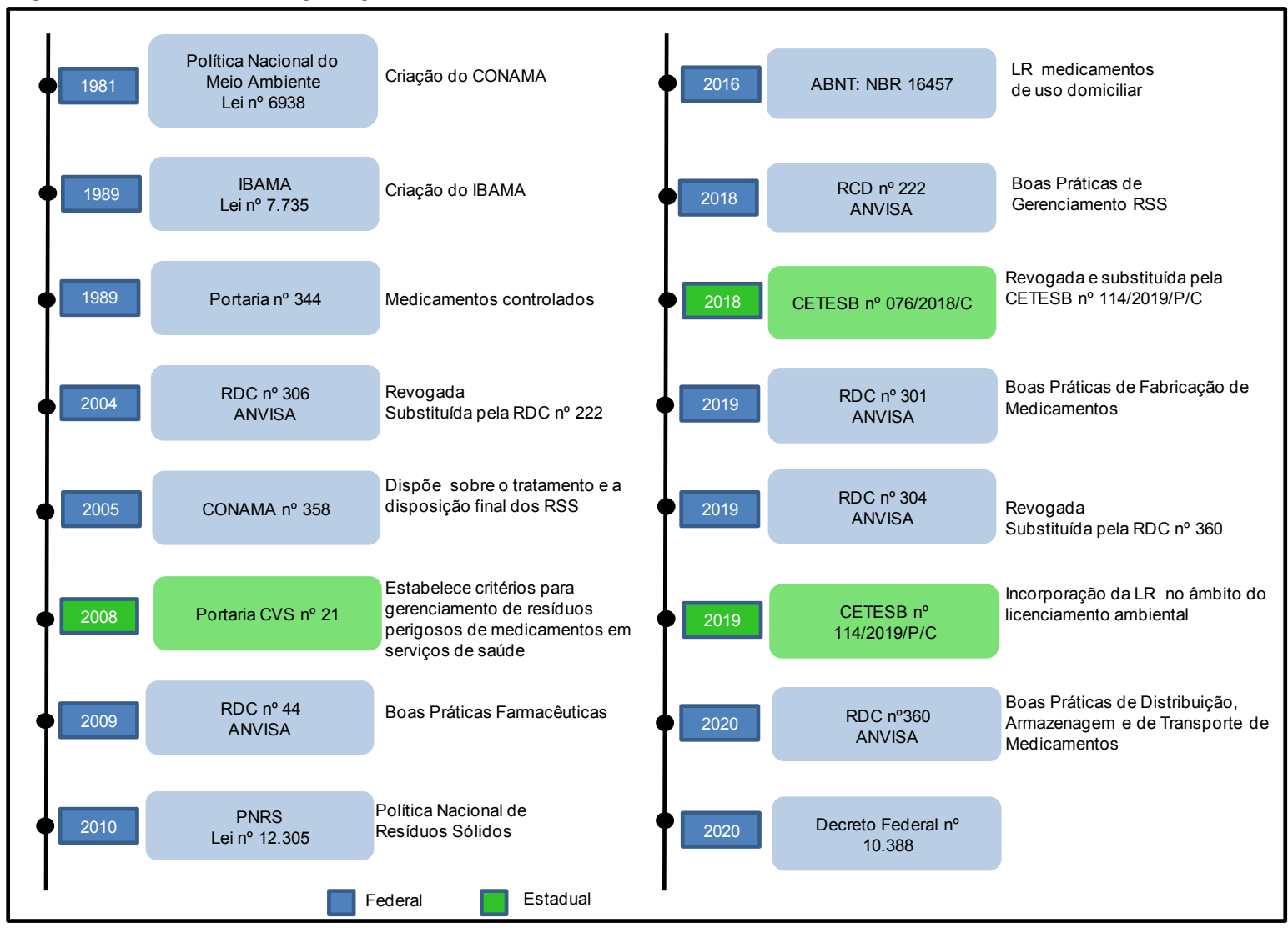

Fonte: Autor.

\subsection{CATEGORIAS DA LR}

Com o objetivo de identificar as práticas da LR na cadeia farmacêutica, foi elaborada a Tabela 3 que mostra as categorias identificadas nos artigos e normas relacionadas à LR associadas aos participantes da PSC, que originou um questionário (vide Tabela 4) para execução das entrevistas em campo. Cada bloco citado na Tabela 3 está ligado às perguntas do questionário da Tabela 4. 
Tabela 3 - Categorias da LR com base nos artigos e normas (continua)

\begin{tabular}{|c|c|c|c|c|c|c|c|c|}
\hline Autor & Categorias da LR & 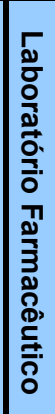 & 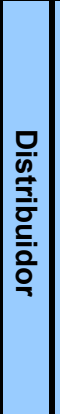 & 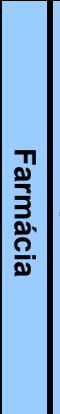 & 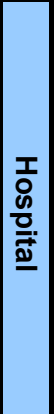 & 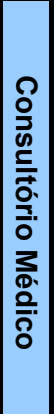 & 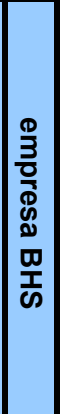 & \begin{tabular}{|c|} 
Protocolo \\
para \\
levantamento \\
de dados - \\
Questionário \\
(Tabela 4)
\end{tabular} \\
\hline $\begin{array}{l}\text { Jones, Voulvoulis e Lester (2003) } \\
\text { Musson et al. (2007) } \\
\text { Guide e Wassenhove (2009) } \\
\text { Tong, Peake e Braund (2011) } \\
\text { Bravo e Carvalho (2015) } \\
\text { Kongar et al. (2015) } \\
\text { Campos et al. (2017) } \\
\text { Luna e Viana (2017) } \\
\text { Pereira et al. (2017) } \\
\text { Aquino et al. (2018) }\end{array}$ & $\begin{array}{l}\text { Sustentabilidade: impactos sociais e } \\
\text { ambientais Riscos do descarte } \\
\text { incorreto de medicamentos }\end{array}$ & $x$ & $\mathrm{X}$ & $x$ & $\mathrm{X}$ & $x$ & $\mathrm{x}$ & Bloco A \\
\hline 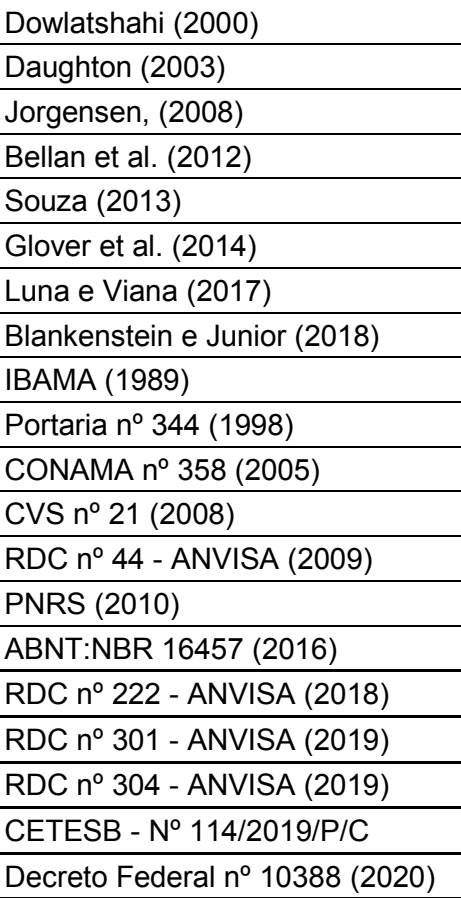 & Regulamentos governamentais & $x$ & $\mathrm{X}$ & $x$ & $\mathrm{x}$ & & $\mathrm{X}$ & 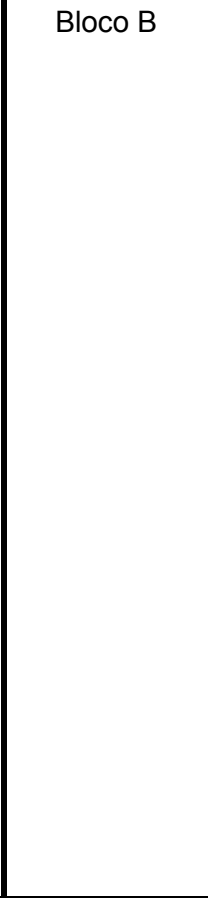 \\
\hline $\begin{array}{l}\text { Bellan et al. (2012) } \\
\text { Medeiros, Moreira e Lopes (2014) } \\
\text { Aquino et al. (2018) } \\
\text { Stocher et al. (2018) } \\
\text { Luna e Viana (2019) } \\
\text { ABNT NBR 16457:2016 } \\
\text { CETESB - No 114/2019/P/C }\end{array}$ & LR de medicamentos domiciliares & $\mathrm{X}$ & $\mathrm{X}$ & $\mathrm{X}$ & $\bar{X}$ & & $\mathrm{X}$ & Bloco C \\
\hline $\begin{array}{l}\text { Bellan et al. (2012) } \\
\text { Kabir (2013) } \\
\text { Narayana, Elias e Pati (2014) } \\
\text { Bravo e Carvalho (2015) } \\
\text { Kongar et al. (2015) } \\
\text { Campos et al. (2017) }\end{array}$ & $\begin{array}{l}\text { Motivos de retorno: Produtos } \\
\text { devolvidos / Recall: reclamações / } \\
\text { recolhimento de medicamentos }\end{array}$ & $\mathrm{X}$ & $\mathrm{X}$ & $\mathrm{X}$ & $\bar{X}$ & $\mathrm{X}$ & $\bar{X}$ & Bloco D \\
\hline
\end{tabular}


Tabela 3 - Categorias da LR com base nos artigos e normas I(continuação)

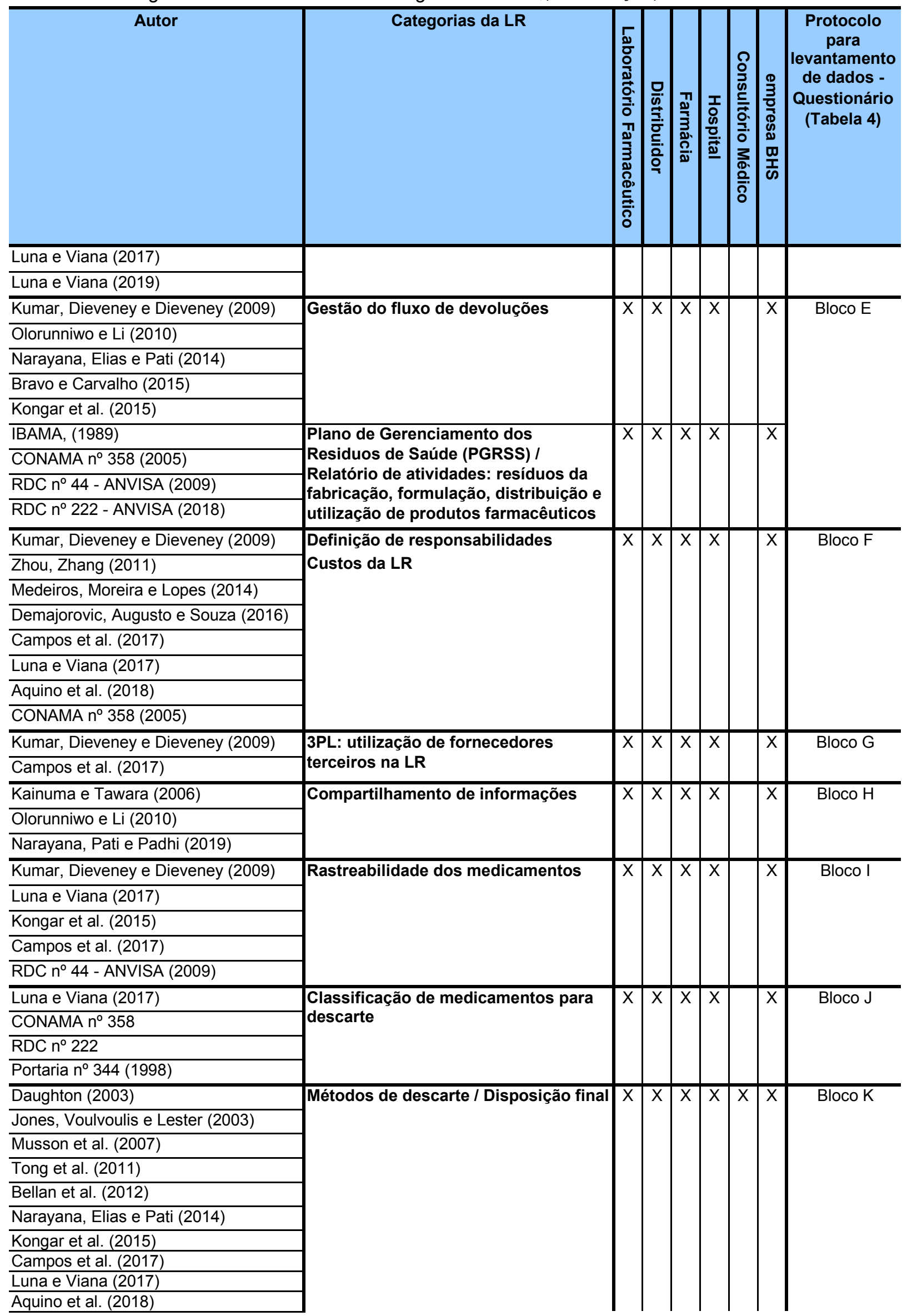


Tabela 3 - Categorias da LR com base nos artigos e normas I(conclusão)

\begin{tabular}{|c|c|c|c|c|c|c|c|c|}
\hline Autor & Categorias da LR & 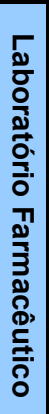 & 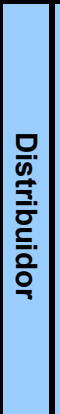 & 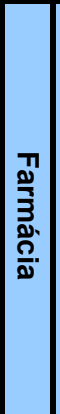 & 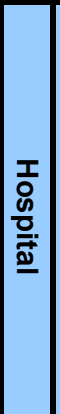 & 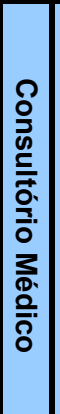 & 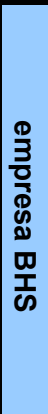 & $\begin{array}{l}\text { Protocolo } \\
\text { para } \\
\text { levantamento } \\
\text { de dados - } \\
\text { Questionário } \\
\text { (Tabela 4) }\end{array}$ \\
\hline $\begin{array}{l}\text { Blankenstein e Junior (2018) } \\
\text { CONAMA n } 358(2005) \\
R D C n^{\circ} 222 \text { - ANVISA (2018) } \\
\end{array}$ & & & & & & & & \\
\hline $\begin{array}{l}\text { Daughton (2003) } \\
\text { Kabir (2013) } \\
\text { Medeiros, Moreira e Lopes (2014) } \\
\text { Kongar et al. (2015) } \\
\text { Narayana, Pati e Padhi (2019) } \\
\end{array}$ & $\begin{array}{l}\text { Reutilização de medicamentos } \\
\text { devolvidos no prazo de validade }\end{array}$ & $\mathrm{X}$ & $\mathrm{X}$ & $\mathrm{X}$ & $\mathrm{X}$ & $\mathrm{X}$ & $\mathrm{X}$ & Bloco L \\
\hline $\begin{array}{l}\text { Daughton (2003) } \\
\text { Vollmer (2010) } \\
\text { Kongar et al. (2015) } \\
\text { Luna e Viana (2017) } \\
\text { Stocher et al. (2018) } \\
\text { RDC nº } 44 \text { - ANVISA (2009) }\end{array}$ & $\begin{array}{l}\text { Destino produtos vencidos / próximos } \\
\text { ao vencimento } \\
\text { Farmácias e Drogarias: pontos de } \\
\text { coleta }\end{array}$ & & & $\mathrm{X}$ & $\mathrm{X}$ & & $\mathrm{X}$ & Bloco M \\
\hline $\begin{array}{l}\text { Daughton (2003) } \\
\text { Guirguis (2010) } \\
\text { Xie e Breen (2012) } \\
\text { Kongar et al. (2015) } \\
\text { Campos et al. (2017) } \\
\text { Luna e Viana (2017) } \\
\text { Pereira et al. (2017) } \\
\text { Aquino et al. (2018) } \\
\text { Stocher et al. (2018) } \\
\text { RDC } \text { n }^{\circ} 44 \text { - ANVISA (2009) } \\
\text { CETESB - No 114/2019/P/C }\end{array}$ & $\begin{array}{l}\text { Conscientização / Campanha de } \\
\text { divulgação }\end{array}$ & $\mathrm{X}$ & $\mathrm{X}$ & $\mathrm{X}$ & $\mathrm{X}$ & $\mathrm{X}$ & $\mathrm{X}$ & Bloco N \\
\hline $\begin{array}{l}\text { Tibben-Lembke e Rogers (2002) } \\
\text { Kumar, Dieveney e Dieveney (2009) } \\
\text { Ye e Zhenhua (2014) } \\
\end{array}$ & $\begin{array}{l}\text { Incerteza: quantidade e qualidade } \\
\text { produtos retornados }\end{array}$ & $\mathrm{X}$ & $\mathrm{X}$ & $\mathrm{X}$ & $\mathrm{X}$ & & $\mathrm{X}$ & Bloco O \\
\hline $\begin{array}{l}\text { Kumar, Dieveney e Dieveney (2009) } \\
\text { Bravo e Carvalho (2015) } \\
\text { Campos et al. (2017) } \\
\text { Luna e Viana (2017) } \\
\end{array}$ & Prática LR: complexidade e desafio & $\mathrm{X}$ & $\mathrm{X}$ & $\mathrm{X}$ & $\mathrm{X}$ & & $\mathrm{X}$ & Bloco P \\
\hline Skinner, Bryant e Richey (2008) & Indicadores da LR & $\mathrm{X}$ & $\mathrm{x}$ & $\mathrm{X}$ & $\mathrm{X}$ & & $\mathrm{X}$ & Bloco Q \\
\hline
\end{tabular}

Fonte: Autor. 


\section{METODOLOGIA}

Yin (2001, p. 19) afirmou que "os estudos de caso representam a estratégia preferida quando se colocam questões do tipo "como" e "por que", quando o pesquisador tem pouco controle sobre os eventos e quando o foco se encontra em fenômenos contemporâneos inseridos em algum contexto da vida real". Meredith (1998) complementou que o estudo de caso ajuda o pesquisador a compreender porque certas características ocorrem ou não ocorrem. Pode ser utilizada metodologia tanto quantitativa quanto qualitativa na compreensão dos fenômenos (EISENHARDT, 1989; MEREDITH, 1998).

Em estudos de caso, o pesquisador determina as variáveis em um estudo de pesquisa com base na literatura. Assim, identificam-se as variáveis que afetam o fenômeno em estudo, estima-se sua variabilidade, determina-se seu tamanho e efeito, e entende-se seu funcionamento e como se relacionam (MEREDITH, 1998).

Coerência e fundamentação em evidências são as bases de um estudo de caso (EISENHARDT, 1989).

$\mathrm{Na}$ aplicação do estudo de caso, utilizam-se métodos de coleta de dados através de arquivos (acervo), entrevistas, questionários e observações (EISENHARDT, 1989; MEREDITH, 1998).

O estudo de caso pode ser restrito a um único cenário, chamado de estudo de caso único ou estudo de casos múltiplos, quando várias configurações são investigadas para ajudar a estender a generalização dos resultados (MEREDITH, 1998; YIN, 2001). Yin (2001) sugere o uso de múltiplas fontes de evidências como forma de garantir a validade do constructo e ser considerado mais robusto. Segundo Miguel (2007), a adoção de uma abordagem metodológica, como o estudo de caso, deve responder à questão de pesquisa.

O propósito desta pesquisa foi identificar as práticas da LR adotadas na indústria farmacêutica brasileira, com enfoque no estado de São Paulo, para o descarte apropriado de medicamentos, utilizando como metodologia estudo de caso único com várias unidades incorporadas, com caráter exploratório e abordagem qualitativa dos dados, a fim de se mostrar a realidade do fluxo reverso de medicamentos. O estudo se caracteriza por ser de caso único pelo estudo ser focado na cadeia farmacêutica e incorporado, por haver mais de uma unidade de 
análise na pesquisa. As unidades de análise utilizadas na pesquisa foram delimitadas da seguinte forma:

- 3 laboratórios farmacêuticos, sendo um laboratório nacional de medicamentos disponíveis no varejo, um laboratório de medicamentos oncológicos e antirretrovirais importados e um laboratório nacional de medicamentos antirretrovirais e osteoporose;

- 2 Distribuidores;

- 3 Redes de farmácia (2 grande porte / 1 pequeno porte);

- 2 Hospitais (público / privado);

- 3 Consultórios médicos

- BHS - Brasil Health Service: empresa gestora do programa de LR de medicamentos domiciliares, diretamente associada à Interfarma Associação da Indústria Farmacêutica de Pesquisa.

Os critérios utilizados para a escolha das empresas são essenciais para a qualidade dos resultados (EISENHARDT, 1989). As unidades de referência foram selecionadas por conveniência por conhecer pessoas no ramo, mas procurando manter uma diversidade na escolha das empresas entrevistadas,

O intuito de replicar a pesquisa com atores de cada setor da PSC é traçar um comparativo e desenvolver linhas de investigação convergentes de investigação em um processo de triangulação (YIN, 2001). A coleta de dados se realizou por meio de entrevistas, observação direta e análise de documentos, sendo que o escopo se limitou a empresas localizadas no Estado de São Paulo.

Com base nos procedimentos recomendados na literatura (YIN, 2001), foram adotadas as seguintes etapas da metodologia:

1. Projeto do protocolo do estudo de caso;

2. Coleta de dados nas empresas;

3. Análise das evidências do estudo de caso;

4. Conclusões, recomendações e implicações com base nas evidências.

Para coleta de dados, foi elaborado um protocolo baseado na literatura e posteriormente, foram conduzidas entrevistas semiestruturada nas empresas selecionadas, juntamente com a análise de documentos e registros relacionados ao descarte de medicamentos ao longo de toda cadeia de suprimentos farmacêutica (ver Tabela 4). 
Tabela 4 - Protocolo para levantamento de dados

\begin{tabular}{|c|c|c|c|}
\hline Categorias da LR & Bloco & \# item & Questionário \\
\hline \multirow{2}{*}{$\begin{array}{l}\text { Sustentabilidade: impactos } \\
\text { sociais e ambientais }\end{array}$} & \multirow[t]{2}{*}{ A } & 1 & A empresa tem programas implementados voltados à sustentabilidade? \\
\hline & & 2 & $\begin{array}{l}\text { Quais os riscos / impactos ambientais gerados pelo descarte incorreto } \\
\text { dos medicamentos fabricados pela empresa? }\end{array}$ \\
\hline \multirow{2}{*}{$\begin{array}{l}\text { Regulamentos governamentais } \\
\text { IBAMA / CONAMA } n^{\circ} 358 \text { / } \\
\text { ABNT:NBR } 16457 \\
\text { ANVISA: RDC } n^{\circ} 222 \text { e RDC } n^{\circ} 44 \text { / } \\
\text { CETESB }\end{array}$} & \multirow[t]{2}{*}{ B } & 3 & $\begin{array}{l}\text { Existe alguma norma governamental que a sua empresa tem que } \\
\text { obedecer em relação ao descarte de medicamentos? }\end{array}$ \\
\hline & & 4 & $\begin{array}{l}\text { Qual é a responsabilidade da sua empresa referente à logística reversa } \\
\text { em relação às normas aplicáveis? }\end{array}$ \\
\hline \multirow{3}{*}{$\begin{array}{l}\text { LR de medicamentos domiciliares } \\
\text { ABNT NBR 16457:2016 } \\
\text { CETESB }\end{array}$} & \multirow[t]{3}{*}{ C } & 5 & $\begin{array}{l}\text { Como estão trabalhando para implantação da Decisão da Diretoria da } \\
\text { CETESB } n^{\circ} 114 / 2019 / P / C ?\end{array}$ \\
\hline & & 6 & $\begin{array}{l}\text { Existe alguma ação de sua empresa em relação à norma ABNT:NBR } \\
16457 \text { - Logística reversa de medicamentos de uso humano vencidos } \\
\text { e/ou em desuso? }\end{array}$ \\
\hline & & 7 & $\begin{array}{l}\text { Você tem conhecimento de alguma programa destinado à devolução } \\
\text { segura e/ou reaproveitamento de medicamentos? }\end{array}$ \\
\hline \multirow{2}{*}{$\begin{array}{l}\text { Motivos de retorno: Produtos } \\
\text { devolvidos / Recall: reclamações I } \\
\text { recolhimento de medicamentos } \\
\text { RDC } \mathrm{n}^{\circ} 222\end{array}$} & \multirow[t]{2}{*}{ D } & 8 & $\begin{array}{l}\text { Em quais situações aplica-se a logística reversa? Quais motivos para o } \\
\text { retorno? }\end{array}$ \\
\hline & & 9 & $\begin{array}{l}\text { Tem conhecimento de algum processo de recall de medicamentos no } \\
\text { últimos anos? }\end{array}$ \\
\hline \multirow{4}{*}{$\begin{array}{l}\text { Gestão do fluxo de devoluções } \\
\text { CONAMA } n^{\circ} 358 \text { / RDC } n^{\circ} 222 \text { / } \\
\text { RDC } n^{\circ} 44 \text { / CETESB / IBAMA }\end{array}$} & \multirow[t]{4}{*}{$\mathrm{E}$} & 10 & Como é feita a gestão do fluxo de devoluções dos medicamentos? \\
\hline & & 11 & Desenhe ou detalhe o fluxo da logística reversa na sua empresa \\
\hline & & 12 & Quais as principais atividades envolvidas na logística reversa? \\
\hline & & 13 & $\begin{array}{l}\text { Quais relatórios sobre descarte de medicamentos são elaborados pela } \\
\text { empresa e para quais entidades ou agências estes relatórios são } \\
\text { submetidos? }\end{array}$ \\
\hline \multirow[t]{2}{*}{$\begin{array}{l}\text { Definição de responsabilidades } \\
\text { Custos da LR }\end{array}$} & \multirow[t]{2}{*}{$\mathrm{F}$} & 14 & $\begin{array}{l}\text { As responsabilidades entre agentes da cadeia farmacêutica estão bem } \\
\text { definidas na logística reversa? Descreva. }\end{array}$ \\
\hline & & 15 & A logística reversa é vista como custo? \\
\hline \multirow{2}{*}{$\begin{array}{l}\text { 3PL: utilização de fornecedores } \\
\text { terceiros na LR }\end{array}$} & \multirow[t]{2}{*}{ G } & 16 & Quem realiza o transporte na LR e como é feito? \\
\hline & & 17 & $\begin{array}{l}\text { Como são definidas as responsabilidades do transporte LR e como se } \\
\text { controla? }\end{array}$ \\
\hline \multirow[t]{2}{*}{$\begin{array}{l}\text { Compartilhamento de } \\
\text { informações }\end{array}$} & \multirow[t]{2}{*}{$\mathrm{H}$} & 18 & $\begin{array}{l}\text { Como você definiria a colaboração da cadeia de suprimentos em relação } \\
\text { à LR? }\end{array}$ \\
\hline & & 19 & $\begin{array}{l}\text { Há um compartilhamento de informações na cadeia farmacêutica } \\
\text { visando otimização do sistema de LR? Como é feito? }\end{array}$ \\
\hline $\begin{array}{l}\text { Rastreabilidade dos } \\
\text { medicamentos } \\
\text { RDC } n^{\circ} 44\end{array}$ & I & 20 & $\begin{array}{l}\text { Há rastreabilidade dos medicamentos durante o processo de logística } \\
\text { reversa? }\end{array}$ \\
\hline $\begin{array}{l}\text { Classificação de medicamentos } \\
\text { para descarte CONAMA }{ }^{\circ} 358 \text { / } \\
\text { RDC } n^{\circ} 222 \text { / IBAMA }\end{array}$ & $\mathrm{J}$ & 21 & Existe alguma classificação dos medicamentos para descarte? \\
\hline $\begin{array}{l}\text { Métodos de descarte / Disposição } \\
\text { final CONAMA } n^{\circ} 358 \text { / RDC } n^{\circ} 222\end{array}$ & $\mathrm{~K}$ & 22 & Quais são os métodos utilizados para o descarte de medicamentos? \\
\hline \multirow[t]{2}{*}{$\begin{array}{l}\text { Reutilização de medicamentos } \\
\text { devolvidos no prazo de validade }\end{array}$} & & 23 & $\begin{array}{l}\text { É possível reutilização de medicamentos devolvidos no prazo de } \\
\text { validade? }\end{array}$ \\
\hline & & 24 & É feito teste de estabilidade para averiguar sua qualidade? \\
\hline \multirow{3}{*}{$\begin{array}{l}\text { Devolução de medicamentos I } \\
\text { pontos de coleta } \\
\text { Destino produtos vencidos / } \\
\text { próximos ao vencimento } \\
\text { Farmácias e Drogarias: pontos de } \\
\text { coleta RDC } n^{\circ} 44\end{array}$} & \multirow[t]{3}{*}{$\mathrm{M}$} & 25 & Como é feita a devolução de medicamentos nos pontos de coleta? \\
\hline & & 26 & $\begin{array}{l}\text { Toda farmácia pode receber medicamentos expirados e/ou não } \\
\text { utilizados? }\end{array}$ \\
\hline & & 27 & $\begin{array}{l}\text { O consumidor final tem o hábito de devolver medicamentos expirados } \\
\text { e/ou não utilizados? }\end{array}$ \\
\hline \multirow{2}{*}{$\begin{array}{l}\text { Conscientização / Campanha de } \\
\text { divulgação } \\
\text { CETESB / RDC n } 44\end{array}$} & \multirow[t]{2}{*}{$\mathrm{N}$} & 28 & $\begin{array}{l}\text { Existe alguma orientação ao consumidor final sobre os riscos do } \\
\text { descarte incorreto de medicamentos? }\end{array}$ \\
\hline & & 29 & $\begin{array}{l}\text { Há campanhas de conscientização para o consumidor final sobre } \\
\text { descarte adequado de medicamentos? }\end{array}$ \\
\hline \multirow[t]{2}{*}{$\begin{array}{l}\text { Incerteza: quantidade e qualidade } \\
\text { produtos retornados }\end{array}$} & \multirow[t]{2}{*}{$\mathrm{O}$} & 30 & $\begin{array}{l}\text { Há mensuração do volume retornado? Qual o volume mensal }(\mathrm{kg}) \text { de } \\
\text { produto retornado? }\end{array}$ \\
\hline & & 31 & Como a empresa lida com as incertezas da LR? Detalhar \\
\hline $\begin{array}{l}\text { Prática LR: complexidade e } \\
\text { desafio }\end{array}$ & $\mathrm{P}$ & 32 & $\begin{array}{l}\text { No contexto da logística reversa, quais seriam facilitadores / restrições } \\
\text { em todas as etapas? }\end{array}$ \\
\hline \multirow[t]{2}{*}{ Indicadores da LR } & \multirow[t]{2}{*}{ Q } & 33 & Quais são os indicadores associados à logística reversa? \\
\hline & & 34 & Os resultados da logística reversa são medidos e monitorados? \\
\hline
\end{tabular}

Fonte: Autor baseado na literatura e legislação. 
A análise de dados consiste em examinar, categorizar, tabular ou de alguma outra forma, recombinar evidência para abordar as proposições iniciais de um estudo (YIN, 2001). O método utilizado foi análise de conteúdo que consiste em:

\footnotetext{
Um conjunto de técnicas de análise das comunicações,visando obter por procedimentos sistemáticos e objetivos de descrição do conteúdo das mensagens indicadores (quantitativos ou não) que permitam a inferência de conhecimentos relativos às condições de produção/recepção (variáveis inferidas) dessas mensagens" (BARDIN, 2011, p. 48).
}

Os resultados encontrados nas entrevistas foram analisados criticamente a luz da revisão da literatura e confrontados com a legislação pertinente.

O pesquisador deve constantemente comparar teoria (construto) e dado coletado a fim de estabelecer ou não a validade do constructo. Quando o dado se comprova em fontes distintas, o achado é forte e melhor fundamentado. O processo está intimamente ligado com a evidência empírica (EISENHARDT, 1989).

O estudo de caso deve ser conduzido com rigor, exigindo uma observação detalhada, triangulação, determinação cuidadosa de cadeias de causa e efeito e inferência lógica (MEREDITH, 1998). 


\section{APRESENTAÇÃO DAS EMPRESAS ANALISADAS}

As entrevistas foram realizadas com profissionais de diversas áreas e de diferentes níveis hierárquicos, indicados pelo conhecimento do tema e por participarem diretamente dos processos avaliados. A Tabela 5 indica as empresas e os cargos dos entrevistados, cujos nomes não serão divulgados a fim de preservar as empresas e a identidade das pessoas.

Tabela 5 - Empresas entrevistadas

\begin{tabular}{|c|c|c|c|}
\hline Empresa & Segmento & Localização & Cargo do entrevistado \\
\hline \multirow{2}{*}{$\begin{array}{l}\text { Laboratório } \\
\text { Farmacêutico } 1\end{array}$} & \multirow{2}{*}{$\begin{array}{l}\text { Grupo de empresas } \\
\text { farmacêuticas - varejo }\end{array}$} & \multirow{2}{*}{$\begin{array}{l}\text { Estado de São } \\
\text { Paulo }\end{array}$} & Diretor de Logística \\
\hline & & & Coordenadora da Qualidade \\
\hline $\begin{array}{l}\text { Laboratório } \\
\text { Farmacêutico } 2\end{array}$ & $\begin{array}{l}\text { Laboratório farmacêutico - } \\
\text { oncológico, antirretroviral }\end{array}$ & $\begin{array}{l}\text { Município de } \\
\text { São Paulo }\end{array}$ & Coordenadora de EHS \\
\hline $\begin{array}{l}\text { Laboratório } \\
\text { Farmacêutico } 3\end{array}$ & $\begin{array}{l}\text { Laboratório farmacêutico - } \\
\text { antirretroviral, osteoporose }\end{array}$ & $\begin{array}{l}\text { Estado de São } \\
\text { Paulo }\end{array}$ & Gerente da Controladoria \\
\hline \multirow[t]{2}{*}{ Distribuidor 1} & \multirow[t]{2}{*}{ Distribuição de medicamentos } & \multirow{2}{*}{$\begin{array}{l}\text { Estado de São } \\
\text { Paulo }\end{array}$} & Diretor Comercial \\
\hline & & & Setor Regulatório \\
\hline \multirow[t]{2}{*}{ Distribuidor 2} & \multirow[t]{2}{*}{ Distribuição de medicamentos } & \multirow{2}{*}{$\begin{array}{l}\text { Estado de São } \\
\text { Paulo }\end{array}$} & Gerente de Logística \\
\hline & & & Farmacêutica responsável \\
\hline Farmácia 1 & Rede de drogarias & $\begin{array}{l}\text { Município de } \\
\text { São Paulo }\end{array}$ & Diretora de Compras \\
\hline Farmácia 2 & Rede de drogarias & $\begin{array}{l}\text { Município de } \\
\text { São Paulo } \\
\end{array}$ & Farmacêutico responsável \\
\hline \multirow[t]{2}{*}{ Farmácia 3} & \multirow[t]{2}{*}{ Drogaria independente } & \multirow{2}{*}{$\begin{array}{l}\text { Município de } \\
\text { São Paulo }\end{array}$} & Farmacêutica responsável \\
\hline & & & CEO \\
\hline \multirow[t]{2}{*}{ Hospital 1} & \multirow[t]{2}{*}{ Hospital Privado } & \multirow{2}{*}{$\begin{array}{l}\text { Município de } \\
\text { São Paulo }\end{array}$} & Gerente da Farmácia \\
\hline & & & $\begin{array}{l}\text { Coordenadora da Gestão } \\
\text { Ambiental }\end{array}$ \\
\hline \multirow[t]{2}{*}{ Hospital 2} & \multirow[t]{2}{*}{ Hospital Público } & \multirow{2}{*}{$\begin{array}{l}\text { Município de } \\
\text { São Paulo }\end{array}$} & Responsável Logístico \\
\hline & & & Bombeiro \\
\hline Consultório 1 & $\begin{array}{l}\text { Consultório Médico - } \\
\text { Gastroenterologia }\end{array}$ & $\begin{array}{l}\text { Município de } \\
\text { São Paulo }\end{array}$ & Médico \\
\hline Consultório 2 & $\begin{array}{l}\text { Consultório Médico - } \\
\text { Ginecologia }\end{array}$ & $\begin{array}{l}\text { Município de } \\
\text { São Paulo } \\
\end{array}$ & Médico \\
\hline Consultório 3 & Consultório Odontológico & $\begin{array}{l}\text { Município de } \\
\text { São Paulo }\end{array}$ & Dentista \\
\hline $\begin{array}{l}\text { BHS } \\
\text { (Interfarma) }\end{array}$ & $\begin{array}{l}\text { Empresa especializada em } \\
\text { logística reversa de } \\
\text { medicamentos }\end{array}$ & $\begin{array}{l}\text { Município de } \\
\text { São Paulo }\end{array}$ & Coordenador LR \\
\hline
\end{tabular}

Fonte: Autor. 
A coleta de dados foi realizada no período de outubro de 2019 até fevereiro de 2020, onde foram executadas 11 entrevistas. Em decorrência da pandemia do Covid-19, não foi possível dar continuidade às entrevistas, as quais ficaram suspensas, retornando em setembro de 2020, com conclusão em novembro de 2020 das 3 entrevistas restantes

Nos próximos tópicos, uma breve apresentação de cada empresa avaliada, baseada em informações dos entrevistados, pesquisa nos sites das empresas e associações farmacêuticas.

\subsection{LABORATÓRIO FARMACÊUTICO 1}

O Laboratório farmacêutico 1 é um conglomerado de empresas com mais de 70 anos de experiência no segmento farmacêutico brasileiro. Sua sede situa-se no interior do Estado de São Paulo, com 6 fábricas espalhadas pelo Brasil, além de aquisições de laboratórios no exterior. Possui uma linha ampla de medicamentos que também são exportados. Dentre suas principais especialidades está a fabricação e comercialização de medicamentos genéricos, com exportações para mais de 40 países na Europa, Ásia, África, América Latina e Oriente Médio. Emprega mais de sete mil colaboradores.

A entrevista foi realizada com o Diretor de Logística do grupo farmacêutico que para responder a determinadas perguntas, obteve assessoria do Customer Service e da Coordenadora de Qualidade. A entrevista durou cerca de 3 horas e foi finalizada com uma visita ao centro de distribuição logístico, acompanhada pelo Gerente de Transporte da empresa.

\subsection{LABORATÓRIO FARMACÊUTICO 2}

O Laboratório farmacêutico 2 é uma empresa biofarmacêutica americana com filiais em todos os continentes. No Brasil, não possui unidade fabril e o escritório central que está localizado na cidade de São Paulo somente importa e distribui os medicamentos. Entre as principais áreas de atuação da companhia estão a oncologia, virologia, imunologia, neurologia, cardiovascular e fibrose, onde investe constantemente em pesquisas para desenvolvimento de novas drogas, conduzindo estudos clínicos no Brasil. Os medicamentos são importados e de alto custo não 
sendo comercializados diretamente nas farmácias e drogarias, distribuídos diretamente às instituições de saúde públicas e privadas, Secretaria da Saúde e Ministério da Saúde.

A entrevista foi realizada com a Coordenadora de EHS - Saúde, Segurança e Meio Ambiente e durou cerca de 1 hora e 10 minutos. Os apontamentos realizados na entrevista foram validados por ela em uma nova reunião com duração de 30 minutos a fim de esclarecer pontos específicos.

\subsection{LABORATÓRIO FARMACÊUTICO 3}

O Laboratório farmacêutico 3 é uma empresa brasileira com mais de 30 anos no mercado, com 2 fábricas no Estado de São Paulo que produzem medicamentos nas áreas de tratamento antirretroviral, osteoporose e também atua na fabricação de ingredientes farmacêuticos ativos. Investe continuamente em pesquisa, inovação e desenvolvimento, buscando sempre criar soluções para as novas demandas do mercado, tanto em matérias-primas quanto em medicamentos. Seus medicamentos são distribuídos mais fortemente para o governo (SUS - Sistema Único de Saúde) através de leilão online e outra parcela é distribuída diretamente para drogarias, como Ultrafarma, Onofre, Drogasil, Droga Raia, Pacheco e Drogaria São Paulo.

A entrevista foi realizada com o Gerente de Controladoria que trabalha na empresa há 3 anos, mas atua no ramo farmacêutico há mais de 10 anos. A entrevista durou cerca de 2 horas.

\subsection{DISTRIBUIDOR 1}

Com 19 anos de experiência no mercado de distribuição, a empresa está situada no interior do estado de São Paulo. Conta com uma estrutura para lidar com 15000 SKU's (unidade de manutenção de estoque) e capacidade de armazenamento de $30000 \mathrm{~m}^{3}$. Para ganhos em agilidade e minimização de erros, utilizam o sistema ROWA que é um robô de última geração para separação de produtos de alto custo, sem contato manual, eliminando o processo de conferência. As esteiras automatizadas facilitam a movimentação dos volumes e sistema de "picking by light" proporciona separação de produtos 5 vezes mais rápida. Empregam cerca de 100 funcionários. 
A entrevista foi realizada com o Diretor Comercial da empresa e durou cerca de 50 minutos. Algumas questões foram direcionadas e respondidas pela responsável do setor regulatório em entrevista com duração de 15 minutos.

\subsection{DISTRIBUIDOR 2}

Empresa localizada no interior do estado de São Paulo, atuando há 46 anos no setor de distribuição de medicamentos. Conta com uma sólida carteira de clientes e atendimento dos pedidos em até 24 horas, propiciando um serviço diferenciado e inovador aos seus clientes. Representa os mais importantes laboratórios de medicamentos genéricos e similares do mercado. Atualmente, pertence ao grupo das cinco maiores distribuidoras de similares e genéricos de São Paulo. Atende aproximadamente 5.000 clientes mensais e está presente em 400 municípios.

A entrevista foi realizada, primeiramente, com o Gerente de Logística e na sequência, com a responsável pela farmacêutica responsável, com duração de cerca de 2 horas.

\subsection{FARMÁCIA 1}

A Farmácia 1 é uma rede de drogarias brasileira pioneira no setor de comercialização de medicamentos genéricos, tendo mais de 15 mil produtos disponíveis para venda através do E-commerce e lojas. Com 20 anos de atuação e cerca de 1000 funcionários, está fortemente estabelecida na cidade de São Paulo. Conta também com um centro de distribuição para atendimento às unidades da rede.

A entrevista na Farmácia 1 foi realizada com a Diretora de Compras e durou cerca de 1 hora, sendo bastante objetiva.

\subsection{FARMÁCIA 2}

A entrevista na farmácia 2 foi realizada com um dos Farmacêuticos Responsável e durou cerca de 1 hora. A Farmácia 2 faz parte de uma rede de drogarias de um grupo varejista internacional com forte atuação no mercado brasileiro, possuindo mais 360 mil colaboradores na Europa, Ásia e América Latina. 
No Brasil, conta com 72 mil colaboradores distribuídos em cerca de 500 lojas, espalhadas em 26 estados e Distrito Federal.

\subsection{FARMÁCIA 3}

Com 3 colaboradores, a Farmácia 3 é um drogaria independente com apenas uma loja física localizada em um bairro na zona sul do município de São Paulo.

A entrevista na Farmácia 3 contou com a participação da farmacêutica responsável e do proprietário da farmácia, durando cerca de 1 hora.

\subsection{HOSPITAL 1}

O Hospital 1 é um hospital brasileiro privado localizado na zona sul do município de São Paulo. Com cerca de 15000 funcionários e mais de 60 anos de existência, o hospital possui programas de assistência social em parceria com a prefeitura e voluntários.

A entrevista no Hospital 1 foi realizada, primeiramente, com o Gerente da farmácia hospitalar e durou cerca de 1 hora. Depois, fui encaminhada para entrevista com a Coordenadora de Gestão Ambiental com duração de 3 horas. Durante a entrevista, pude visitar a farmácia do hospital e as áreas de armazenamento para descarte dos resíduos hospitalares.

\subsection{HOSPITAL 2}

O Hospital 2 é um hospital público municipal com 5 anos de existência, administrado por uma grande instituição hospitalar privada por meio de um convênio com Ministério da Saúde através do PROADI (Programa de Apoio ao Desenvolvimento Institucional) e Prefeitura Municipal de São Paulo. É considerado um hospital de alta complexidade que atende pacientes SUS em São Paulo.

A entrevista no Hospital 2 foi realizada com o responsável pela área logística, sendo que os assuntos relacionados à destinação de resíduos e legislação foi respondida pelo bombeiro responsável. A entrevista durou cerca de 1 hora e 30 minutos. 


\subsection{CONSULTÓRIO 1}

O Consultório 1 é uma clínica particular cuja especialidade é gastroenterologia e está localizada na zona sul do município de São Paulo. O médico entrevistado tem experiência em sustentabilidade por implantar programas ligados a este tema quando atuava na área hospitalar. A entrevista teve duração aproximada de 30 minutos.

\subsection{CONSULTÓRIO 2}

O Consultório 2 é uma clínica particular cuja especialidade é ginecologia e obstetrícia e está localizado na zona sul do município de São Paulo. O médico entrevistado atende em outro consultório na zona oeste do município de São Paulo. A entrevista teve duração de 20 minutos.

\subsection{CONSULTÓRIO 3}

O Consultório 3 é um consultório odontológico localizado na zona sul do município de São Paulo. A entrevista no Consultório 3 durou cerca de 45 minutos e foi realizada no próprio consultório com a dentista que também atua em um posto de saúde da rede municipal.

\subsection{BHS - BRASIL HEALTH SERVICE (INTERFARMA)}

Fundada no ano 2000, a BHS iniciou suas atividades no segmento de saúde, oferecendo serviços de LR de medicamentos ao varejo farmacêutico. A BHS promove a responsabilidade compartilhada no maior programa de LR de medicamentos do país, sendo responsável pelo Programa Descarte Consciente para os medicamentos vencidos ou em desuso pela população. Esse serviço de gestão visa obter padronização e economia nos processos de separação, segregação, coleta, transporte e destinação final. Os displays estão instalados em 34 farmácias na cidade de São Paulo.

A Interfarma - Associação da Indústria Farmacêutica de Pesquisa, fundada em 1990, é uma entidade setorial, sem fins lucrativos, que representa empresas e 
pesquisadores nacionais ou estrangeiros responsáveis pela inovação em saúde no Brasil. Atualmente, a Interfarma é composta por laboratórios nacionais e internacionais de pesquisa e uma start up, mas pesquisadores nacionais, instituições, fundações, universidades, institutos e até mesmo pessoas físicas podem se associar também. Para estar alinhada com a Decisão de Diretoria da CETESB $n^{\circ}$ 076/2018/C em relação à LR, a Interfarma nomeou a BHS como a gestora operacional do sistema de LR de medicamentos, emitindo relatórios periódicos por peso, ponto de coleta e região, com rastreabilidade dos resíduos até a certificação final, adequado a proposta da Norma ABNT:NBR 16457 de LR de Medicamentos.

$\mathrm{O}$ representante da BHS preferiu responder o questionário por escrito e o mesmo foi encaminhado e recebido através de email. 


\section{RESULTADO DA PESQUISA EM CAMPO}

A pesquisa em campo foi realizada através de questionário semiestruturado mostrado na Tabela 4. Antes de aplicá-lo, o questionário foi validado por duas especialistas da área farmacêutica e alguns ajustes foram realizados, principalmente no direcionamento das perguntas que seriam mais pertinentes para cada setor da cadeia de suprimentos de medicamentos. Durante as entrevistas foram verificados documentos como procedimentos, relatórios, laudos e certificados, apresentações, indicadores e sistemas de monitoramento, juntamente com observação direta dos processos da empresa a fim de efetuar o processo de triangulação.

Para melhor compreensão dos dados coletados, estes serão apresentados obedecendo a sequência das perguntas do questionário e separados em blocos de acordo com os temas abordados. Os resultados encontrados nas entrevistas foram sintetizados na Tabela 6. 
Tabela 6 - Resumo da pesquisa em campo

\begin{tabular}{|c|c|c|c|c|c|c|c|c|c|c|c|c|c|c|c|}
\hline Categorias da LR & Tema & 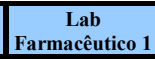 & $\begin{array}{l}\text { Lab } \\
\text { Farmacêutico } 2 \\
\end{array}$ & $\begin{array}{l}\text { Lab } \\
\text { Farmacéutico } 3 \\
\end{array}$ & Distribuidor 1 & Distribuidor 2 & Farmácia 1 & Farmácia 2 & Farmácia 3 & Hospital 1 & \begin{tabular}{|l|} 
Hospital 2 \\
\end{tabular} & $\begin{array}{c}\text { Consultório } \\
\text { Médico 1 }\end{array}$ & $\begin{array}{c}\text { Consultório } \\
\text { Médico 2 }\end{array}$ & $\begin{array}{c}\text { Consultório } \\
\text { Médico } 3\end{array}$ & BHS - Interfarma \\
\hline $\begin{array}{l}\text { Sustentabilidade: impactos } \\
\text { sociais e ambientais }\end{array}$ & \begin{tabular}{|l} 
Sustentabilidade \\
$\begin{array}{l}\text { Risco do descarte incorreto ao } \\
\text { meio ambiente }\end{array}$
\end{tabular} & $\begin{array}{c}\text { Aplica } \\
\text { Tem } \\
\text { conhecimento }\end{array}$ & \begin{tabular}{|c|} 
Aplica \\
Temm \\
conhlecimento
\end{tabular} & $\begin{array}{c}\text { Aplica } \\
\text { Tem } \\
\text { conhecimento }\end{array}$ & $\begin{array}{l}\text { Não aplica } \\
\text { Tem } \\
\text { conhecimento }\end{array}$ & $\begin{array}{c}\text { Aplica } \\
\text { Tem } \\
\text { conhecimento }\end{array}$ & $\begin{array}{l}\text { Não aplica } \\
\text { Tem } \\
\text { conhecimento }\end{array}$ & $\begin{array}{l}\text { Nã̃a aplica } \\
\text { Tem } \\
\text { conhecimento }\end{array}$ & $\begin{array}{l}\text { Não aplica } \\
\text { Tem } \\
\text { conhecimento }\end{array}$ & $\frac{\text { Aplica }}{\text { Tem conhecimento }}$ & \begin{tabular}{|l|} 
Aplica \\
Tomhecime \\
conhec
\end{tabular} & $\begin{array}{c}\text { Não aplica } \\
\text { Năo tem } \\
\text { conhececimento }\end{array}$ & $\begin{array}{l}\text { Não a aplica } \\
\text { Nấ tem } \\
\text { conhecimento }\end{array}$ & \begin{tabular}{|c|} 
Aplica \\
Tem \\
conhecimento
\end{tabular} & $\frac{\text { Aplica }}{\text { Tem conheciment }}$ \\
\hline $\begin{array}{l}\text { Regulamentos } \\
\text { governamentais }\end{array}$ & Normas governamentais & $\begin{array}{l}\text { Conaman } \\
35880^{\circ} \\
\text { RDC } \mathrm{n}^{\circ} \\
222 / 2018\end{array}$ & $\begin{array}{c}\text { Conama } \mathrm{n}^{\circ} \\
35882005 \\
\text { RDC } \mathrm{n}^{\circ} \\
222 / 2018 \\
\text { PNRS 2010 } \\
\end{array}$ & 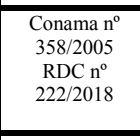 & $\begin{array}{l}\mathrm{RDC}^{\mathrm{R}} \\
222212018\end{array}$ & $\begin{array}{c}\text { Conama } \mathrm{n}^{\circ} \\
358822005 \\
\mathrm{RDC} \mathrm{n}^{\circ} \\
222 / 2018 \\
\mathrm{CVS} \mathrm{n}^{\circ} 21 / 2008 \\
\end{array}$ & 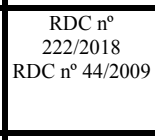 & $\operatorname{RDC~n} n^{4} 44 / 2009$ & $\mathrm{RDC} \mathrm{n}^{\circ} 44 / 2009$ & $\begin{array}{c}\text { Conama }^{0} \mathrm{n}^{0} 358 / 2005 \\
\text { RDC } \mathrm{n}^{0} 22222018 \\
\text { PNRS 22010 } \\
\text { CETESB / SABESP }\end{array}$ & \begin{tabular}{|l|l|}
$\mathrm{RDC} \mathrm{n}^{\circ}$ \\
$222 / 2018$ \\
\end{tabular} & & & & 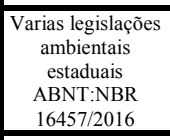 \\
\hline \multirow[t]{2}{*}{$\begin{array}{l}\text { LR de medicamentos } \\
\text { domiciliares }\end{array}$} & \begin{tabular}{|l} 
CETESB N $N^{\circ} 144 / 2019 / \mathrm{P} / \mathrm{C}$ \\
ABNT:NBR 16457/2016
\end{tabular} & $\begin{array}{c}\text { Não aplica } \\
\text { Aplica } \\
\text { parcialmente }\end{array}$ & $\begin{array}{l}\text { Aplica } \\
\text { Aplica }\end{array}$ & $\begin{array}{l}\text { Aplica } \\
\text { Aplica }\end{array}$ & $\begin{array}{l}\text { Não aplica } \\
\text { Nấa aplica }\end{array}$ & $\begin{array}{l}\text { Não aplica } \\
\text { Nấo aplica }\end{array}$ & $\begin{array}{l}\text { Não aplica } \\
\text { Nấa aplica }\end{array}$ & $\begin{array}{l}\text { Aplica } \\
\text { Aplica }\end{array}$ & $\begin{array}{l}\text { Não aplica } \\
\text { Nấa aplica }\end{array}$ & $\begin{array}{l}\text { Não aplica } \\
\text { Nấ aplica }\end{array}$ & \begin{tabular}{|l|l|} 
Não aplica \\
Nẫ aplica
\end{tabular} & & & & $\begin{array}{l}\text { Aplica } \\
\text { Aplica }\end{array}$ \\
\hline & $\begin{array}{l}\begin{array}{l}\text { Reaproveitamento de } \\
\text { medicamentos }\end{array} \\
\end{array}$ & $\begin{array}{c}\text { Nâo tem } \\
\text { conhecimento }\end{array}$ & $\begin{array}{c}\text { Nào tem } \\
\text { conheceimento }\end{array}$ & $\begin{array}{c}\text { Nåa tem } \\
\text { conhecimento }\end{array}$ & $\begin{array}{c}\text { Não tem } \\
\text { conhecimento }\end{array}$ & $\begin{array}{c}\text { Nân tem } \\
\text { conheceimento }\end{array}$ & $\begin{array}{c}\text { Năo tem } \\
\text { conhecimento }\end{array}$ & $\begin{array}{l}\text { Nâa tem } \\
\text { conhecimento }\end{array}$ & $\begin{array}{l}\text { Năo tem } \\
\text { conhecimento }\end{array}$ & $\begin{array}{l}\text { Năo tem } \\
\text { conhecimento }\end{array}$ & $\begin{array}{c}\text { Nầ tem } \\
\text { conheceime } \\
\text { nto }\end{array}$ & & & & $\begin{array}{l}\text { Nåo tem } \\
\text { conhecimento }\end{array}$ \\
\hline \multirow[t]{2}{*}{ 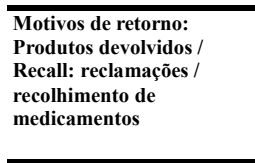 } & Motivos de retorno & \begin{tabular}{|l}
$-\begin{array}{r}- \text { Problema } \\
\text { operacional } \\
\text { - Prazo de } \\
\text { validade } \\
\text { - Avarias }\end{array}$ \\
\end{tabular} & 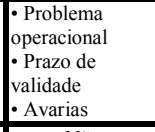 & $\begin{array}{l}-\begin{array}{l}\text { Prazo de } \\
\text { validade } \\
\text { - Avarias }\end{array} \\
\end{array}$ & 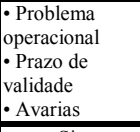 & $\begin{array}{l}\text { P. Problema } \\
\text { operacional } \\
\text { Prazo ole } \\
\text { valdade } \\
\text { avareas } \\
\text { Avarias }\end{array}$ & \begin{tabular}{|l}
$-\begin{array}{r}\text { Problema } \\
\text { operaciconal } \\
\text { - Prazo de } \\
\text { validade } \\
\text { - Avarias }\end{array}$ \\
\end{tabular} & 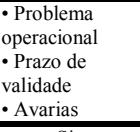 & $\begin{array}{l}\text { Problema } \\
\text { operacional } \\
\text { Prazo ode } \\
\text { valdade } \\
\text { Avarias } \\
\text { Avarias }\end{array}$ & 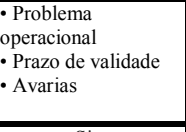 & 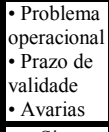 & $\begin{array}{l}\text { Prazo de } \\
\text { validade } \\
\text { - Avarias }\end{array}$ & $\begin{array}{l}\text { - Prazo de } \\
\text { validade }\end{array}$ & $\begin{array}{l}\text { - Prazo de } \\
\text { validade } \\
\text { - Avarias }\end{array}$ & - Diversos motivos \\
\hline & $\begin{array}{l}\text { Recall } \\
\text { Costand }\end{array}$ & Sim & \begin{tabular}{|l} 
Não \\
\end{tabular} & Não & Sim & $\frac{\operatorname{sim}}{\text { Sim }}$ & Sim & Sim & Sim & Sim & Sim & $\operatorname{Sim}$ & Não & Naัo & Não \\
\hline $\begin{array}{l}\text { Gestão do fluxo de } \\
\text { devoluçôes }\end{array}$ & \begin{tabular}{|l|l|l|l|l|l|l|l} 
Relatórios \\
\end{tabular} & $\begin{array}{c}\text { Lanido } \\
\text { Incineracão }\end{array}$ & $\begin{array}{c}\text { Lanudo } \\
\text { Incineracão }\end{array}$ & $\begin{array}{c}\text { Lanudo } \\
\text { Incineracão }\end{array}$ & $\begin{array}{c}\text { Lapudo } \\
\text { Incineração }\end{array}$ & $\frac{\substack{\text { Lpaudo } \\
\text { Incineracão }}}{c}$ & $\begin{array}{c}\text { Lapudodo } \\
\text { Incineracão }\end{array}$ & 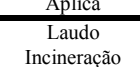 & $\begin{array}{c}\text { Aplica } \\
\text { Llaudo } \\
\text { Incineraço }\end{array}$ & $\frac{\text { Aplica }}{\text { Laudo Incineração }}$ & $\begin{array}{c}\text { Appica } \\
\text { Incido } \\
\text { Incinaracão }\end{array}$ & --- & $-\overline{--}$ & $-\overline{--}$ & $\begin{array}{c}\text { Aplica } \\
\begin{array}{c}\text { Documentos } \\
\text { comprobatórios }\end{array}\end{array}$ \\
\hline $\begin{array}{l}\text { Definicãa o de } \\
\text { responsabilidades } \\
\text { Custos da LR }\end{array}$ & $\begin{array}{l}\begin{array}{l}\text { Responsabilidades LR bem } \\
\text { definidas? }\end{array} \\
\end{array}$ & Sim & Sim & Sim & $\operatorname{Sim}$ & $\operatorname{Sim}$ & $\operatorname{Sim}$ & $\operatorname{Sim}$ & Sim & Sim & Não & --- & --- & --- & Não \\
\hline $\begin{array}{l}\text { Custos da LR } \\
\text { 3PL: tilizacão de empresas } \\
\text { terceirizadas na LR }\end{array}$ & \begin{tabular}{|l|} 
ALR é vista como custo? \\
Utilização de $3 P L$ na LR \\
\end{tabular} & $\frac{\operatorname{Sim}}{\operatorname{Sim}}$ & $\frac{\operatorname{Sim}}{\operatorname{Sim}}$ & $\frac{\operatorname{Sim}}{\operatorname{Sim}}$ & $\frac{\operatorname{Sim}}{\operatorname{Sim}}$ & $\frac{\operatorname{Sim}}{\operatorname{Sim}}$ & $\frac{\operatorname{sim}}{\operatorname{Sim}}$ & $\frac{\operatorname{Sim}}{\operatorname{Sim}}$ & $\frac{\operatorname{Sim}}{\operatorname{Sim}}$ & $\frac{\operatorname{Sim}}{\operatorname{Sim}}$ & $\frac{\operatorname{Sim}}{\operatorname{Sim}}$ & -- & -- & $-\overline{--}$ & $\frac{\operatorname{sim}}{\operatorname{Sim}}$ \\
\hline $\begin{array}{l}\text { Compartilihamanto de } \\
\text { informaçes }\end{array}$ & $\begin{array}{l}\text { Colaboracã̃o } \\
\begin{array}{l}\text { Compartillamento de } \\
\text { informaçes }\end{array}\end{array}$ & $\frac{\operatorname{Sim}}{\text { Não }}$ & $\begin{array}{ll}\text { Não } \\
\text { Não }\end{array}$ & $\frac{\operatorname{Sim}}{\text { Não }}$ & $\frac{\operatorname{Sim}}{\text { Não }}$ & $\frac{\operatorname{sim}}{\text { Não }}$ & $\frac{\operatorname{sim}}{\operatorname{Sim}}$ & $\frac{\operatorname{Sim}}{\operatorname{Sim}}$ & $\frac{\text { Não }}{\text { Não }}$ & $\frac{\operatorname{Sim}}{\text { Nầ }}$ & $\begin{array}{l}\text { Não } \\
\text { Sim }\end{array}$ & $-\cdots$ & - & $\cdots$ & $\frac{\text { Não }}{\text { Nầo }}$ \\
\hline $\begin{array}{l}\begin{array}{l}\text { Rastreabilidadade dos } \\
\text { medicamentos }\end{array} \\
\end{array}$ & Rastreabilididade LR & $\mathrm{NF}$ & $\mathrm{NF}$ & $\mathrm{NF}$ & $\mathrm{NF}$ & $\mathrm{NF}$ & $\mathrm{NF}$ & $\mathrm{NF}$ & $\mathrm{NF}$ & MTR & MTR & 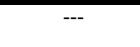 & $\cdots$ & -- & Sim \\
\hline 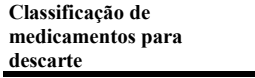 & $\begin{array}{l}\text { llassificacã̃o de medicamento } \\
\text { para descarte }\end{array}$ & $\begin{array}{c}\text { Sim } \\
\text { mrdicamentos } \\
\text { controlados }\end{array}$ & Sim & Sim & Sim & Sim & Sim & Sim & Sim & Sim & Sim & --- & --- & --- & Sim \\
\hline 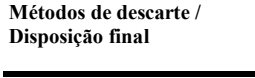 & Método de descarte & Incineraçãoo & Incineração & Incineração & Incineração & Incineração & Incineração & Incineração & Incineração & $\begin{array}{c}\text { Incineracẵo } \\
\text { Esgotot: liberados } \\
\text { pela SABESP } \\
\end{array}$ & [nncineraçăo & lixo & lixo & Incineração & Incineração \\
\hline \multirow{3}{*}{ 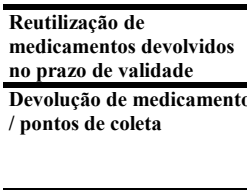 } & $\begin{array}{l}\text { Reutilizacãoode medicamentos } \\
\text { Teste de estabilidade LR }\end{array}$ & $\begin{array}{l}\text { Não } \\
\text { Nâo }\end{array}$ & $\frac{\text { Não }}{\text { Nầo }}$ & $\frac{\operatorname{Sim}}{\operatorname{Sim}}$ & Não & Não & Não & Não & Não & Não & Não & $\begin{array}{l}\text { Sim (informal) } \\
\end{array}$ & Sim(informal) & $\frac{\operatorname{sim} \text { (informal) }}{---}$ & $\begin{array}{ll}\text { Não } \\
\text { Não }\end{array}$ \\
\hline & $\begin{array}{l}\text { Recebe medicamento expirado } \\
\text { e/ou em desuso? }\end{array}$ & $\cdots$ & $\cdots$ & $-\bar{x}$ ( & $\cdots$ & -- & Não recebe & Recebe & $\begin{array}{l}\text { Recebe } \\
\text { (informalmente) }\end{array}$ & $\begin{array}{l}\text { Recebe } \\
\text { (informalmente) }\end{array}$ & Não recebe & --- & --- & --- & $\begin{array}{l}\text { Recebe } \\
\text { Ren }\end{array}$ \\
\hline & $\begin{array}{l}\text { Consumidor tem habitito de } \\
\text { devolver medicamento? }\end{array}$ & -- & $\cdots$ & 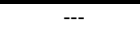 & 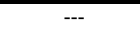 & - & Não & Não & Não & Não & Não & & & & Não \\
\hline \multirow{3}{*}{ 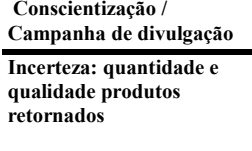 } & \begin{tabular}{|l} 
Orientaç̃̃o \\
Oento
\end{tabular} & $\begin{array}{lll}\text { Não } \\
\text { ฟăn }\end{array}$ & $\begin{array}{lll}\text { Não } \\
\text { k̃anas }\end{array}$ & Não & Não & Não & Não & $\begin{array}{l}\text { Sim (informal) } \\
\text { (infmal }\end{array}$ & Nã̃ & Sim (informal) & Não & Não & $\frac{\text { Não }}{\text { Nân }}$ & Sim (informal) & Sim \\
\hline & $\begin{array}{l}\text { Campanhas de Conscientizacã } \\
\text { Volume LR }\end{array}$ & \begin{tabular}{|l} 
Nào \\
Insignificante
\end{tabular} & $\begin{array}{l}\text { Não } \\
\text { Insignificante }\end{array}$ & $\frac{\text { Não }}{\text { Insignificante }}$ & $\frac{\text { Não }}{\text { Insignificante }}$ & $\begin{array}{c}\text { Não } \\
\text { Insignificante }\end{array}$ & $\begin{array}{l}\text { Não } \\
\text { Insignificante }\end{array}$ & $\frac{\operatorname{Sim} \text { (CCF) }}{\text { Insignificante }}$ & $\frac{\text { Nâo }}{\text { Insignificante }}$ & $\frac{\text { Nào }}{\text { Insignificante }}$ & \begin{tabular}{|l|} 
Nồ \\
Insignifica
\end{tabular} & Não & Năo & $\frac{\text { Nào }}{-\cdots-}$ & $\frac{\text { Não }}{6 \text { toneladas } / \text { mes }}$ \\
\hline & Incertezas & não relevante & \begin{tabular}{|l|l} 
não relevante \\
\end{tabular} & não relevante & não relevante & não relevante & não relevante & não relevante & não relevante & não relevante & \begin{tabular}{|l|} 
nte \\
não
\end{tabular} & & & & Relevante \\
\hline Prática LR: complexidade e & Complexidade e desafio & Sim & Sim & Sim & Sim & $\operatorname{Sim}$ & Sim & Sim & Sim & Sim & Sim & & & $\cdots$ & Sim \\
\hline Indicadores da LR & $\begin{array}{l}\begin{array}{l}\text { Resultados medidos } \\
\text { monitorados? }\end{array} \\
\text { mont }\end{array}$ & Sim & Sim & Sim & Sim & Sm & Sim & Sim & Não & Sim & Sim & -- & -- & -- & Sim \\
\hline
\end{tabular}

Fonte: Autor, baseado nas entrevistas. 


\subsection{SUSTENTABILIDADE: IMPACTOS SOCIAIS E AMBIENTAIS (BLOCO A)}

\section{- A sua empresa tem preocupação com a sustentabilidade?}

\section{- Quais os riscos do descarte incorreto do seu produto no meio ambiente?}

Laboratório 1: demonstrou uma preocupação constante com o meio ambiente e com a orientação sobre o descarte apropriado de materiais através do plano de gerenciamento de resíduos, suportado pelo Sistema de Gestão Ambiental e evidenciado durante a entrevista através de procedimentos e da certificação ISO 14001. São unânimes em afirmar que, quando descartados incorretamente, os medicamentos fabricados pela sua empresa podem contaminar o solo e as águas e expor riscos à saúde da população. O diretor de Logística também enfatizou sobre o risco de algum indivíduo tomar um medicamento do lixo, o que poderia trazer graves consequências a sua saúde.

Laboratório 2: evidenciou uma grande preocupação com a sustentabilidade ressaltando o gerenciamento de resíduos de seu Laboratório de Controle de Qualidade (RSS - químicos). Existe consciência sobre impactos ambientais gerados pelo descarte incorreto de medicamentos, com consequente contaminação da água e do solo, gerando riscos à saúde dos seres vivos. Salientou também sobre os riscos à saúde pública na eventualidade da ocorrência de desvios na cadeia de fornecimentos devido à falsificação de medicamentos.

Laboratório 3: a empresa lida com solventes químicos inflamáveis e altamente contaminantes e tem uma preocupação maior com a sustentabilidade em sua unidade de fabricação de insumos farmacêuticos ativos, pois caso aconteça algum acidente, a contaminação ambiental será elevada. Na sua unidade de produção de medicamentos, o risco ambiental é menor, mas segue toda legislação sanitária suportada pelas Boas Práticas Farmacêutica - RDC 301, fazendo uso de uma empresa especializada para a destinação correta dos resíduos de fabricação farmacêutica.

Distribuidor 1: não há nenhum tipo de programa voltado à sustentabilidade e as questões ambientais, seguem apenas a legislação vigente, pois o não cumprimento é passível de multa. Existe consciência de que o descarte incorreto de 
medicamentos pode contaminar o solo, principalmente, pelo fato de que quase todo medicamento conter alumínio, que demora anos para se decompor. Mencionou também sobre os riscos da automedicação pela sobra de medicamentos nos domicílios e pelo descarte incorreto destes medicamentos na natureza.

Distribuidor 2: em relação à sustentabilidade, há apenas programas para reciclagem de papel. Tem consciência dos riscos em relação à contaminação do meio ambiente no descarte de medicamentos diretamente no solo e na água que podem contaminar as águas, solo e lençol freático, por isso, utilizam uma empresa certificada para efetuar o descarte de medicamentos.

Farmácia 1: não mostrou nenhum programa de sustentabilidade. Praticam o descarte correto dos medicamentos, destinando-os para incineração. Demonstrou preocupação quanto aos riscos dos descartes incorretos dos medicamentos e seus efeitos diretos na contaminação do meio ambiente, além da possibilidade do uso indevido e sem controle dos mesmos.

Farmácia 2: não há programas voltados para sustentabilidade. Tem consciência que os medicamentos descartados incorretamente contaminam o solo e água e afirmou que aplicam a regulamentação da ANVISA para o descarte correto de medicamentos.

Farmácia 3: não há programas que demonstrem preocupação com a sustentabilidade. Salienta que o medicamento quando descartado incorretamente, é um risco para a saúde das pessoas, além da possibilidade de contaminação do meio ambiente.

Hospital 1: tem como missão, entre outros valores, a preocupação com a sustentabilidade e almeja ser referência na questão sócio ambiental, fato este que está evidenciado no relatório de sustentabilidade disponível em seu site. A Coordenadora de Gestão Ambiental, além de citar a missão do hospital, apresentou indicadores de geração de resíduos, consumo de água e energia, emissão de gases de efeito estufa e porcentagem de reciclados. Em relação aos riscos do descarte do medicamento, o Gerente da Farmácia ratificou que descartando-se um medicamento na água ou no esgoto, pode haver a contaminação do meio ambiente e, dependendo do tipo de medicamento como hormônios e antibióticos, poderão não ser removidos na estação de tratamento de água e esgoto, acarretando efeitos nocivos aos seres 
humanos, à fauna e flora. A Coordenadora Ambiental também citou os danos ao meio ambiente e mencionou a lei $n^{\circ} 9.605 / 98$ sobre crimes ambientais e o documento normalizado FDSR - Ficha de Dados de Segurança de Resíduos Químicos, o qual o hospital utiliza para reportar sobre todo resíduo químico gerado (Classe B - tóxicos), sendo que os medicamentos estão incluídos nesta categoria.

Hospital 2: o responsável da logística afirmou que a empresa se preocupa com a sustentabilidade pela separação do lixo comum e reciclável e pela destinação correta dos resíduos gerados. Adiantou que os medicamentos são enquadrados na categoria dos produtos químicos classe $\mathrm{B}$ e devem ser descartados em caixas clean box cor laranja, sendo resíduos classificados como tóxicos, considerados perigosos, que podem gerar impactos ambientais quando descartados incorretamente. Também destacou os perigos das ampolas de medicamentos que podem cortar e perfurar, ocasionando riscos ao ser humano e aos animais.

Consultório 1: o médico gastroenterologista adquiriu um grande conhecimento em sustentabilidade, por sua atuação hospitalar, onde ajudou na implantação das normas ISO 9001 e 14001, mas não há programa de sustentabilidade no seu consultório. Ele afirma que os tipos de medicamentos que têm em seu consultório não afetam o meio ambiente. São na maioria medicamentos para estômago, distribuídos pelos propagandistas como amostra grátis.

Consultório 2: o médico ginecologista afirmou que não há programas de sustentabilidade nos consultórios médicos em que trabalha. Não soube avaliar se os medicamentos em seus consultórios representam risco ao meio ambiente.

Consultório 3: a doutora dentista relata haver uma preocupação com a sustentabilidade na segregação do lixo que é separado e identificado. Existe um processo de colocação de etiquetas de identificação no lixo contaminado. Tem ciência de que os medicamentos descartados incorretamente podem causar contaminação do lençol freático dos rios com consequente dano aos animais e pessoas. Ela comentou sobre estudos que evidenciam que os peixes não estão procriando pelos altos índices de resíduos de hormônios nas águas dos rios.

Empresa BHS: o representante relatou que, de uma forma geral, a cadeia farmacêutica tem programas implantados voltados à sustentabilidade, inclusive, 
salienta: "algumas redes atuam voluntariamente patrocinando programas como o nosso". Quanto ao descarte, ele disse que os medicamentos possuem princípios ativos que em contato com o meio ambiente acabam por contaminar o solo e consequentemente, os lençóis freáticos. Mesmo descartados no vaso sanitário, suas moléculas, que não são eliminadas pelas estações de tratamento, ocasionam problemas cardíacos, renais, hepáticos e podem afetar o sistema nervoso.

\subsection{REGULAMENTOS GOVERNAMENTAIS (BLOCO B)}

- Existe alguma norma governamental que a sua empresa tem que obedecer em relação a geração de resíduos?

- Qual é a responsabilidade de sua empresa em relação a $L R$ em relação às normas aplicadas?

Laboratório 1: em relação às normas governamentais, o Diretor de Logística enfatizou que a ANVISA é muito rigorosa, sendo que a Coordenadora de Qualidade descreve que seguem as normas ambientais CONAMA $n^{\circ} 358 / 2005$ e a RDC $n^{\circ}$ 222/2018. Especificamente sobre a aplicação da LR, emitem os relatórios sobre os resíduos gerados ao IBAMA (CONAMA $\left.n^{\circ} 358\right)$ e à ANVISA (RDC $\left.n^{\circ} 222\right)$. Além disso, é necessária a emissão para controle da ANVISA do laudo dos medicamentos destinados à incineração.

Laboratório 2: as normas utilizadas sobre descarte de medicamentos são a RDC $n^{\circ}$ 222/2018 e Conama $n^{\circ} 358 / 2005$, respaldadas pela PNRS. A RDC no 304/2019 para o transporte e armazenamento dos medicamentos.

Laboratório 3: seguem as normas sobre descarte de resíduos sólidos, a RDC $n^{\circ}$ 222/2018 e Conama $n^{\circ} 358$, reportando a geração de resíduos também ao IBAMA. O Gerente da Controladoria também salientou estar em linha com a RDC $n^{\circ}$ 301/2019 pelas Boas Práticas Farmacêuticas e RDC n 304/2019 para distribuição, armazenagem e transporte de medicamentos. Ele comentou que a PNRS não se aplica, por não fazer menção específica ao segmento farmacêutico.

Distribuidor 1: a pessoa responsável pelo regulatório mostrou que o seu plano de gerenciamento de resíduos segue a RDC no 222/2018 da ANVISA. Em relação à 
RDC n 304/2019 sobre Boas Práticas de Distribuição, Armazenagem e Transporte de Medicamentos, por ter sido publicada em setembro de 2019, ainda estão adequando seus procedimentos à norma. Seguem as legislações pertinentes à LR, realizando devolução aos laboratórios se permitido em acordo comercial ou utilizam uma empresa terceirizada para encaminhar diretamente para incineração.

Distribuidor 2: o Gerente da Logística disse que seguem a legislação da ANVISA, mas não soube dizer quais normas especificamente aplicam. A Farmacêutica afirmou que seguem a normativa da ANVISA RDC $n^{\circ}$ 222/2018 e a CONAMA $n^{\circ}$ 358/2005, ANVISA RDC n 304/2019 sobre as Boas Práticas de Distribuição, Armazenagem e Transporte de Medicamentos e a portaria do Estado São Paulo CVS 21 de 10/09/2008 sobre gerenciamento de resíduos perigosos de medicamentos em serviços de saúde.

Farmácia 1: em atendimento aos regulamentos governamentais, a Farmácia 1 baseia-se nas normas da ANVISA RDC n²22/2018 e RDC n 44/2009. A Diretora de Compras afirmou que seguem todos os procedimentos especificados pela ANVISA, mostrando a conexão com a ANVISA através do site. Salientou a retenção dos relatórios de devolução de medicamentos e dos laudos da incineração conforme mostrado durante a entrevista.

Farmácia 2: o farmacêutico responsável esclareceu que segue a normativa RDC $\mathrm{n}^{\circ}$ 44/2009 que dispõe sobre as boas práticas farmacêuticas em farmácias e drogarias e aplicam a regulamentação da ANVISA para o descarte correto de medicamentos.

Farmácia 3: seguem a normativa da ANVISA RDC n 44/2009, recebendo a visita da vigilância sanitária a cada 3 anos para fiscalização e liberação do alvará de funcionamento. Seguem as "Boas Práticas da Farmácia" e mostrou o procedimento para gerenciamento dos resíduos durante a entrevista.

Hospital 1: o Gerente da Farmácia tem ciência da existência de normas governamentais sobre o descarte de medicamentos, porém ele não soube detalhar, uma vez que o Departamento de Gestão Ambiental é o responsável pelo procedimento. Seguem a normativa para descarte de medicamentos vencidos ou não utilizados, descartando-os em caixas na cor laranja dos resíduos químicos (Classe B - tóxicos) espalhadas em determinados pontos do hospital. Segundo a 
Coordenadora de Gestão Ambiental, o Hospital 1 segue a legislação federal ANVISA RDC $n^{\circ}$ 222/2018, PNRS/2010 e CONAMA n 358/2005 e estadual CETESB sobre separação e descarte de resíduos, sendo de sua responsabilidade reportar à ANVISA, IBAMA, CETESB e SABESP o tipo e quantidade de resíduos gerados. Todos os resíduos químicos manipulados no hospital devem ter um laudo de sua composição química efetuado por empresa autorizada que atenda a norma ABNT a fim de obter autorização da SABESP do método de descarte adequado. Durante a entrevista, ela apresentou as normas e diversos relatórios a fim de comprovar o atendimento ao regulamento.

Hospital 2: sobre a legislação aplicada, utilizam fundamentalmente a RDC $n^{\circ}$ 222/2018 e existe a necessidade de cadastrar no site da Amlurb (Autoridade Municipal de Limpeza Urbana) para discriminar a quantidade e o tipo de resíduos que serão gerados. Os resíduos são recolhidos uma vez por semana pela empresa da prefeitura Loga e Ecourbis e destinados a uma UTR - Central de Tratamento de Resíduos.

Consultórios 1, 2 e 3: não se aplica.

Empresa BHS: afirma ter conhecimento de legislações estaduais que obrigam as farmácias a receberem os medicamentos da população. Existe também a norma técnica da ABNT NBR 16457/2016 que orienta e especifica como deve ser todo o processo. E existe também o Decreto Federal do MMA que está para ser executado. Em sua opinião, como principal agente na cadeia de responsabilidade dos medicamentos, cabe à indústria e às outras entidades representativas envolvidas, participarem de forma ativa e econômica dessa LR.

\subsection{LR DE MEDICAMENTOS DOMICILIARES (BLOCO C)}

- Como estão trabalhando para implementação da revisão da CETESB?

- Como é aplicada a ABNT:NBR 16457 em relação a LR de medicamentos em desuso?

- Você tem conhecimento de programas de reaproveitamento de medicamentos devolvidos? 
Laboratório 1: em relação à Decisão de Diretoria da CETESB No 114/2019/P/C, o Diretor de Logística não tem conhecimento. A área de qualidade e de Customer Service tem conhecimento da diretiva da CETESB, mas ainda não está sendo aplicada. Quanto à ABNT:NBR 16457 sobre LR de medicamentos de uso humano vencidos ou em desuso, a Coordenadora de Qualidade mencionou que a empresa implantou coletores de medicamentos de uso domiciliar em farmácias, no entanto, o programa foi suspenso pelo fato dos consumidores descartarem medicamentos de todos laboratórios e não ter havido um acordo de compartilhamento de responsabilidades e principalmente, os custos. Optaram, então, pelo fracionamento de medicamentos para vender a quantidade que o paciente necessita, mas não pode ser aplicável para todo medicamento por risco de contaminação cruzada, pois há necessidade de ter embalagem institucional para acondicionar o medicamento fracionado e o atendente da farmácia poderia guardar um medicamento fracionado na caixa de outro medicamento.

Tanto a Coordenadora de Qualidade quanto o Diretor de Logística desconhecem programas de devolução segura ou reaproveitamento de medicamentos mesmo dentro do prazo de validade, pois uma vez que o medicamento deixou o controle do laboratório, distribuidor e/ou farmácias, não se sabe em que condições de temperatura e umidade foi armazenado o produto, não sendo liberado pela ANVISA o reaproveitamento de medicamentos.

Laboratório 2: a Coordenadora de EHS relata que já está no ramo farmacêutico há 11 anos e quando do surgimento da PNRS sobre a LR, devido a sua generalidade, nunca conseguiram implementar e dar prosseguimento. As dificuldades relacionadas à segurança do medicamento, possibilidades de roubo de carga e falsificações de medicamentos, além da questão ambiental, todos esses fatores levaram o MMA a pressionar a CETESB com intuito de criar um direcionamento para os medicamentos de uso domiciliar atrelados à licença das farmacêuticas. Quem não aderisse ao plano, perderia a licença de operação. Aderiram aos requisitos da Decisão de Diretoria da CETESB No 114/2019/P/C, mas não teriam a obrigatoriedade por seus medicamentos não estarem disponíveis nas redes de farmácias ou drogarias, financiando dois pontos de coleta em farmácias que atendem a LR de medicamentos de uso humano vencidos ou em desuso também expressas na ABNT:NBR 16457/2016. Não tem conhecimento de programas de reaproveitamento de 
medicamentos, pois não há garantias de armazenamento correto em relação à temperatura e umidade.

Laboratório 3: explicou que não existia uma legislação específica para LR de medicamentos domiciliares até o advento da Decisão de Diretoria da CETESB No 114/2019/P/C, onde as empresas tiveram que se adequar em um curto espaço de tempo a fim de não perderem sua licença de operação LT (licença técnica) e o CBPF (Certificado de Boas Práticas Farmacêuticas). Enfatizou que há laboratórios farmacêuticos que entraram com uma ação contra esta decisão. Em sua opinião, utilizaram uma norma genérica para descarte de alguns itens e acrescentaram os medicamentos de uso domiciliar, ainda sem avaliar as especificidades deste segmento. Como o volume de vendas de medicamentos ao mercado privado, ou seja, distribuídos diretamente às farmácias é muito baixo, representando apenas $1 \%$ do seu volume de vendas total, foi mais vantajosa a adesão de sua empresa à LR de medicamentos domiciliares da CETESB No 114/2019/P/C, em conjunto com um conglomerado de empresas associando-se ao SINDUSFARMA. Através desta adesão, acabaram se adequando a normativa ABNT:NBR 16457/2016 sobre LR de medicamentos de uso humano vencidos ou em desuso. Não há conhecimento sobre programas para reaproveitamento de medicamentos por riscos de armazenamento incorreto nos lares do consumidor.

Distribuidor 1: em relação à norma ABNT:NBR 16457/2016, a responsável do regulatório afirma não ter acesso a essa norma e quanto a norma da CETESB $N^{\circ}$ 114/2019/P/C, não estão aplicando nem foram cobrados por isso.

O diretor comercial não tem conhecimento de nenhum programa de reaproveitamento de medicamentos, mesmo porque a ANVISA não permite.

Distribuidor 2: a farmacêutica relatou que a Decisão da Diretoria da CETESB N ${ }^{\circ}$ 114/2019/P/C não se aplica para o segmento de distribuição, mas devido a falta de clareza desta normativa em relação ao descarte de medicamentos do consumidor final, há um decreto federal $n^{\circ} 10.388$ de 5 de junho de 2020 que está em andamento e institui o sistema de LR de medicamentos domiciliares vencidos ou em desuso. Ela me explicou que a cada 10.000 habitantes, haverá a necessidade de disponibilizar um coletor de medicamentos em farmácias ou drogarias. Outro ponto importante salientado por ela, é que os medicamentos não serão mais classificados 
como produtos perigosos no transporte da LR e será emitido um manifesto de registro para transportá-lo sem necessidade de emissão de Nota Fiscal (NF). Ela desconhece programas de reaproveitamento de medicamentos.

Farmácia 1: a Diretora de Compras não tem conhecimento da decisão da Diretoria da CETESB No 114/2019/P/C em relação à LR de medicamentos domiciliares. Em relação à ABNT:NBR 16457/2016, ela conhece a norma, mas não a aplicam em sua rede de farmácias, pois não há coletores de medicamentos domiciliares.

Não tem conhecimentos de programas de reaproveitamento de medicamentos, mesmo porque não se garante que o produto tenha sido armazenado em temperatura adequada pelo consumidor.

Farmácia 2: a ação que a Farmácia 2 tomou para adequação à CETESB № 114/2019/P/C e ABNT:NBR 16457/2016 foi a adesão à máquina de descarte ao público. Ele afirmou que não há programas de reaproveitamento de medicamentos e a devolução segura seria entrando em contato com o laboratório farmacêutico para troca, no caso de avarias.

Farmácia 3: a farmacêutica responsável e o proprietário da farmácia desconhecem a Decisão da Diretoria da CETESB No 114/2019/P/C, bem como a normativa ABNT:NBR 16457/2016 sobre a LR de medicamentos domiciliares. Essa farmácia não recusa recolher os medicamentos vencidos ou sobra de medicamentos entregues pelo consumidor final. A farmacêutica salienta que não é possível a reutilização de medicamentos devolvidos mesmo dentro do prazo de validade, uma vez que não há garantias de que o medicamento tenha sido manuseado e armazenado corretamente após sua saída da farmácia.

Hospital 1: a Coordenadora Ambiental salientou que estão avaliando a necessidade de se adequar à norma da CETESB No 114/2019/P/C, reportando-se o volume de resíduos gerados. Quanto à norma ABNT:NBR 16457/2016, por se tratar especificamente de medicamentos domiciliares vencidos ou em desuso, não é aplicada. Devolvendo-se as sobras de medicamentos no hospital, mesmo estando dentro da validade, estes não serão reaproveitados por não saber as condições de armazenamento e serão destinados à incineração. 
Hospital 2: o responsável da Logística afirmou que não há nenhuma tratativa sobre medicamentos de uso domiciliar no hospital para reaproveitamento ou mesmo se aceita que o paciente devolva medicamentos não utilizados ou expirados para destiná-los à incineração.

Consultório 1, 2 e 3: não se aplica.

Empresa BHS: a gestão dos medicamentos vencidos ou devolvidos é todo um processo bem complexo que vai desde a implantação dos coletores, passando por todas as leis municipais, treinamentos dos responsáveis, orientação à população, definição de empresas coletoras dos resíduos e as de destinação final, registro dos lotes em plataforma digital, disponibilização de relatórios, documentos e certificados. Quanto à decisão da Diretoria da CETESB No 114/2019/P/C, alguns laboratórios estão entrando como patrocinadores de pontos de coleta tendo à sua disposição um hotsite com acesso ao que é registrado nesses pontos.

Os pontos de coleta gerenciados pela BHS já seguem todos os requisitos da norma ABNT:NBR 16457/2016 - "LR de medicamentos de uso humano vencidos e/ou em desuso". Já em relação ao reaproveitamento de medicamentos, mesmo que os medicamentos em desuso, em poder da população, estejam ainda dentro do período de validade, segundo a Vigilância Sanitária, não devem ser reaproveitados, pois as condições de armazenamento, temperatura, etc. não são controladas.

\subsection{MOTIVOS DE RETORNO / RECALL (BLOCO D)}

\section{- Em quais situações se aplica a LR? Quais motivos para retorno?}

\section{- Tem conhecimento de algum recall?}

Laboratório 1: os motivos para retorno dos medicamentos enumerados por eles durante a entrevista são:

- Problemas operacionais (quantidade, lote, preço errado)

- Prazo de validade (acordo comercial)

- Qualidade / avaria (caixas danificadas) - problemas no transporte

- Recall 
O recall mais recente que os envolveu foi da Ranitidina em Janeiro de 2020, remédio para úlceras no estômago ou duodeno por risco de contaminação por nitrosamina, substância que pode causar câncer. Outro recall foi da Valsartana/Losartana em Maio de 2019, remédio para pressão alta. Os lotes são recolhidos e a responsabilidade é do laboratório fabricante.

Laboratório 2: há uma política de devolução de medicamentos documentada nos seguintes casos:

1. Mercadorias Avariadas: desde que a notificação seja observada no conhecimento de entrega e comunicada oficialmente em até 48 horas;

2. Problemas de Qualidade: problemas comprovados e diretamente ligados à qualidade do produto, desde que os mesmos estejam dentro do prazo de validade;

3. Reclamação de Cliente: quando identificada divergência física da quantidade recebida em relação à quantidade mencionada na NF e comunicada em até 48 horas;

4. Produto Vencido: desde que o produto tenha sido faturado com prazo de validade igual ou inferior a 12 (doze) meses e esteja a um mês do vencimento ou vencido há no máximo 60 dias.

Como os medicamentos são de alto custo, os controles na logística direta relativos ao transporte, armazenamento e distribuição são extremamente rigorosos, o que praticamente não gera devoluções pelos motivos acima apresentados que constam na política da empresa. A Coordenadora de EHS desconhece a ocorrência de um recall com algum produto distribuído pelo Laboratório 2 .

Laboratório 3: o Gerente da Controladoria relatou a ocorrência de somente dois retornos em um período de 7 anos. Um deles foi relativo ao mercado privado, onde medicamentos venceram em uma farmácia que por acordo comercial, aceitaram a devolução. A outra ocorrência foi no mercado público por embalagem danificada. Neste caso, através dos testes pertinentes asseguraram que o lote poderia ser reaproveitado. Em 36 anos de existência de sua empresa, nunca houve a ocorrência de um recall com seus produtos.

Distribuidor 1: o Diretor Comercial informou que os motivos para retornar os medicamentos englobam casos de recall, produtos danificados e erros de entrega 
que contemplam material errado, quantidade errada e medicamento próximo ao vencimento. Exemplificou que a Ranitidina foi um caso recente de recall, onde emitiu um comunicado a todos os clientes.

Distribuidor 2: tanto o Gerente Logístico quanto a farmacêutica responsável informaram que os motivos para retornar os medicamentos são: produto amassado, danificado, pedido não reconhecido, pedido errado, quantidade maior do que o solicitado, atraso na entrega e medicamento próximo ao vencimento, conforme o acordo comercial com o cliente. Já passaram por vários recalls, onde informam ao laboratório responsável o endereço dos locais onde o lote do produto foi comercializado para que o laboratório se responsabilizasse pelo recolhimento. Citou o recall da Allexofedrin com recolhimento de lotes específicos devido à rotulagem estar em desacordo com a norma, por não trazer a informação de que se trata de uma nova formulação.

Farmácia 1: a Diretora de Compras explicou que a LR se aplica em 2 situações:

1) Devoluções do consumidor final para Farmácia 1: ocorre principalmente nas compras pela internet nos seguintes casos: avarias como produto amassado, aparelho de pressão em muitos casos pelo consumidor não saber usar; produto próximo ao vencimento. Nestes casos o medicamento poderia ser devolvido ao laboratório farmacêutico conforme a política praticada em acordo comercial, porém, na maioria dos casos, será direcionado para incineração pela própria Farmácia 1.

2) Devoluções da Farmácia 1 para o laboratório farmacêutico: vencimento próximo, conforme a política de devoluções estabelecida em acordo comercial; avarias / produtos danificados; no ato da entrega por erro de quantidade, preço, vencimento próximo e lote errado e recall.

A Diretora de Compras confirmou que os recentes recalls que ela teve ciência foram sobre os medicamentos Ranitidina e Valsartana. Averiguam no site da ANVISA sobre a veracidade dessas informações para então, disparar um comunicado a todas as unidades da rede.

Farmácia 2: os motivos que o farmacêutico listou para retorno de um medicamento são: produtos próximos à data de vencimento ou expirados, avarias, envio errado e 
recall. Ele explicou que, recentemente, a ANVISA comunicou o recall da Ranitidina e o medicamento foi segregado e recolhido pelos laboratórios responsáveis.

Farmácia 3: os motivos pelos quais a Farmácia 3 devolve os medicamentos para os distribuidores ou representantes dos laboratórios farmacêuticos são: apresentação do medicamento divergente do pedido, produtos incorretos por erro de digitação no televendas ou produtos danificados. Recentemente, participaram do recall da Ranitidina e por se tratar de um lote com pequena quantidade e o processo de geração de NF eletrônica de devolução ser muito burocrático, a Farmácia 3 se responsabilizou em segregá-lo e destiná-lo para incineração.

Hospital 1: o Gerente da Farmácia explicou que há perda de medicamentos por manipulação, por cair no chão, por avaria na embalagem e por vencimento, sendo esses são os principais motivos que levam ao descarte de medicamentos. No recebimento da farmácia, se o lote do medicamento chegar danificado ou com quantidade incorreta ou produto errado, efetua-se a devolução ao distribuidor no momento do recebimento.

Em casos de recall, quando a ANVISA emite um comunicado, um processo formal de recolhimento é realizado pelo fabricante ou distribuidor.

Hospital 2: nos medicamentos dentro do hospital, o responsável logístico explicou que a LR ocorre por ruptura, quebra ou danos no medicamento que impossibilitem seu uso. No processo de unitarização pode haver perdas, por falha no processo logístico (usam o sistema FEFO - First Expire First out), por medicamentos que não tem muito uso, mas necessitam ter no hospital e que são classificados como risco assumido e podem expirar e por sazonalidade, ou seja, em pandemias, onde o índice de expiração elevou-se dos medicamentos oncológicos por pacientes não procurarem o tratamento por temor ao Covid-19.

A ocorrência de um recall é chamada de Evento Sentinela, onde ele mostrou no sistema o exemplo recente do Predsim $20 \mathrm{mg}$ cujo lote foi devolvido para instituição privada por descrição errada.

Consultório 1: os motivos enumerados pelo médico para descarte de medicamentos são por data de validade expirada ou medicamentos com problema de qualidade. O médico Gastro relatou que precisou fazer a devolução de uma 
anestesia sem efeito. Em relação à recall, em janeiro de 2020, a ranitidina foi recolhida preventivamente por suspeita de substância nitrosamina causar câncer.

Consultório 2: o médico Ginecologista explica que nunca precisou fazer a devolução de um medicamento, nem tampouco participou de um recall. O motivo de retorno de medicamentos é somente pela data de validade vencida.

Consultório 3: a dentista cita que a LR ocorre no caso de medicamentos vencidos ou problemas de qualidade. Ela exemplificou a conservação não adequada do anestésico no posto de saúde que alterou o ph do anestésico e a anestesia teve que ser descartada. Nunca participou de nenhum processo de recall.

Empresa BHS: o representante da BHS afirma que são diversos os motivos para o retorno dos medicamentos, mas a principal preocupação do programa de LR de medicamentos domiciliares é o motivo ambiental. Ele desconhece qualquer envolvimento da Interfarma ou BHS quando há algum recall.

\subsection{GESTÃO DO FLUXO DE DEVOLUÇÕES (BLOCO E)}

\section{- Como é feita a gestão do fluxo de devoluções dos medicamentos?}

- Desenhe ou detalhe o fluxo da LR na sua empresa.

- Quais as principais atividades envolvidas na LR?

\section{- Quais os relatórios e entidades envolvidos no processo de LR?}

Laboratório 1: o Diretor da Logística disse que os medicamentos não são comercializados em prazo de validade inferior a 12 meses. Com 6 meses próximo ao vencimento, são segregados. Os medicamentos devolvidos mesmo dentro do prazo de validade são $100 \%$ destruídos. Ficam em uma área segregada para analisar os motivos da devolução e depois são encaminhados à incineração. A área de Customer Service recebe os pedidos de retorno dos clientes, apura o motivo da devolução e aciona a logística para devolução. Toda devolução é fundamentada na NF de origem da venda para rastreabilidade e na a emissão de uma NF de devolução. A mercadoria entra bloqueada no sistema, sendo destinada a uma área 
de quarentena a fim de se apurar os motivos da devolução. O produto é avaliado em relação à reclamação e após comprovação, encaminhado à destruição. Mantêm-se os laudos da incineração arquivados em sistema em caso de auditorias. Na LR, a devolução dos clientes retorna diretamente para os laboratórios do grupo que produziu a mercadoria.

Na Figura 7, é possível verificar o fluxo direto e reverso do Laboratório 1.

Figura 7 - Fluxo Direto e Reverso do Laboratório 1

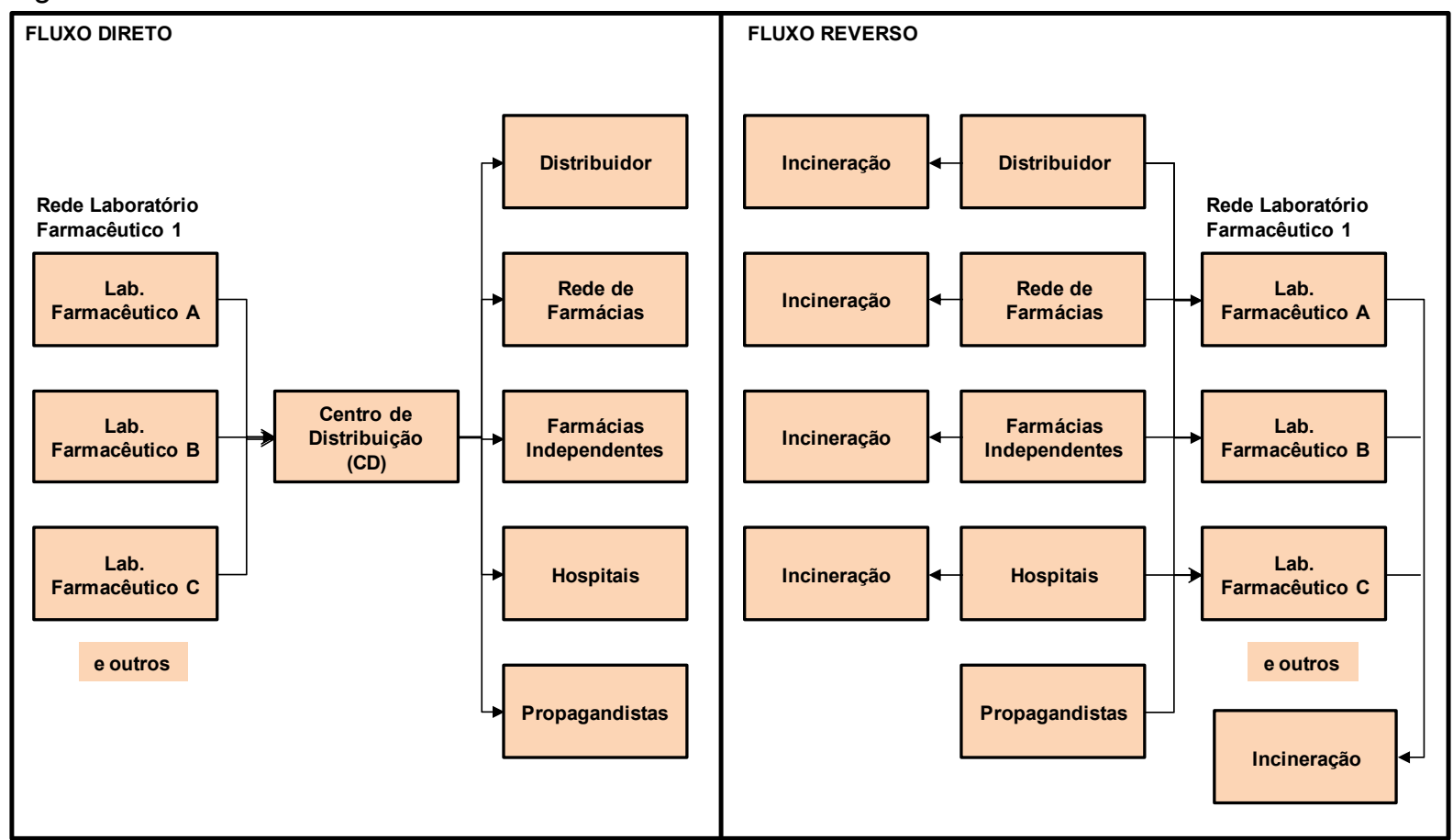

Fonte: Autor baseado na entrevista com Laboratório 1.

Laboratório 2: os medicamentos do Laboratório 2 são importados, vindo dos sites de manufatura localizados no exterior. O transporte, armazenamento e distribuição são realizados por uma empresa terceirizada e, conforme pedido de compras, distribuídos diretamente às Instituições de saúde públicas e privadas, Secretaria da Saúde e Ministério da Saúde. Se houver devolução pelos clientes, o que é praticamente raro ocorrer, há uma empresa contratada responsável pelo gerenciamento de resíduos destinados à incineração que, após liberação junto à ANVISA, fazem todo o acompanhamento do fluxo reverso juntamente com a área de security até a entrada no forno. Em relação aos dois coletores em farmácias, a gestão da LR e os laudos emitidos para incineração são de responsabilidade da BHS - Brasil, supervisionados pelo Laboratório 2. 
Veja na Figura 8, o fluxo direto e reverso tanto do Laboratório Farmacêutico 2 quanto das farmácias, onde há os coletores sob sua responsabilidade.

Figura 8 - Fluxo Direto e Reverso Laboratório 2

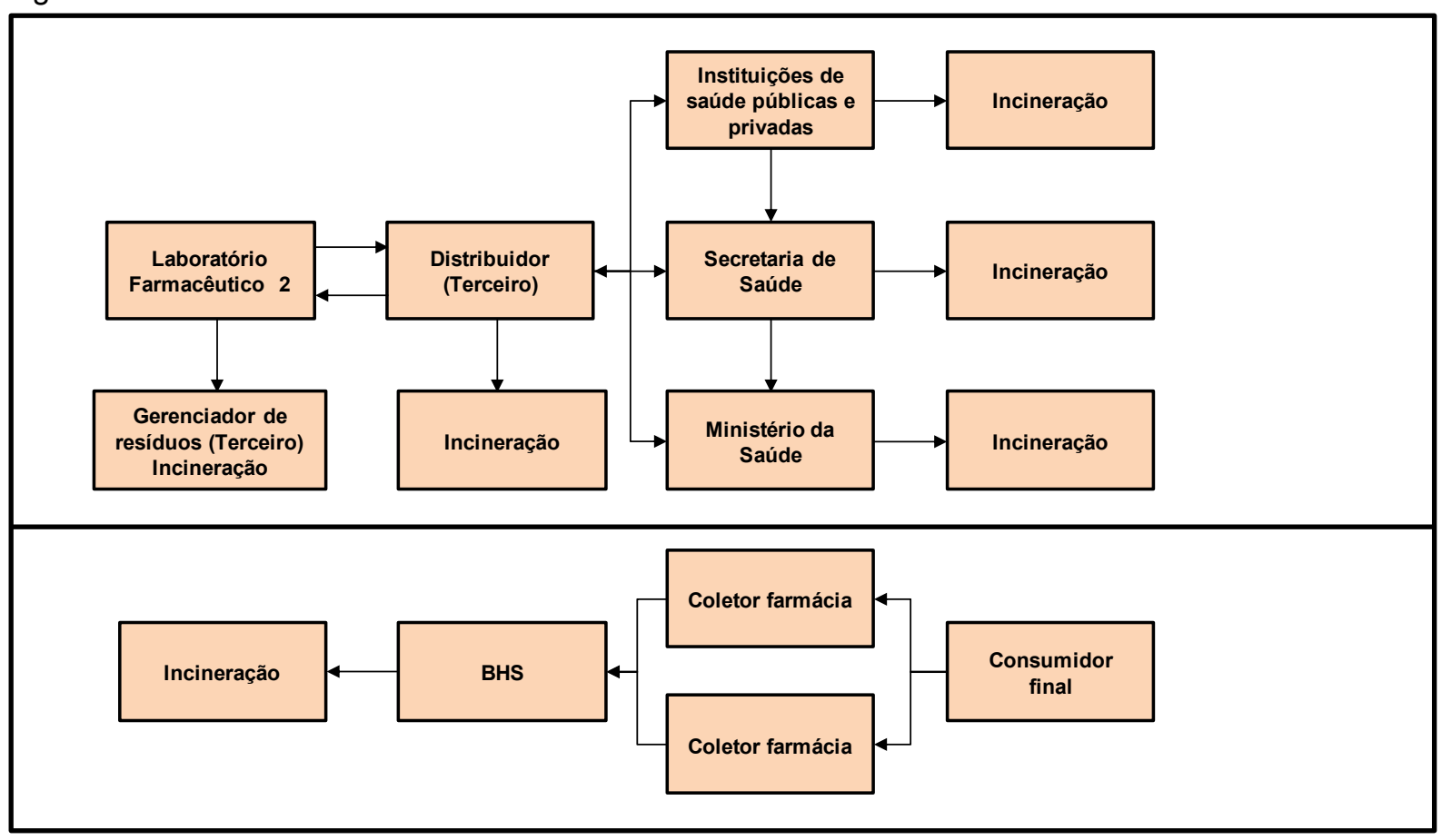

Fonte: Autor baseado na entrevista com Laboratório 2.

Laboratório 3: os medicamentos do Laboratório 3 são distribuídos para o mercado privado e mercado público através do leilão online. No mercado privado, os medicamentos são distribuídos diretamente para redes de farmácia e drogarias, como Ultrafarma, Drogaria Onofre, Drogasil, Droga Raia, Pacheco e Drogaria São Paulo. Para o setor público, o governo distribui para farmácias populares, postos de saúde e hospitais. A gestão de devoluções é feita pela área de garantia de qualidade juntamente com a área de logística (Supply Chain). No caso do consumidor final, as devoluções e reclamações são gerenciadas pelo SAC - Serviço de Atendimento ao Consumidor. Há uma área específica na empresa para segregação dos medicamentos devolvidos até que sejam avaliados e dada a correta destinação. Quando o motivo é data de validade expirada, após os registros no sistema e emissões de NF, os medicamentos são destruídos, através da incineração. As bulas, cartuchos, blister juntamente com o medicamento são incinerados, não havendo uma separação da embalagem para reciclagem. A incineração é realizada por empresas parceiras homologadas pela ANVISA. Os relatórios anuais sobre descarte são emitidos aos órgãos ambientais, como CONAMA e IBAMA, CETESB e 
bombeiros e ficam disponíveis para auditoria da ANVISA que ocorre a cada dois anos. Durante a entrevista, o Gerente da Controladoria apresentou o relatório da destinação final da destruição, onde consta o nome do medicamento, quantidade, número do lote, NF dos produtos, as licenças ativas das empresas responsáveis pelo gerenciamento do resíduo e incineração, certificado de movimentação de resíduos ambiental e detalhamento fotográfico do lote e do caminhão, sendo que esses relatórios devem ser mantidos como registros para eventuais checagens e como evidências nas auditorias da ANVISA. Já se um lote retornado estiver dentro do prazo de validade, o produto segregado passa por todos os testes de laboratório, como teste de estabilidade a fim de validar a eficácia de seus princípios ativos. Conforme laudo das análises realizadas, a área de qualidade decide pela correta destinação do produto.

A Figura 9 representa o fluxo direto e reverso do Laboratório 3.

Figura 9 - Fluxo Direto e Reverso Laboratório 3

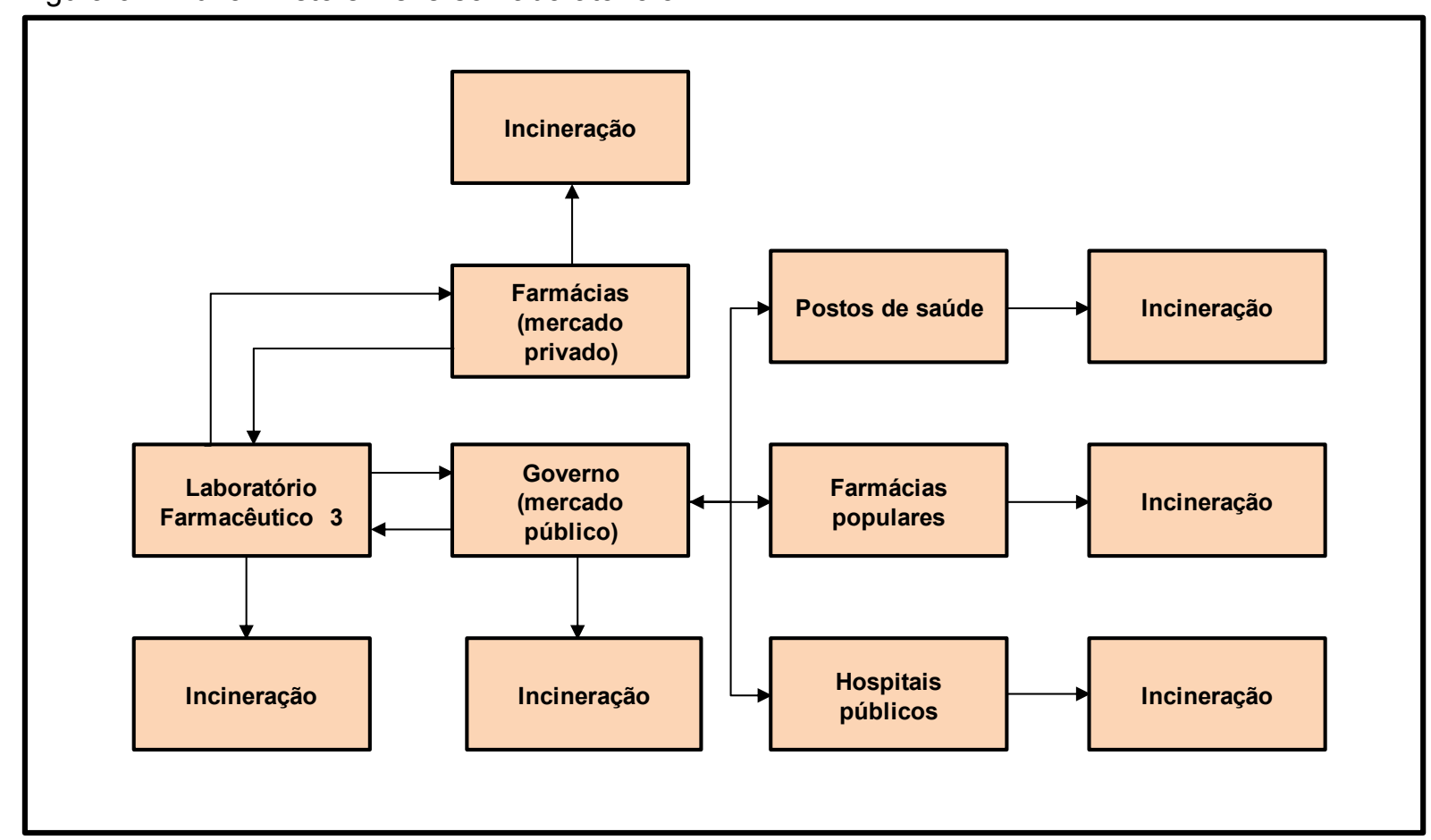

Fonte: Autor baseado na entrevista com Laboratório 3.

Distribuidor 1: o Diretor Comercial informa que a ANVISA permite que os produtos vencidos ou devolvidos destinados à incineração fiquem no máximo 2 anos em uma área segregada. Assim que se tem uma quantidade significativa, destina-se para incineração realizada pela empresa da prefeitura. Os medicamentos são segregados 2 meses antes de vencer e ficam bloqueados no sistema. 
Para toda a devolução, é necessária a NF de devolução e a NF de origem, entretanto, em caso de recall com notificação da ANVISA de âmbito nacional, aceitam recolher o produto sem NF de origem, emitindo uma Ordem de Serviço para coleta pela transportadora, que recolhe o lote comprometido diretamente nas farmácias. O laboratório paga pelo produto recolhido, mas os custos logísticos são do Distribuidor.

O departamento regulatório elabora o laudo da incineração que foi mostrado durante a entrevista, onde consta a especificação do produto, quantidade, lote e a NF. No caso dos medicamentos controlados, o laudo da incineração deve ser submetido à Vigilância Sanitária (portaria 344). Por acordo comercial, os medicamentos controlados, são devolvidos aos laboratórios fabricantes.

Na Figura 10, pode-se evidenciar o fluxo direto e reverso do Distribuidor 1.

Figura 10 - Fluxo Direto e Reverso do Distribuidor 1

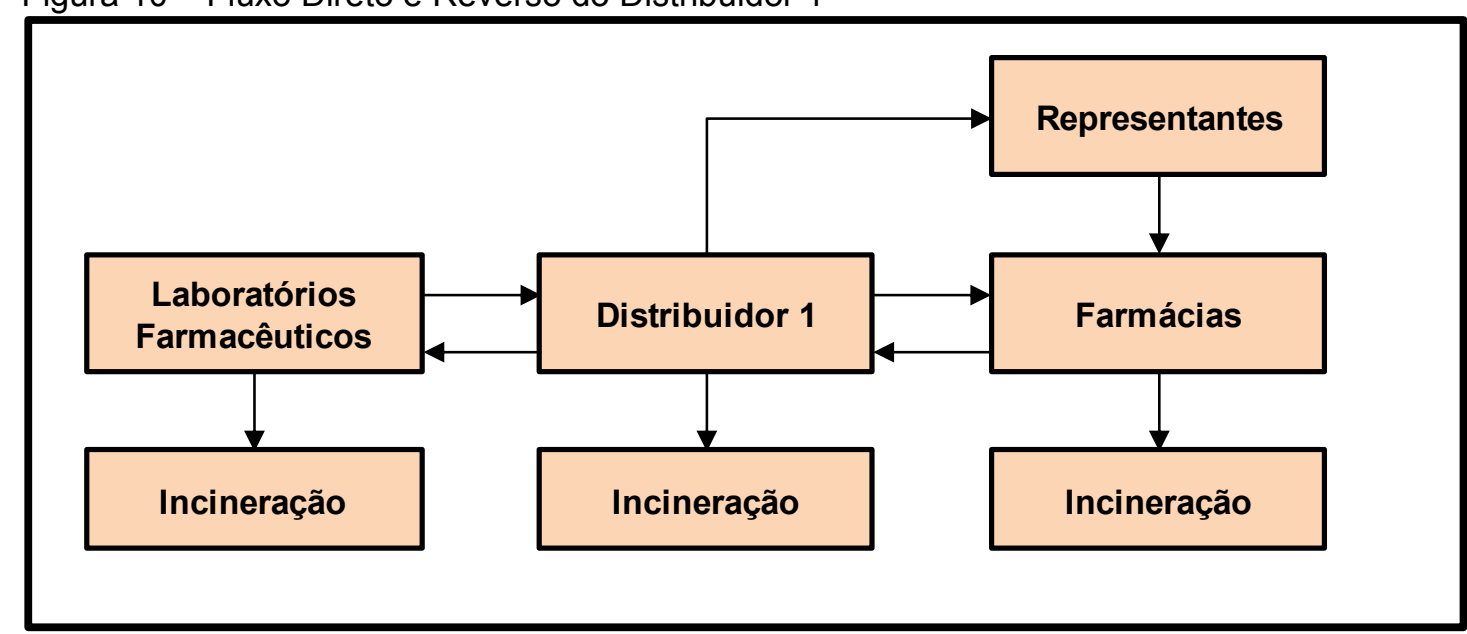

Fonte: Autor baseado na entrevista com o Distribuidor 1.

Distribuidor 2: em relação à $L R$, realizam devolução aos laboratórios se permitido em acordo comercial ou utilizam a empresa terceirizada Ambicamp para encaminhar diretamente para incineração. Os produtos devolvidos ou expirados ficam em uma área segregada acondicionados em barricas até a correta destinação. Os medicamentos são segregados 60 dias antes do vencimento. A área de Compras é informada para averiguar qual o acordo comercial vigente com o laboratório farmacêutico para definir se o acordo permite a devolução ao laboratório. A área de marketing também é envolvida para análise do lote a expirar em caso de viabilidade de fazer uma promoção. $A$ área de produtos expirados é monitorada para que não ocupe um espaço significativo na empresa. Conforme atinge um determinado 
volume, em média $80 \mathrm{~kg}$, a empresa Ambicamp é acionada para o recolhimento dos produtos e destinação à incineração. Os resíduos permanecem armazenados temporariamente no site da Ambicamp, atendendo as legislações Sanitárias e Ambientais vigentes, até o momento de serem encaminhados para a correta destinação final. O processo é documentado, com quantidade, especificação do produto, número do lote e NF para rastreabilidade. Para cada incineração, tem que ser preenchido o CADRI - Certificado de Movimentação de Resíduos de Interesse Ambiental - instrumento que aprova o encaminhamento de resíduos de interesse aos locais de reprocessamento, armazenamento, tratamento ou disposição final, licenciados ou autorizados pela CETESB, pois há um limite de carga anual para classificação do gerador de resíduo e cálculo da respectiva taxa. Quando a devolução é feita pelo cliente, o processo reverso envolve o SAC. A farmacêutica mostrou no site da Ambicamp, o relatório de Certificado de destinação de resíduos que reporta o que será destinado à incineração.

Na Figura 11, pode-se evidenciar o fluxo direto e reverso do Distribuidor 2.

Figura 11 - Fluxo Direto e Reverso do Distribuidor 2

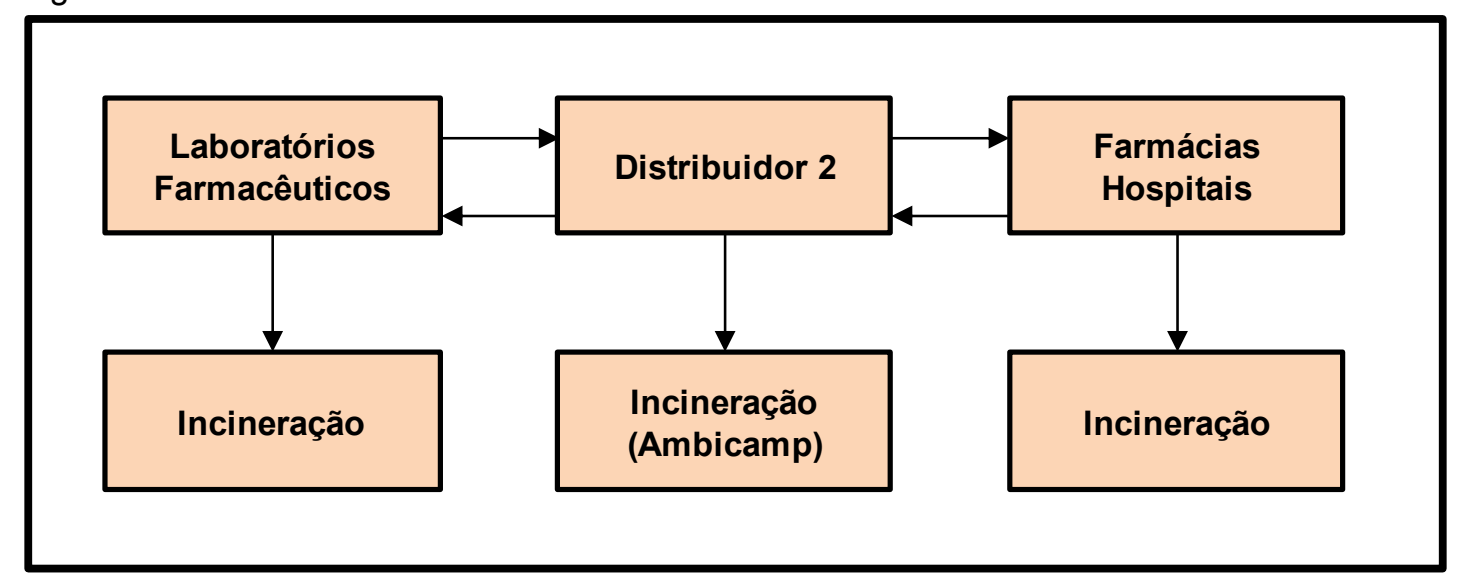

Fonte: Autor baseado na entrevista com o Distribuidor 2.

Farmácia 1: a Diretora de Compras explicou que, depende do acordo comercial, mas na maioria dos casos, compram os medicamentos dos laboratórios e distribuidores com o prazo de validade não inferior a 12 meses e quando o produto está a 6 meses de vencer, já segregam para colocá-los em promoção. Há pela internet medicamentos com prazo de validade de 4 meses que entram em oferta. Os medicamentos são retirados quando faltam 3 meses para vencer. Esses medicamentos vão para o CD da Farmácia 1, onde entram em uma área segregada, aguardando o encaminhamento para incineração ou para o laboratório responsável, 
dependendo do acordo comercial. Eles identificam NF de origem, emitem NF de devolução, cadastram os motivos do retorno, lote, fornecedor, quantidade. A empresa Limpurg da prefeitura de São Paulo emite os laudos da incineração e retira os produtos, transportando-os para incineração. Os laudos de incineração com as NFs são emitidos semestralmente para ANVISA.

A Figura 12 mostra o fluxo direto e reverso da Farmácia 1.

Figura 12 - Fluxo direto e reverso da Farmácia 1

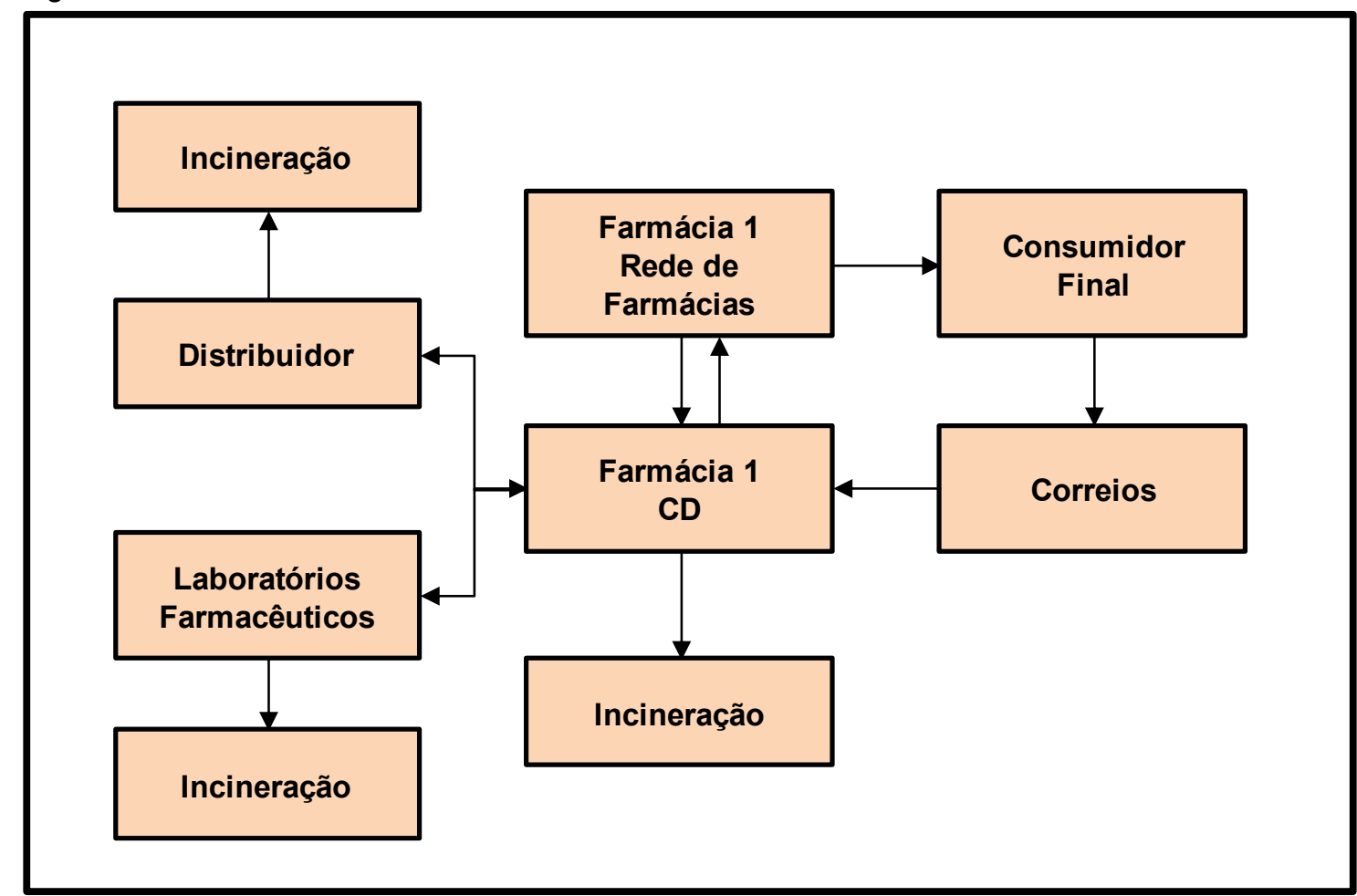

Fonte: Autor baseado na entrevista com a Farmácia 1.

Farmácia 2: a Farmácia 2 controla o vencimento de seus medicamentos no sistema, segregando os medicamentos controlados 2 meses antes do vencimento e os outros medicamentos 1 mês antes do vencimento. Ele mostrou o controle realizado através de programa no computador durante a entrevista. A gestão do fluxo de devoluções é feita através da NF de devolução, rastreada com a NF de origem. Os medicamentos que chegam avariados e com erros no envio ao pedido retornam para os distribuidores ou representantes dos laboratórios farmacêuticos, conforme acordo comercial. Se os medicamentos vencem ou sofrem avarias no manuseio dentro da Farmácia 2, ela é responsável para a destiná-los à incineração. Os medicamentos controlados expirados têm que ser reportados à ANVISA. Para a sobra de medicamentos ou medicamentos vencidos do consumidor final, foi instalada a 
máquina de coleta cuja gestão é realizada pela empresa BHS. A Farmácia 2 recolhe, notifica, pesa e empacota os medicamentos da máquina para a coleta da BHS. São emitidos relatórios de quebra de produto para incineração a fim de controlar os motivos, quantidades e tipo de produto para incineração e o laudo para ANVISA no descarte de medicamentos controlados. A BHS se responsabiliza pela emissão dos laudos dos medicamentos descartados pelo consumidor.

Na Figura 13, mostra-se o fluxo direto e reverso da Farmácia 2.

Figura 13 - Fluxo direto e reverso da Farmácia 2

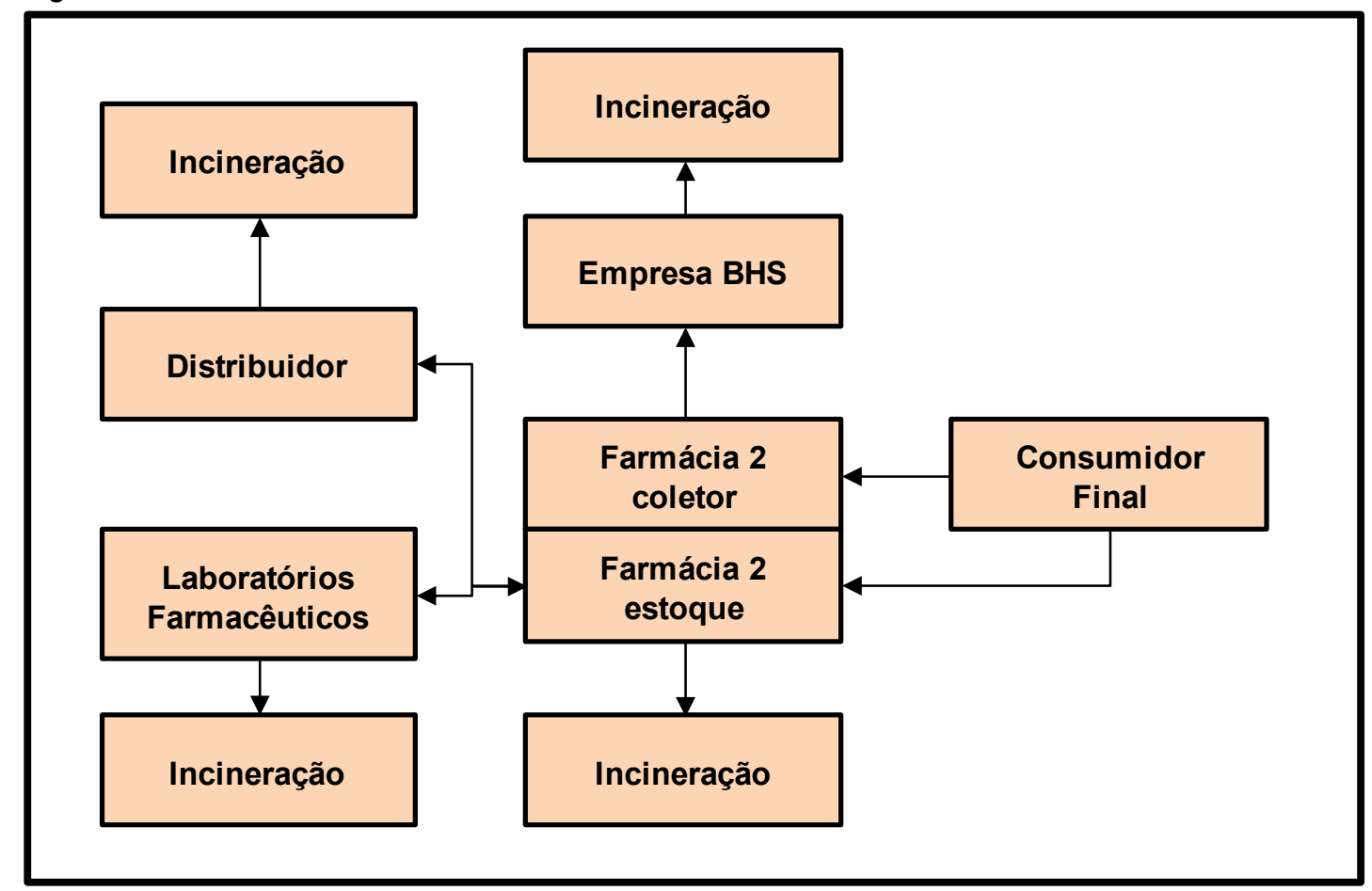

Fonte: Autor baseado na entrevista com a Farmácia 2.

Farmácia 3: no caso de uma devolução de medicamentos incorretos ou danificados vendidos pelo distribuidor ou representante do laboratório, abre-se a ocorrência na internet ou por telefone a fim de solicitar o recolhimento do lote, explicando o motivo. Quando se efetiva a devolução, gera-se um crédito com o distribuidor. Para concretizar esta devolução, é necessária a NF de origem e a geração eletrônica da NF para devolução. Em um prazo de 72 horas, o lote é recolhido pelo responsável da venda realizada.

Como seu estoque é pequeno, a farmacêutica responsável controla a validade dos medicamentos em um caderno, onde constantemente verifica quais estão a 1 mês do vencimento para recolhê-los das prateleiras. A empresa da 
prefeitura Limpurb passa 2 vezes na semana para levar os resíduos para incineração. Os medicamentos controlados expirados ficam segregados em um armário trancado. Preenche-se o formulário de Solicitação de Inutilização de Medicamentos Controlados, mostrado durante a entrevista, destinado por email à praça de atendimento regional, que avalia a solicitação e encaminha uma Autoridade Sanitária para conferir e lacrar o lote. Este formulário contém os dados da farmácia, dados do farmacêutico, nome do produto, o princípio ativo, quantidade e data de validade dos medicamentos. Após a autorização, a farmácia entra em contato com a Limpurb e apresenta o Termo de Inutilização para que esta proceda com a coleta e incineração do medicamentos..

A farmacêutica responsável explicou que retiram os medicamentos da prateleira de venda 1 mês antes da data de sua expiração, separando a bula e o cartucho (embalagem secundária) para reciclagem. Entretanto, como a coleta dos materiais recicláveis ocorre uma vez por semana, a farmácia, por ser de pequeno porte, às vezes se vê obrigada a colocar esses materiais (bulas e cartuchos) no lixo comum, pois não podem manter resíduos dentro das dependências da farmácia.

Na Figura 14 abaixo, é possível verificar fluxo direto e reverso da Farmácia 3.

Figura 14 - Fluxo direto e reverso da Farmácia 3

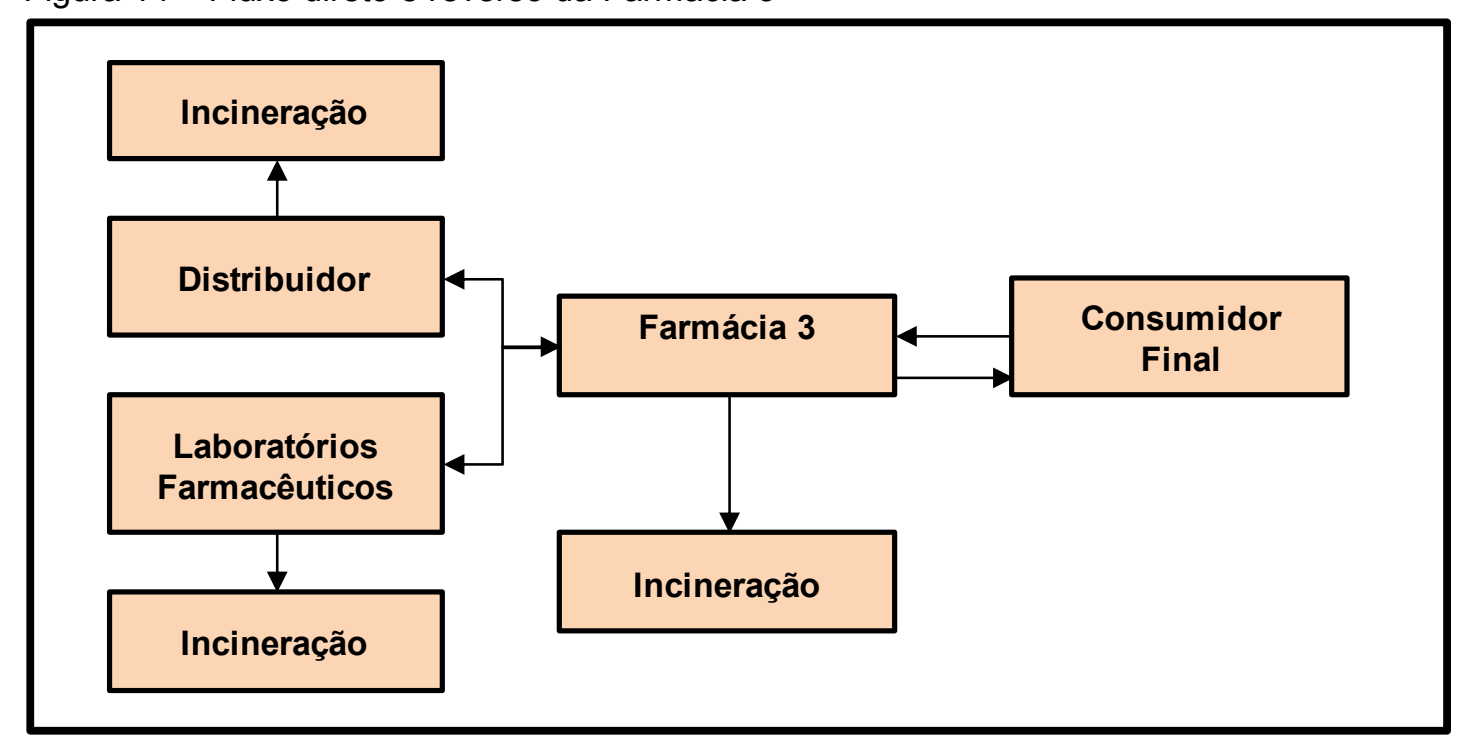

Fonte: Autor baseado na entrevista com a Farmácia 3.

Hospital 1: a política do hospital é receber medicamentos com data de validade acima de 12 meses, a não ser medicamentos importados ou medicamentos específicos como oncológicos cujo vencimento é mais curto. Há casos em que a 
indústria oferta medicamentos com prazo de validade menor que 12 meses com um preço mais acessível. Se o hospital for consumir antes do vencimento, pode aceitar, depende do acordo comercial. Os medicamentos a serem descartados são acondicionados na caixa laranja identificada como resíduo químico classe B tóxicos e há um contrato com a prefeitura que retira os medicamentos, leva para incineração e paga-se uma taxa para a prefeitura dar a destinação ao resíduo.

A Coordenadora Ambiental detalhou o fluxo envolvido na gestão de resíduos hospitalares. O técnico do laboratório identifica o tipo do material, quantidade e qual a composição química. Preenche FDSR e agrupa por tipologia, pois essa identificação deve ir ao caminhão da empresa Loga da prefeitura para que, em caso de acidentes, saibam a composição do produto que está carregando, quais os riscos ambientais e primeiros socorros. Todos os produtos da classe $B$ químicos que inclui os medicamentos o destino é incineração, separados por tipologia. O resíduo é pesado, pois se deve informar à prefeitura, ANVISA, CETESB, IBAMA qual volume de resíduos está sendo gerado mensalmente. Ela mostrou o site da prefeitura, onde há os valores pagos conforme o volume gerado. Todo resíduo transportado é acompanhado do documento MTR - Manifesto de Transporte de Resíduos.

A Figura 15 mostra o fluxo direto e reverso do Hospital 1.

Figura 15 - Fluxo direto e reverso do Hospital 1

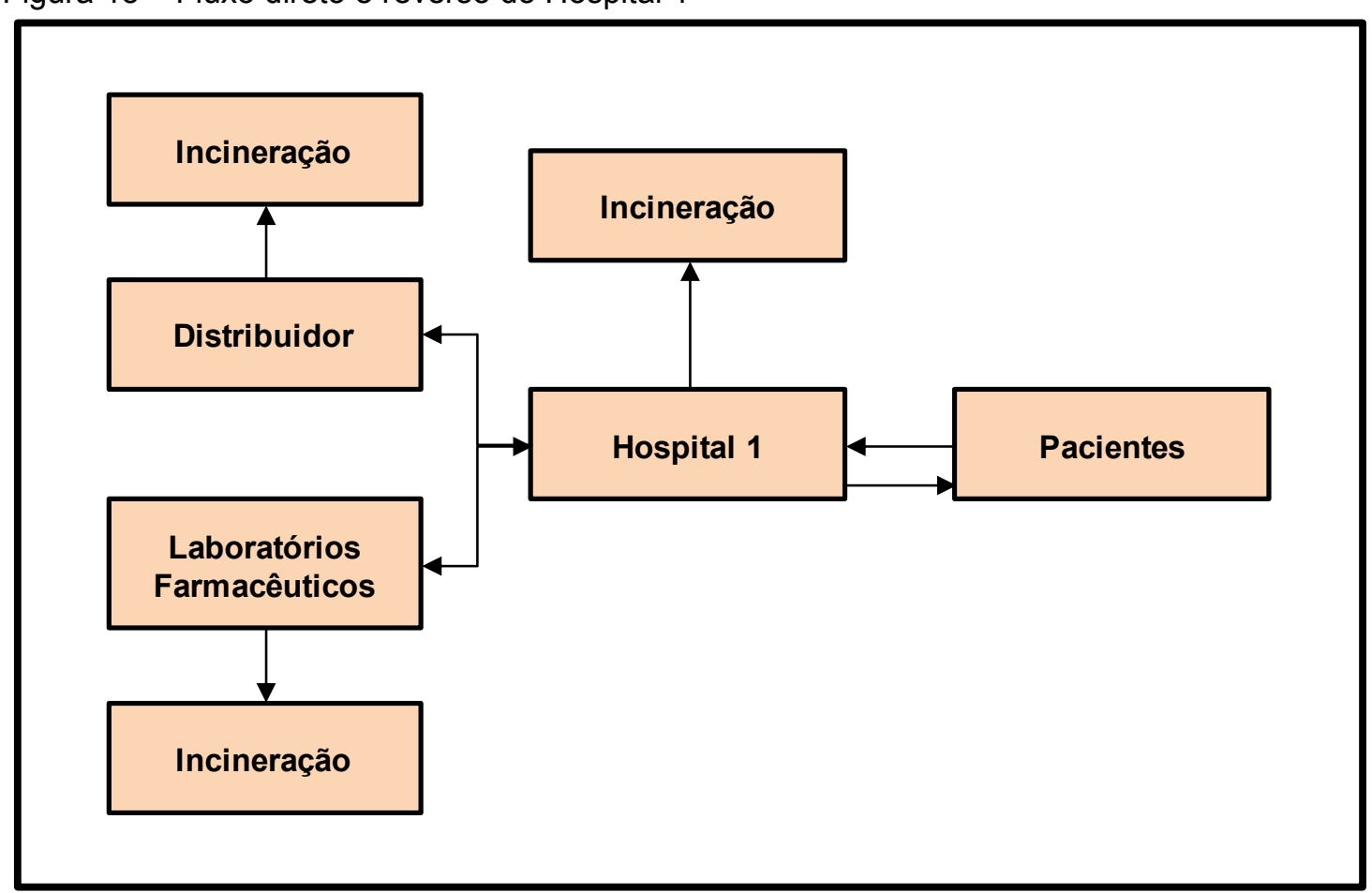

Fonte: Autor baseado na entrevista com o Hospital 1. 
Hospital 2: o responsável logístico explicou que três meses antes do vencimento, eles verificam se alguma unidade tem a necessidade do medicamento para realizar a transferência entre os hospitais e evitar que um medicamento expire. Retiram do estoque um mês antes do vencimento. Já os medicamentos expirados ou danificados são descartados nas caixas laranja. As caixas são consolidadas por andar e o bombeiro as leva até a área de armazenamento, onde uma vez por semana, a prefeitura os retira para incineração. Paga-se uma taxa para a prefeitura dar a destinação ao resíduo. A incineração pode ser realizada pelas empresas homologadas Essencis ou Silcon. Para cada caminhão que recolhe os resíduos, emite-se a MTR em três vias. Ele comentou que a MTR se tornará federal a partir de Janeiro de 2021, de acordo com a portaria $\mathrm{n}^{\circ} 280$ de 29 de Junho de 2020. A partir deste decreto, o MTR será uma ferramenta online, o que no seu ponto de vista, facilitará muito o processo de assinaturas. Há também o Certificado de Destinação de Incineração que é emitido pela prefeitura (Amlurb) e juntamente com o MTR, devem ser guardados por 5 anos.

Veja o fluxo logístico direto e reverso na Figura 16.

Figura 16 - Fluxo direto e reverso do Hospital 2

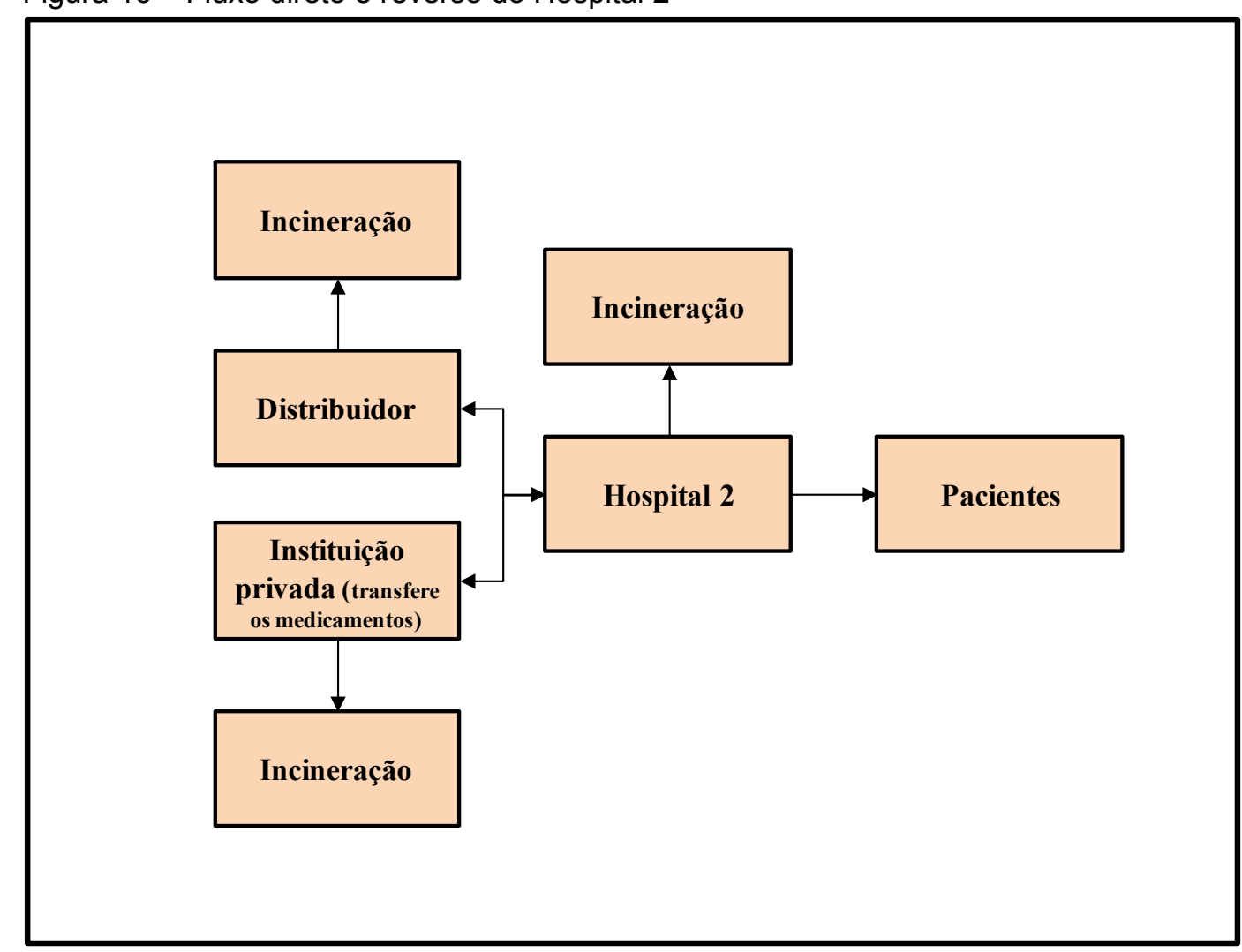

Fonte: Autor baseado na entrevista com o Hospital 2. 
Consultórios 1,2 e 3: não se aplica

Empresa BHS: as principais atividades envolvidas na LR realizadas pela BHS são orientação à população, treinamento dos responsáveis pelo ponto de coleta, programação do transporte dos resíduos, encaminhamento para a destinação final dos mesmos e emissão dos documentos comprobatórios. Ficam à disposição dos supervisores das redes, os relatórios e todas as informações referentes a cada ponto de coleta. Cabe às redes submeterem para as entidades de seu interesse.

\subsection{DEFINIÇÃO DE RESPONSABILIDADES / CUSTO DA LR (BLOCO F)}

\section{- As responsabilidades estão bem definidas na LR? Descreva}

\section{- A LR é vista como um custo?}

Laboratório 1: o Diretor Logístico afirma que a LR é vista como custo, mas que não há uma preocupação em otimizar o fluxo logístico direto com reverso, visto que o retorno é insignificante ( $0,08 \%$ do volume produzido). Segundo comentado, o fator que mais impacta não é o custo da LR e sim, o processo de NF por ser muito burocrático. Sua filosofia é "qualidade em primeiro lugar, pois as consequências podem levar a um custo muito maior".

Dependendo do acordo comercial, um produto vencido pode retornar ao laboratório de origem, mas não é responsabilidade do fabricante e sim, dos distribuidores ou das farmácias gerenciar seus estoques e dar a destinação correta no caso de medicamentos expirados. A responsabilidade do Laboratório 1 sobre a LR limita-se a envios incorretos, recall e avarias no produto. A gestão de estoque é responsabilidade de cada cliente.

Laboratório 2: segundo a visão da Coordenadora de EHS, a LR é um custo, mas é um custo associado ao produto que faz parte do processo. Como a quantidade de medicamentos comercializada pelo Laboratório 2 é baixa se comparado aos laboratórios fabricantes que atendem diretamente ao varejo, os custos pela associação ao programa da LR da Interfarma não são expressivos, apesar de seus medicamentos serem de alto valor. O contrato com a BHS foi muito bem discutido a 
fim de que as responsabilidades estivessem bem claras e a segurança do produto garantida.

Dentro da empresa e com os parceiros terceiros, as responsabilidades estão bem definidas, no entanto, não está suficientemente claro o papel da população nesta cadeia.

Laboratório 3: o Gerente da Controladoria afirmou que a LR é vista como um custo para as empresas, por esse motivo, poucos laboratórios farmacêuticos tinham um programa de LR do consumidor final antes da diretriz da CETESB Nº76/2018/C em abril de 2018. No seu ponto de vista, as responsabilidades da LR estão bem definidas na cadeia pelo contrato comercial e após, abril 2018, pela imposição da CETESB, as empresas tiveram que se adequar e muitas delas não estavam preparadas.

Distribuidor 1: o Diretor comercial enxerga a LR como custo, mas no seu ponto de vista, faz parte de uma prestação de serviço. Ele acredita que as responsabilidades estão bem definidas conforme acordo comercial. O encaminhamento para incineração dos produtos vencidos nas farmácias e/ou no seu Centro de distribuição (CD) são de responsabilidade de cada agente, no entanto, dependendo do acordo comercial entre farmácia/CD, CD/laboratório, essa responsabilidade pode ser compartilhada.

Distribuidor 2: o Gerente de Logística enxerga a LR como uma perda para empresa, ou seja, custo. Ele acredita que as responsabilidades estão bem definidas conforme acordo comercial. Já a farmacêutica também compartilha da mesma opinião, mas salientou que com o decreto federal $n^{\circ} 10.388$ vai melhorar as responsabilidades no que diz respeito ao consumidor final.

Farmácia 1: a Diretora de Compras enfatizou que considera a LR como um custo, porém necessário. Ela acha que as responsabilidades estão bem definidas entre as lojas da rede de farmácias e o $C D$, bem como o custo entre os parceiros diretos estão bem discriminados pelos acordos comerciais.

Farmácia 2: na opinião do farmacêutico responsável, a LR é custo, mas as responsabilidades estão bem definidas em relação à administração dos itens da 
farmácia. Em relação à máquina da coleta, ele não soube relatar quem paga os custos da máquina de descarte de medicamentos do consumidor.

Farmácia 3: o proprietário da farmácia considera que a LR é um custo. Eles pagam uma taxa mensal para Limpurb e estão cadastrados na tabela de valor pelo volume mínimo de resíduo gerado que é até $5 \mathrm{~kg}$. A farmacêutica responsável acredita que as responsabilidades sobre a LR estão bem determinadas e definidas no procedimento de Geração de resíduos. Ela atualiza este procedimento a cada revisão e segue também a frequência anual de treinamento estabelecida pela ANVISA.

Hospital 1: o Gerente da Farmácia informou que não há um departamento específico de LR na farmácia hospitalar. A LR representa custo, mas há um planejamento e estratégias para minimizar desperdícios e diminuir a geração de resíduos. Ele considera que as responsabilidades estão bem definidas em relação à geração dos resíduos e seu destino. A Coordenadora Ambiental também enxerga a LR como custo e acredita que as responsabilidades estão bem definidas conforme o organograma e pelos treinamentos sobre o tema ministrados pela sua área. Ela ainda explicou que toda a responsabilidade sobre o resíduo gerado é do hospital até a destinação final, desta forma, mesmo no caso da empresa Loga, onde se paga a taxa à prefeitura conforme o volume de resíduo gerado, existe um acompanhamento periódico do caminhão e auditorias realizadas pelo hospital a fim de verificar se o resíduo está sendo transportado, armazenado e incinerado conforme a legislação pertinente. Ela comentou que o hospital já recebeu uma multa da Vigilância Sanitária pelo fato do resíduo não estar armazenado corretamente na empresa Loga. O hospital recorreu e repassou a multa para a empresa Loga, mas o primeiro a ser acionado foi o próprio hospital

Hospital 2: o responsável de Logística opinou que a LR representa custo, mas ele vê como oportunidade de segurança e garantia da sustentabilidade. Assim, há um monitoramento através dos indicadores para diminuir a sucata. O Bombeiro explicou que a responsabilidade é do gerador de resíduo até sua destinação final, mas no caso de problemas de transporte com a prefeitura, a responsabilidade é compartilhada. O responsável logístico acha que as responsabilidades ainda não 
estão bem definidas por quem deveria ser feito e isso pode gerar sobrecarga em uma pessoa ou em uma parte da cadeia.

Consultório 1,2 e 3: não se aplica.

Empresa BHS: existem vários departamentos envolvidos na LR tanto internamente na BHS quanto externamente na cadeia farmacêutica. Ele disse que a LR é vista como um custo adicional. Ele considerou que as responsabilidades da LR na cadeia ainda não estão bem definidas, principalmente em relação ao custo. $O$ acordo setorial previa definir a participação de cada agente da cadeia no processo, mas o trabalho não foi conclusivo; por isso, aguarda-se um decreto do Ministério do Meio Ambiente para que se definam as responsabilidades.

\subsection{PL: UTILIZAÇÃO DE PRESTAÇÃO DE SERVIÇOS TERCEIRIZADOS NA LR (BLOCO G)}

\section{- Quem realiza o transporte na LR e como é feito?}

- Como são definidas as responsabilidades do transporte na LR e como são controladas?

Laboratório 1: quanto ao transporte, apesar de ser realizado por empresa terceirizada, o Diretor Logístico salientou que são criteriosos em controlar indicadores como pontualidade, avarias e eficiência. A transportadora é certificada, o processo é documentado, os funcionários são treinados, seguindo todos os procedimentos de qualidade. Tanto no Centro de Distribuição (CD) quanto no caminhão, as temperaturas são controladas, seguindo a norma RDC n 304/2019. Nos casos da LR, é realizado pela mesma transportadora.

Laboratório 2: todos os serviços de transporte, armazenamento e distribuição são realizados por uma empresa terceirizada que tem vastos conhecimentos nos padrões e regulamentos do mercado farmacêutico, como garantia da temperatura, embalagens e entrega direta aos clientes. O gerenciamento dos resíduos para incineração também é realizado por outra empresa terceirizada e especializada. No caso do coletor em farmácias, o destino dos medicamentos recolhidos é direcionado pela BHS - Brasil, empresa associada à Interfarma responsável pela gestão da LR. 
A Coordenadora de EHS também comentou que está em discussão no Congresso Nacional, no MMA, se a LR deveria seguir a tratativa de transporte de produtos perigosos, conforme a $R D C n^{\circ} 304 / 2019$.

Laboratório 3: o transporte logístico é realizado por empresa terceirizada, seguindo a normativa RDC 304/2019, respeitando todo procedimento relativo à medição de temperatura, umidade, carga mínima e máxima, emitindo um relatório de controle dos lotes. A mercadoria é paletizada e devido a todos esses controles citados, raramente reportam problemas de danos no produto pelo transporte em seus indicadores. Em caso de LR, a mesma empresa terceirizada realiza a coleta da mercadoria para análise. Como seu produto é de alto valor agregado, a LR obedece aos mesmos padrões de transporte da logística direta para manter a integridade até chegada à área de segregação dos medicamentos devolvidos que ficarão em quarentena para a correta disposição após análise. Como o Gerente da Controladoria mencionou, na sua empresa pode haver reaproveitamento do medicamento, desde que todos os testes de validação sejam aprovados. O gerenciamento dos resíduos para incineração também é realizado por uma empresa terceirizada parceira e especializada, homologada pela ANVISA.

Distribuidor 1: o transporte envolvido na $L R$ é realizado por empresa terceirizada. A empresa transportadora é controlada e certificada. No caso, a empresa responsável pela coleta para incineração é da prefeitura.

Distribuidor 2: o transporte envolvido na LR é realizado por empresa terceirizada. O Gerente de Logística e a farmacêutica entendem que é de responsabilidade da Ambicamp o fluxo da LR desde a coleta, transporte até a correta destinação dos resíduos dos medicamentos.

Farmácia 1: o transporte é terceirizado, onde a empresa terceirizada de segurança fiscaliza os caminhões. São monitoradas avarias do transporte, temperatura, lacre na logística direta. Para a LR, os controles são fiscais para saída e incineração. A empresa Limpurg da prefeitura de São Paulo é responsável pela destinação dos medicamentos para incineração.

Farmácia 2: o recolhimento dos produtos para incineração é feito pela gestão da central da rede no qual a Farmácia 2 está subordinada. $\mathrm{O}$ transporte é terceirizado e 
controlado pela central da rede da Farmácia 2, mas o farmacêutico responsável não soube detalhar.

Farmácia 3: o transporte dos medicamentos no processo da LR destinados à incineração é efetuado pela empresa Limpurb da prefeitura de São Paulo.

Hospital 1: a Coordenadora Ambiental explica que os resíduos gerados classe A (Infectantes), classe B (Químicos), classe C (Radioativos) e Classe E (perfuro cortantes) devido à lei municipal, deve obrigatoriamente utilizar o serviço da prefeitura através da empresa Loga para coleta, transporte e destinação final dos resíduos nos quais os medicamentos estão incluídos na classe B.

Hospital 2: o responsável logístico disse que o transporte é realizado pela prefeitura através da empresa Loga ou Ecourbis, que destinam a uma UTR - Central de tratamento de resíduos. A incineração pode ser realizada pelas empresas homologadas Essencis ou Silcon.

Consultório 1, 2 e 3: não se aplica.

Empresa BHS: são várias empresas prestadoras de serviço envolvidas na LR de acordo com regiões de atuação, custos e desempenho. A responsabilidade é compartilhada com os agentes e o controle é feito pelo sistema implantado.

\subsection{COLABORAÇÃO / COMPARTILHAMENTO DE INFORMAÇÕES (BLOCO H)}

- Como você definiria a colaboração da cadeia de suprimentos em relação à LR?

- Há um compartilhamento de informações na cadeia visando otimizar o sistema de LR? Como é feito?

Laboratório 1: o Diretor de Logística acredita que a colaboração de todos os atores da cadeia farmacêutica em relação à LR é efetiva, onde os papéis estão bem definidos, mas não há um compartilhamento de informações, visando uma otimização do sistema de LR. 
Laboratório 2: a Coordenadora de EHS ressaltou que infelizmente, nem todos os laboratórios farmacêuticos estão comprometidos com a LR. Ela também comentou que as indústrias farmacêuticas que possuem centro de pesquisa aderiram mais facilmente à Decisão da Diretoria da CETESB N 114/2019/P/C. Muitos laboratórios que precisavam aderir à diretiva da CETESB, por risco de perda da licença de operação, entraram com uma liminar na justiça para suspensão do programa.

Laboratório 3: o Gerente da Controladoria acredita que há colaboração na cadeia farmacêutica, mas ainda não há uma parceria no compartilhamento de informações a fim de otimizar a LR, por risco de compliance por divulgação de informações. Ele comentou que, no futuro, pode haver melhorias no compartilhamento de informações devido ao surgimento de empresas que vendem os serviços de LR, centralizando essas informações em uma empresa especializada neste tipo de serviço.

Distribuidor 1: o Diretor Comercial classifica como bem colaborativa a participação dos clientes na LR, pois a farmácia não quer ficar com o produto, quer devolver quanto antes. Já com os alguns laboratórios, há representantes com atuação direta em farmácias que fazem pedidos ao distribuidor, e que muitas vezes, para bater metas de vendas, colocam o pedido errado em relação à quantidade e produto, gerando transtornos e devoluções. Quanto ao compartilhamento de informações no intuito de otimizar estoque e minimizar a necessidade de LR, não há, pois para ele quanto mais vender, melhor.

Distribuidor 2: o Gerente de Logística classificou como colaborativa, em geral, as ações dos clientes em relação à LR, apesar de já terem ocorridos casos onde clientes efetuaram devoluções de mercadorias que não haviam sido fornecidas por sua empresa. Já com os fornecedores, o viés é mais comercial do que colaborativo.

Farmácia 1: a diretora de Compras define a colaboração na cadeia de suprimentos em relação à LR como ativa e eficiente, principalmente em relação ao SAC, uma vez que é passível de devolução pelos clientes as compras adquiridas pela internet. Há o compartilhamento de uma planilha para controle de estoque com determinados laboratórios, objetivando otimizar os pedidos e melhorar o gerenciamento de estoque. Esta planilha foi mostrada durante a entrevista. 
Farmácia 2: o farmacêutico responsável considera a cadeia de suprimentos farmacêutica colaborativa na prática da $L R$, sendo que as informações são compartilhadas a respeito do estoque com os representantes de laboratórios farmacêuticos e distribuidores que visitam periodicamente a Farmácia 2.

Farmácia 3: por ser uma farmácia de pequeno porte e ficar um pouco isolada das grandes redes, a farmacêutica responsável afirma que não há uma colaboração da cadeia farmacêutica na LR e nem mesmo o compartilhamento de informações, visando um melhor fluxo da LR.

Hospital 1: o Gerente da Farmácia considera que há colaboração internamente. Para a LR acontecer, há um conjunto de atividade desde a compra até o descarte e na sua visão, cada um sabe o que faz. Em relação aos fornecedores que são os distribuidores e laboratórios farmacêuticos, já se tentou negociar a retirada de medicamentos vencidos, mas só ocorre conforme acordo comercial. Entre as unidades do hospital, o estoque é pulverizado, o que dificulta o controle. Às vezes, não vale a pena transportar 5 comprimidos que estariam para vencer em alguma unidade para aproveitar em outra unidade devido ao tempo de demora e/ou custo logístico, mas quando viável, isso é feito entre as unidades para evitar geração de resíduos. Já a Coordenadora Ambiental julga que o viés é muito mais econômico e político, cada um olhando sua empresa sem um objetivo comum.

Hospital 2: pelo fato de estarem ligados a outras unidades hospitalares, o responsável logístico considera haver compartilhamento de informações, principalmente para transferências de estoque e minimizar perdas. Nas atividades envolvidas que vão desde a compra até o descarte, na sua visão, cada um sabe o que faz. Espera-se que com a portaria $n^{\circ} 280$ de 29 de junho de 2020 que institui o MTR on line, facilite a colaboração da prefeitura neste processo, segundo o bombeiro. Ele enfatizou que mais pesquisas como esta deveriam ser feitas para a conscientização e melhoria ambiental.

Consultório 1, 2 e 3: não se aplica.

Empresa BHS: ainda não existe essa colaboração na cadeia de suprimentos em relação à LR dos medicamentos, nem tampouco um compartilhamento de informações para otimizar o fluxo reverso. 


\subsection{RASTREABILIDADE DE MEDICAMENTOS (BLOCO I)}

\section{- Há rastreabilidade dos produtos na LR?}

Laboratório 1: a rastreabilidade de qualquer lote é feita pelo controle da NF. O Diretor Logístico salientou que há mais de 20 anos ouve falar na implementação da etiqueta RFID para controle do lote transportado, o que na realidade, nunca ocorreu, e hoje, em sua opinião, acredita que a tendência é do uso de QR Code.

Laboratório 2: a rastreabilidade na logística direta ocorre através do controle do lote desde a importação até a distribuição para os clientes. Não há rastreabilidade até o paciente. Em relação à $L R$, há o controle pela emissão da NF efetuado pela empresa que gerencia os resíduos para incineração e no caso da reversa dos coletores das farmácias, o controle é efetuado pela BHS.

Laboratório 3: a rastreabilidade do lote ocorre até seus clientes diretos através da emissão da NF e número do lote, tanto na logística direta quanto na LR.

Distribuidor 1: o Diretor Comercial mencionou que a rastreabilidade para a LR é realizada pela NF emitida para incineração.

Distribuidor 2: a rastreabilidade da LR é assegurada pela empresa Ambicamp. Nas devoluções das farmácias, todo controle é efetuado no sistema que me mostraram durante a entrevista. O SAC recebe a reclamação que é cadastrada no sistema, avaliada e se procedente, é feito o recolhimento do lote. O controle é feito pela NF e número de lote.

Farmácia 1: a rastreabilidade do medicamento destinado para incineração é feita somente pela NF gerada.

Farmácia 2: a rastreabilidade dos medicamentos da LR é feita através da NF gerada.

Farmácia 3: a farmacêutica responsável diz haver a rastreabilidade dos medicamentos na LR, somente pela NF e o canhoto de devolução. 
Hospital 1: o Gerente da farmácia indica que quando se descarta nas caixas laranja, ele sabe o produto e quantidade descartada, pois tem que dar baixa no sistema da farmácia. Já para o resíduo que sai do hospital para a destinação final, a Coordenadora Ambiental, explica que há um relatório chamado Manifesto de Transporte - MTR para cada resíduo com a informação de onde foi gerado, quem está transportando, para onde é o destino, horário, dados, assinatura de cada um deles, via assinada. Ela vai à prefeitura (empresa Loga) mensalmente para solicitar a devolução de uma cópia do manifesto assinado. Para cada manifesto, tem a destinação final dos resíduos: quantidade de container, qual o peso, a destinação. $O$ Hospital 1 faz visitas periódicas aos locais de destino dos resíduos, além de seguir o caminhão de transporte eventualmente.

Hospital 2: o responsável pela logística mostrou que toda rastreabilidade do medicamento é feita no sistema SAP, segue-se o número do lote interno do medicamento, em qual prateleira está disposto, para qual farmácia satélite e para qual paciente será ministrado. Caso o medicamento expire ou danifique neste processo, dá-se baixa no SAP com uma justificativa. Já para o medicamento que sai do hospital como resíduo classe $B$, segue a rastreabilidade através do MTR cujo documento o bombeiro me mostrou durante a entrevista. O MTR contém a identificação do gerador, identificação do resíduo, quantidade, classe, acondicionamento, quem está transportando e a identificação do destinador com datas e assinaturas de cada responsável.

Consultórios 1, 2 e 3: não se aplica.

Empresa BHS: Sim.

\subsection{CLASSIFICAÇÃO DE MEDICAMENTOS PARA DESCARTE (BLOCO J)}

\section{- Existe alguma classificação dos medicamentos para descarte?}

Laboratório 1: o Diretor Logístico confirma que pela portaria 344 da ANVISA, os medicamentos controlados são incinerados na íntegra, sem prévia separação das embalagens. Já com os demais medicamentos, separam-se as embalagens para reciclar e incineram somente os medicamentos. 
Laboratório 2: no caso dos medicamentos segregados no coletor, a farmácia separa os medicamentos controlados e os antibióticos dos demais medicamentos para emissão do laudo técnico para incineração pela BHS. No próprio coletor, há uma separação em 3 compartimentos: "pomadas e comprimidos" com o blister, "líquidos e sprays" nos seus recipientes fechados e "caixas e bulas".

Laboratório 3: o Gerente da Controladoria mencionou que, pela Ficha de Informação de Segurança dos Produtos Químicos (FISPQ), averigua-se a necessidade de um pré-tratamento antes da incineração. Já participou de uma discussão em uma feira farmacêutica sobre embalagens verdes para medicamentos, mas só tem conhecimento de um medicamento que adotou esta embalagem ecologicamente correta. Também salientou como conhecimento pela portaria $n^{\circ}$ 344/98 da ANVISA, os medicamentos controlados têm que ser classificados separadamente para o descarte, sendo o controle mais rigoroso. O material fica segregado em gaiola e deve ser reportado mensalmente à Vigilância Sanitária. Nas farmácias, a receita fica retida com os dados do usuário final, ou seja, a rastreabilidade chega até o consumidor final.

Distribuidor 1: os medicamentos são separados em controlados e não controlados. Os medicamentos controlados devem ser reportados para a Vigilância Sanitária em cumprimento à portaria 344/98 da ANVISA, discriminando produtos, quantidade e lote, conforme evidenciado em documento durante a entrevista. Mesmo em relação aos medicamentos não controlados, não há uma separação do cartucho e bula, onde tudo é enviado para incineração.

Distribuidor 2: segundo o Gerente de Logística, os medicamentos são separados como controlados e não controlados, mas a responsabilidade é da empresa Ambicamp que faz a gestão dos resíduos. A farmacêutica explicou que quando o medicamento é controlado, a Vigilância Sanitária Municipal libera um documento que tem que ser protocolado, discriminando a quantidade e a especificação de cada produto. Agenda-se a vinda de um fiscal que irá lacrar o lote. Pelo número do lacre, é possível efetuar a rastreabilidade do lote a ser incinerado. No Certificado de Destinação de Resíduos, é informado o número do lacre que deverá ser reportado para a Vigilância Sanitária. 
Farmácia 1: não há uma separação ou classificação dos medicamentos para descarte, onde tudo é incinerado e somente os medicamentos controlados são separados.

Farmácia 2: o farmacêutico responsável explicou, mostrando diretamente na máquina de coleta de medicamento do consumidor, que o público passa o medicamento por um leitor de código de barras e em seguida, deposita o medicamento de acordo com três classificações orientadas na própria máquina de descarte: medicamentos sólidos (pomadas e comprimidos), líquidos (líquidos e sprays) e papel (caixas e bulas). Os medicamentos segregados para incineração do estoque da farmácia são separados somente na categoria dos medicamentos controlados que necessitam da emissão do laudo para a ANVISA. O restante dos medicamentos, ele não soube dizer se há uma separação das embalagens secundárias antes da incineração, ele acredita que incinera tudo.

Farmácia 3: classificam os resíduos para descarte como: medicamentos controlados, demais medicamentos, resíduos perfurocortantes e o lixo contaminado. Os resíduos são segregados em sacos brancos, salienta a farmacêutica responsável.

Hospital 1: os medicamentos para descarte são separados em líquidos e sólidos, classificados dentro da categoria $B$ de produtos químicos, tóxicos, mas em nenhum momento o Gerente da Farmácia ou a Coordenadora Ambiental mencionaram uma separação dos medicamentos controlados.

Hospital 2: todos os medicamentos são classificados como classe B resíduos tóxicos. No caso de medicamentos controlados, ainda devem ser reportados à ANVISA e ficam segregados em uma área trancada até que a autoridade sanitária realize a inspeção. Através do Termo de Inutilização de Medicamentos Controlados, a empresa transportadora poderá realizar o transporte e seguir com o descarte do medicamento pela incineração.

Consultório 1, 2 e 3: não se aplica.

Empresa BHS: os medicamentos para descarte são classificados como resíduos perigosos do grupo $\mathrm{B}$. 


\subsection{MÉTODOS DE DESCARTE / DISPOSIÇÃO FINAL (BLOCO K)}

\section{- Qual o método utilizado para o descarte dos medicamentos?}

Laboratório 1: para os medicamentos, a disposição final no estado de São Paulo é a incineração.

Laboratório 2: o método utilizado para disposição final dos medicamentos é a incineração.

Laboratório 3: o método utilizado para disposição final dos medicamentos é a incineração.

Distribuidor 1: tanto o Diretor Comercial quanto à responsável do setor regulatório indicam que o método de descarte dos medicamentos é a incineração.

Distribuidor 2: tanto o Gerente de Logística quanto à farmacêutica responsável indicam que o método de descarte dos medicamentos é a incineração.

Farmácia 1: o método utilizado para descarte de medicamentos é a incineração.

Farmácia 2: o método de descarte praticado é a incineração.

Farmácia 3: o método de descarte para os medicamentos é a incineração.

Hospital 1: tanto o Gerente da Farmácia quanto a Coordenadora Ambiental confirmaram que o destino dos medicamentos descartados é a incineração. Ela relatou que alguns tipos de medicamentos, como soros fisiológicos ou vitaminas, são liberados pela SABESP para serem descartados diretamente no lixo comum, sendo que periodicamente o esgoto do hospital é analisado para verificação de conformidade ambiental.

Hospital 2: o responsável logístico e o bombeiro confirmaram que o destino dos medicamentos descartados é a incineração.

Consultório 1: o método de descarte dos medicamentos de amostra grátis expirados no Consultório 1 é o lixo comum recolhido pelas secretarias. 
Consultório 2: os medicamentos expirados são descartados no lixo ou entregues em posto de saúde.

Consultório 3: separam o lixo contaminado em sacos brancos, descarta os resíduos perfurocortantes em caixas amarelas identificadas que são retiradas pela prefeitura mediante ao pagamento de uma taxa e os medicamentos vencidos são levados para descarte no posto de saúde

Empresa BHS: em quase todo Brasil, o destino final dos medicamentos é a incineração. Poucas regiões, como por exemplo, o Rio Grande do Sul, o destino são os aterros industriais classe 1 , que impedem a contaminação do solo.

\subsection{REUTILIZAÇÃO DE MEDICAMENTOS DEVOLVIDOS NO PRAZO DE VALIDADE (BLOCO L)}

- É possível a reutilização de medicamentos dentro do prazo de validade devolvidos?

\section{- São realizados testes de estabilidade para averiguar a validade?}

Laboratório 1: o Diretor Logístico reforçou que não é possível a reutilização de um medicamento devolvido mesmo dentro do prazo de validade. Uma vez que saiu do controle da transportadora, não há garantias de como este medicamento foi acondicionado (temperatura, umidade). Todo o medicamento em produção passa pelo teste de estabilidade, mas não há teste para assegurar sua eficácia após LR; portanto, todo medicamento devolvido é destruído (incineração).

Laboratório 2: se houver medicamentos devolvidos no prazo de validade nos coletores, a Coordenadora EHS afirmou não ser viável a sua utilização por não se saber em que condições de temperatura e umidade foram armazenados. O teste de estabilidade é realizado somente na logística direta, não para assegurar reaproveitamento de medicamentos.

Laboratório 3: como o Gerente da Controladoria mencionou, na sua empresa pode haver reaproveitamento do medicamento vindo dos clientes direto por devolução do lote, desde que todos os testes de validação e estabilidade sejam aprovados, mas 
vindos do consumidor final esta prática não existe, pois não há garantias da integridade do produto, armazenados muitas vezes de forma inadequada.

Distribuidor 1: o Diretor Comercial afirmou que não utilizam medicamentos devolvidos mesmo dentro do prazo de validade por não ter garantia do método de armazenagem após sair do seu CD.

Distribuidor 2: segundo a farmacêutica, não é possível a reutilização de medicamentos devolvidos, mesmo dentro do prazo de validade, pois não há como averiguar a integridade do produto retornado em seu CD.

Farmácia 1: a Diretora Comercial afirmou não ser viável, pois a partir do momento que o produto saiu da gestão da Farmácia 1 não se sabe em que condições de temperatura e umidade ficou armazenado.

Farmácia 2: o farmacêutico responsável disse não haver possibilidade de utilização de medicamentos mesmo dentro do prazo de validade, a ANVISA não permite.

Farmácia 3: a farmacêutica responsável afirmou não ser possível a reutilização de medicamentos mesmo dentro do prazo de validade, não há como garantir o correto armazenamento em relação à temperatura e umidade.

Hospital 1: o Gerente da Farmácia diz que utilizam medicamentos entre unidades, pois sabem em que condições foram armazenadas. O hospital preza pela qualidade, investe em treinamento e segue todas as normas de armazenamento e manuseio preconizadas pela indústria.

Hospital 2: o responsável logístico afirmou que não há programas de reutilização de medicamentos dentro do prazo de validade, somente a transferência entre unidades para que sejam minimizados os desperdícios.

Consultório 1: há uma preocupação do doutor em doar os medicamentos recebidos em amostra grátis aos mais carentes.

Consultório 2: o doutor comentou sobre um programa de reutilização de medicamentos da farmácia dos pobres de um hospital renomado em São Paulo. 
Consultório 3: a dentista afirmou que com cautela e algumas perguntas sobre a conservação, solicita aos seus pacientes que tragam seus medicamentos em desuso para doação.

Empresa BHS: não é possível a reutilização de medicamentos devolvidos mesmo dentro do prazo de validade, também não é feito teste de estabilidade nos medicamentos retornados.

\subsection{DEVOLUÇÃO DE MEDICAMENTOS / PONTOS DE COLETA (BLOCO M)}

- Como é feita a devolução de medicamentos nos pontos de coleta?

- Toda farmácia pode receber medicamentos expirados e/ou não utilizados?

- O consumidor final tem o hábito de devolver produtos expirados e/ou não utilizados?

Laboratórios 1,2 e 3: não se aplica.

Distribuidor 1 e 2: não se aplica.

Farmácia 1: a Diretora de Compras afirmou que não são todas as farmácias que recebem medicamentos em desusos ou expirados pelos consumidores, bem como, a própria Farmácia 1 não os aceita em nenhuma de suas unidades. Aceitam as devoluções somente via SAC por reclamação ou insatisfação dos clientes. Ela também complementa que os consumidores não têm o hábito de devolver os medicamentos não utilizados. Ela própria não tem conhecimento de qualquer ponto de coleta de medicamentos de uso domiciliar.

Farmácia 2: o farmacêutico responsável explicou que nem todas as farmácias aceitam a devolução de sobras de medicamentos ou medicamentos expirados do consumidor final. A Farmácia 2 aderiu ao programa em alinhamento à diretriz da resolução da Diretoria da CETESB No 114/2019/P/C, permitindo a colocação da máquina coletora em suas unidades de farmácia. Ele tem conhecimento que algumas Unidades Básicas de Saúde (UBS) também recolhem medicamentos do público, mas o consumidor final ainda não tem o hábito de descartar os medicamentos em farmácias ou postos de saúde. 
Farmácia 3: a Farmácia 3 não tem restrição em aceitar se o cliente quiser devolver algum medicamento em desuso ou expirado, entretanto, esta ocorrência não é frequente. A farmacêutica responsável incorpora este medicamento devolvido ao estoque expirado da farmácia para incineração pela empresa Limpurb. Além das farmácias, ela não conhece outros meios para que a população descarte os medicamentos, porém nem todas aceitam e tão pouco é divulgado.

Hospital 1: o Gerente da Farmácia esclarece que o hospital pode receber os medicamentos devolvidos pelos pacientes, mas além de raro, não é algo formalizado. Ele indica que já consultaram uma empresa para colocar um coletor de medicamentos até mesmo para monitorar quais tipos de medicamentos seriam descartados, no entanto, este projeto ainda não foi implantado no hospital.

Hospital 2: o Hospital 2 não aceita a devolução de medicamentos dos pacientes ou do consumidor final não utilizados ou expirados para destiná-los à incineração.

Consultórios 1, 2 e 3: não se aplica.

Empresa BHS: os pontos de coleta estão disponibilizados no site da Interfarma, dentro do item LR ou diretamente no site da BHS. As principais atividades da LR são: orientação à população, treinamento dos responsáveis pelo ponto de coleta, programação do transporte dos resíduos, encaminhamento para a destinação final dos mesmos e emissão dos documentos comprobatórios. Ele afirma que a maioria do consumidor final não tem o hábito da devolução de medicamentos em desuso e/ou expirados.

\subsection{CONSCIENTIZAÇÃO / CAMPANHA DE DIVULGAÇÃO (BLOCO N)}

\section{- Existe alguma orientação ao consumidor final sobre os riscos do descarte incorreto?}

\section{- Há campanhas de conscientização?}

Laboratório 1: não há nenhuma orientação ao consumidor final sobre como descartar o medicamento e sobre os riscos que o descarte incorreto pode acarretar ao meio ambiente. $O$ Diretor Logístico pediu para averiguar se a bula trazia alguma 
informação e a Coordenadora de Qualidade confirmou que não há qualquer tipo de orientação. Eles também desconhecem campanhas de conscientização para o consumidor final sobre o descarte adequado de medicamentos.

Laboratório 2: a Coordenadora de EHS afirma que não há uma orientação ao consumidor final sobre os riscos do descarte incorreto de medicamentos, nem campanhas de conscientização de como proceder com os medicamentos vencidos em seus domicílios. Ela comentou que por falta de orientação à população, pode-se chegar ao ponto de fazer LR de Rinosoro descartado no coletor da farmácia, sendo que o rinosoro não polui o meio ambiente.

Laboratório 3: o Gerente da Controladoria afirmou que não há uma orientação ao consumidor final sobre os riscos do descarte incorreto de medicamentos, ressaltando que na bula há somente alerta de riscos do medicamento ao alcance das crianças. Ele enfatizou que o consumidor não sabe o que fazer com os medicamentos vencidos em seus lares, pois não há campanhas de conscientização.

Distribuidor 1: tanto o Diretor Comercial quanto o representante do regulatório afirmam que não há nenhuma orientação aos clientes sobre o risco de descarte incorreto de medicamentos e nem campanhas de conscientização sobre o tema, principalmente ao consumidor final.

Distribuidor 2: afirmam que não há nenhuma orientação aos clientes sobre o risco de descarte incorreto e nem campanhas de conscientização sobre o tema, principalmente direcionadas ao consumidor final.

Farmácia 1: a Diretora de Compras diz que não há uma orientação ao consumidor final sobre os riscos ao meio ambiente do descarte incorreto de medicamentos, nem mesmo a conscientização sobre o descarte adequado de medicamentos. Como consumidora, ela tem o hábito de triturar o medicamento antes de jogá-lo no lixo, evitando-se a possibilidade de que alguém venha a fazer uso do medicamento.

Farmácia 2: ele, como farmacêutico responsável, procura orientar o consumidor final para os riscos do descarte incorreto dos medicamentos, até mesmo destacando a máquina de coleta existente em sua farmácia, mas é raro que haja essa preocupação. O próprio Conselho Regional de Farmácias (CRF) tem campanhas de 
conscientização sobre o descarte adequado de medicamentos, mas, segundo o entrevistado, essa ação é pouco divulgada.

Farmácia 3: a farmacêutica responsável desconhece campanhas de conscientização ou mesmo orientação ao consumidor final para o descarte correto de medicamentos.

Hospital 1: existe orientação ao paciente quando, eventualmente, ligam para o hospital com a finalidade de saber o que fazer com a sobra de medicamentos ao término de um tratamento ou quanto ao medicamento vencido, Orienta-se a levar a um posto de saúde, ou em alguma rede de drogaria, ou mesmo no hospital, disse o Gerente da Farmácia. Já a Coordenadora Ambiental diz que não há orientação ao consumidor final sobre o descarte de medicamentos. Essa orientação é dada somente aos colaboradores do hospital, onde monitoram os acidentes e falhas de descarte por área com os custos gerados e ações recomendadas.

Hospital 2: eles lamentam, mas não há uma campanha de conscientização ou orientação ao paciente de como descartar um medicamento não consumido ou expirado.

Consultório 1: não há campanhas de conscientização sobre descarte correto de medicamentos que chegam aos consultórios médicos. Também comentou que os propagandistas não têm a prática de recolher medicamentos vencidos.

Consultório 2: não há orientação sobre o risco do descarte incorreto de medicamentos, nem orientação aos pacientes ou mesmo campanhas de conscientização sobre a forma correta de se descartar um medicamento vencido.

Consultório 3: a dentista recebe treinamento técnico no posto de saúde sobre descarte de medicamentos e resíduos gerados na área de saúde. Com esses conhecimentos, procura orientar seus pacientes sobre o que fazer com sobras de medicamentos ou medicamentos vencidos. Ela afirma que não há campanhas de conscientização para população sobre os riscos de um medicamento descartado incorretamente ao meio ambiente. 
Empresa BHS: no site da BHS, há orientações para os locais corretos para o descarte dos medicamentos e também em materiais de divulgação, mas ainda não há campanhas para conscientização do consumidor final.

\subsection{INCERTEZA: QUANTIDADE E QUALIDADE DE PRODUTOS RETORNADOS (BLOCO O)}

\section{- Qual o volume mensal $(\mathrm{kg})$ de produto retornado?}

\section{- Como a empresa lida com as incertezas do retorno? Detalhar}

Laboratório 1: a incerteza quanto à quantidade e qualidade do produto retornado não afetam o segmento farmacêutico devido ao volume ser insignificante, representando apenas $0,08 \%$ do volume produzido..

Laboratório 2: o volume retornado dos coletores das farmácias gira em torno de 3 a

$5 \mathrm{~kg}$ por mês. Para se certificar da gestão eficiente da LR e eliminar as incertezas, firmou-se um contrato com a BHS sobre a destinação correta dos medicamentos, as responsabilidades civis, criminais e eventual dano à marca.

Laboratório 3: o volume de medicamentos retornado ao Laboratório 3 fica em torno $0,1 \%$ do seu volume produzido. Devido à alta regulação do mercado farmacêutico e aos volumes estarem adequados à demanda, as incertezas sobre a qualidade $\mathrm{e}$ quantidade de produtos devolvidos não afetam seus controles. Inclusive, como mencionado anteriormente, os produtos que retornam ao laboratório ainda dentro da data de validade são testados a fim de assegurar se poderão ser liberados e comercializados novamente. Além disso, eles comercializam os medicamentos dentro de, no mínimo, $85 \%$ do prazo de validade a expirar, o que visa garantir que a LR por medicamento expirado seja um evento raro.

Distribuidor 1: o volume retornado é insignificante, cerca de $2 \%$ ao ano. O Diretor Comercial salientou que, para todos os produtos retornados são avaliados os motivos do retorno, e se o problema gerado for de sua responsabilidade gera-se um crédito ao cliente que reclamou. Ele reforça que não tem obrigação de aceitar toda devolução. 
Distribuidor 2: o volume retornado é muito insignificante, mas segundo o Gerente da Logística, há casos que retornam produtos sem NF.

Farmácia 1: a Diretora de Compras não soube precisar o volume de medicamentos gerados para LR, mas neste caso, as incertezas sobre as quantidades e qualidades dos produtos retornados não são uma preocupação, pelo volume não ser significativo.

Farmácia 2: a quantidade de produto para incineração é mensurada bem como o custo envolvido. No caso do estoque da farmácia gira em torno de $10 \mathrm{~kg}$ mensais. $\mathrm{O}$ farmacêutico responsável elucida que eles tentam trabalhar para diminuir esta perda. Já da máquina de coleta do consumidor final, entre embalagens, frascos e medicamentos, recolhe-se em média, cerca de $70 \mathrm{~kg}$ por mês.

Farmácia 3: o dono da farmácia confirma que o seu volume de resíduo gerado é insignificante, inferior ao valor mínimo estabelecido de até $5 \mathrm{~kg}$.

Hospital 1: o Gerente da Farmácia indica que eles têm metas para reduzir o descarte de medicamentos com limite de perda por vencimento com a finalidade de redução de custo. Ele explicou que o descarte de medicamentos equivale a 0,02\% quando comparado ao percentual que se consome ao longo do ano. Este percentual é considerado insignificante, mas em termos de valor absoluto, a perda é relevante; por esse motivo, existe planejamento e estratégias para minimizar os custos.

Hospital 2: o responsável logístico informou que eles monitoram os indicadores de giro de estoque e sucata para lidar com as incertezas da LR. No caso de medicamentos, a perda é de $0,05 \%$ ao mês que é considerado insignificante, sendo permitido até $0,16 \%$ do total. Os estoques são baixos, fácil de controlar. No caso dos genéricos, o estoque é maior, trabalham com 30 dias de estoque.

Consultórios 1, 2 e 3: não se aplica.

Empresa BHS: o volume coletado em cada ponto de coleta em média é de $6 \mathrm{~kg}$ por mês. Atualmente, estão coletando cerca de 6 toneladas por mês em todo programa. O representante BHS diz que como este é um programa relativamente novo, eles lidam com as incertezas da LR se aprofundando em tudo que é pertinente e aprimorando o trabalho sempre que possível. 


\subsection{PRÁTICA LR: COMPLEXIDADE E DESAFIO (BLOCO P)}

- No contexto da LR, quais seriam facilitadores/restrições em todas as etapas?

Laboratório 1: a grande dificuldade da LR é o fato do processo administrativo-fiscal ser muito burocrático em relação à emissão da NF de devolução e busca da NF de origem. O volume físico retornado é insignificante, mas o volume de NF gerado é muito grande. Outro obstáculo relatado na entrevista seria a dimensão territorial do Brasil frente à falta de incineradores homologados pela ANVISA nas diversas regiões do país.

Laboratório 2: a Coordenadora de EHS enfatizou que um facilitador da LR seria a divulgação para a população do programa de coleta de medicamentos de uso domiciliar a fim de aumentar a sua abrangência. Em sua opinião, o obstáculo está mesmo nos diversos níveis da cadeia farmacêutica por não darem a devida importância para a questão ambiental.

Laboratório 3: o Gerente da Controladoria destacou como facilitadores da LR o SAC e a alta regulação no fornecimento dentro da cadeia, exceto consumidor final, o qual ele classificou como catastrófico, pois o consumidor final não tem a cultura do retorno, evidenciada também no acondicionamento do produto retornado de qualquer forma. A empresa KPMG fez um estudo sobre a viabilidade da LR em todo país, concluindo que nas regiões Norte e Nordeste, os desafios seriam maiores que nas regiões Sul e Sudeste.

Distribuidor 1: o Diretor Comercial disse que um facilitador para LR de medicamentos seria aumentar a validade do produto e dar benefícios às farmácias pela LR de medicamentos de uso domiciliar.

Distribuidor 2: na opinião do Gerente de Logística, os obstáculos mais relevantes na LR são a devolução de itens que não foram comercializados por eles e devoluções sem NF. Segundo a farmacêutica, apesar da melhora apresentada nos últimos anos em relação à $L R$, ainda há uma demora pela indústria em dar um parecer sobre a destinação final do medicamento. 
Farmácia 1: em relação à complexidade e desafios da LR, a Diretora Comercial destacou duas situações distintas: retorno do consumidor final para Farmácia 1, onde a restrição é não haver um padrão na forma de retorno do produto, onde o cliente devolve acondicionado de qualquer forma; e na situação da devolução da Farmácia 1 para o laboratório, o processo de emissão do NF é muito burocrático. Um facilitador no processo da LR mencionado por ela é a participação muito ativa do SAC.

Farmácia 2: o farmacêutico responsável destaca que a própria máquina de descarte de medicamentos seria um facilitador da LR, mas a divulgação ainda é um desafio.

Farmácia 3: enfatiza que a LR, de forma geral, funciona bem, mas o obstáculo seria a emissão da NF eletrônica de devolução, uma vez que tem que solicitar ao escritório terceirizado de contabilidade por não ter o sistema operando na sede da farmácia. O distribuidor pode fazer até três tentativas para recolher os produtos, sendo que, se não ocorrer pelo fato da NF não ter sido emitida, uma nova ocorrência solicitando o recolhimento do produto deve ser efetuada.

Hospital 1: o Gerente da Farmácia salientou que a falta de informações é um obstáculo na LR. Se a indústria tivesse a informação de quanto se descarta de medicamentos, poderia se sensibilizar, e criar estratégias de embalagem que minimizassem o desperdício. Na opinião da Coordenadora Ambiental, hoje em dia, as pessoas estão mais conscientes em relação ao consumo e descarte correto de medicamentos comparativamente à alguns anos. Além disso, há muitas legislações ambientais de diferentes órgãos abordando o mesmo assunto envolvendo um mesmo parâmetro, o que acaba gerando informações conflitantes que poderiam ser simplificadas.

Hospital 2: o responsável logístico opinou que a LR fica muito restrita a outros segmentos. O setor hospitalar prioriza a assistência. Ele acredita que se houver um setor dedicado à LR com pessoas dedicadas, poderia ser um facilitador para LR. O bombeiro destacou que eles são um hospital público, mas monitorado por uma grande instituição privada e ainda em uma região bem localizada de São Paulo. Em sua opinião, hospitais com pouco recurso e localizados na periferia, tem um desafio maior na LR. 
Consultórios 1, 2 e 3: não se aplica.

Empresa BHS: se a restrição de caracterizar o medicamento descartado como resíduo perigoso fosse classificá-lo como resíduo comum, facilitaria. Um Decreto nacional também ajudaria.

\subsection{INDICADORES DE LR (BLOCO Q)}

\section{- Quais são os indicadores associados à LR?}

\section{- Os resultados da LR são medidos e monitorados?}

Laboratório 1: os resultados da LR são medidos e monitorados. Os laudos da incineração são emitidos, controlados e arquivados de acordo com a data de incineração, especificação dos produtos e quantidades conforme mostrado durante a entrevista. Os indicadores que eles monitoram na LR são: melhoria da qualidade com motivos do retorno e quantidade retornada em porcentagem.

Laboratório 2: os resultados da LR são medidos e monitorados para que sejam atendidas as metas junto à CETESB. Os principais indicadores são os volumes de resíduos coletados por número de coletores instalados e geração de resíduos.

Laboratório 3: como indicadores da LR, fazem o acompanhamento dos retornos, onde investigam as causas raízes do motivo da devolução do lote, gerando um plano de ação cuja finalidade é mitigar os riscos. No que diz respeito à $L R$ do SINDUSFARMA (Sindicato da Indústria de Produtos Farmacêuticos), os indicadores são compartilhados ao conglomerado de laboratórios, onde acompanham os coletores instalados em farmácias de maiores volumes, sendo reportado o volume por região em quantidade recolhida de produtos e quantidade de materiais para reciclagem (embalagens de papelão, blister de alumínio, etc). Este acompanhamento possibilita saber o quanto é destinado a cada empresa do conglomerado a fim de calcular os custos e manter a filiação ao SINDUSFARMA.

Distribuidor 1: como indicadores, eles mensuram mensalmente a porcentagem das vendas não concluídas, analisando os motivos para melhoria dos negócios e a avaliação do volume retornado, objetivando redução de custos. 
Distribuidor 2: como indicadores da $L R$, eles mensuram mensalmente a quantidade de produtos retornados, os motivos, controle de produtos a expirar ou expirados e área de ocupação dos produtos segregados.

Farmácia 1: os indicadores monitorados neste processo atém-se ao volume retornado, motivos do retorno e melhoria da qualidade, objetivando a diminuição das avarias no $\mathrm{CD}$. Além disso, há também o monitoramento da empresa terceirizada de serviço de motoboys, visando minimizar as devoluções ocorridas em decorrência de avarias no transporte.

Farmácia 2: os resultados da LR são medidos e monitorados, sendo um dos indicadores a quantidade mensal de produtos que saem do seu estoque para incineração, que em média, gira em torno de $10 \mathrm{~kg}$ e o custo envolvido nesta operação. Segundo o farmacêutico responsável, a análise deste indicador objetiva a implementação de ações para diminuição destas perdas, bem como melhoria da qualidade e redução de custos.

Farmácia 3: a farmacêutica relatou que não monitora os resultados da $L R$, apenas o crédito gerado no caso de uma reclamação de quem realizou a venda, que pode ser um distribuidor ou representante do laboratório farmacêutico. O proprietário da farmácia declarou que procura entender os produtos com maior giro a fim de otimizar o estoque para minimizar as perdas pela LR.

Hospital 1: para o Gerente da Farmácia, os resultados da LR são medidos e monitorados quanto ao custo do medicamento descartado, sendo que um dos indicadores é a redução de custo. Já na área da Coordenadora Ambiental, os indicadores estão ligados à toda geração de resíduos hospitalar, contemplando o custo dos resíduos, custo logístico, melhoria da qualidade, falhas de segregação, números de acidentes, quantidade de resíduos por passagem, porcentagem de reciclável, consumo de água e energia e emissão de gases de efeito estufa. Esses indicadores foram apresentados durante a entrevista em sua planilha de controle mensal.

Hospital 2: o responsável da farmácia me mostrou os seguintes indicadores: nível de serviço, giro de estoque e sucata (perda). 
Consultório 1, 2 e 3: não se aplica.

Empresa BHS: os resultados da LR são medidos e monitorados, onde os principais indicadores seriam o volume retornado, otimização de tempo, melhoria de qualidade a fim de reduzir custos. 


\section{ANÁLISE E DISCUSSÃO DOS RESULTADOS}

Analisando os resultados coletados durante as entrevistas, foi possível avaliar as práticas da LR na cadeia de suprimentos no estado de São Paulo e discutir os resultados encontrados à luz da literatura, confrontando com as legislações em vigor que estão em constantes mudanças.

\subsection{SUSTENTABILIDADE: IMPACTOS SOCIAIS E AMBIENTAIS}

Vários autores como Kongar et al. (2015), Campos et al. (2017), Luna e Viana (2017), Pereira et al. (2017) e Bravo e Carvalho (2015) destacaram que a geração de resíduos é uma realidade na cadeia farmacêutica, demonstrando uma grande preocupação com os aspectos sociais e ambientais na LR de medicamentos. Nesta pesquisa fica evidente, além do atendimento à legislação vigente, uma preocupação maior com a sustentabilidade nos laboratórios farmacêuticos e hospitais, que são grandes geradores de resíduos, incluso o Laboratório 2 que não produz a medicação e apóia programas de sustentabilidade. Por outro lado, os distribuidores e farmácias tem como foco principal o atendimento à legislação vigente. Já nos consultórios médicos, o tema sustentabilidade está mais ligado à conscientização individual dos médicos. Os laboratórios farmacêuticos e os hospitais cuja missão prioritária é salvar vidas, não consideram a LR no desenvolvimento do produto aliado ao seu ciclo de vida (CLSC) a fim de potencializar sua viabilidade econômica e reduzir impactos ambientais (CAMPOS et al., 2017). Planejar a cadeia de suprimentos pensando não somente na logística direta, mas englobando também a LR, pode ser uma vantagem competitiva e demonstra uma preocupação com questões ambientais, citado por Guide e Wassenhove (2009). Contradizendo os autores citados, no segmento farmacêutico esta evidência não se aplica pelo volume retornado ser insignificante.

Todos os entrevistados foram unânimes em afirmar que os medicamentos descartados nas águas e lixo comum, contaminam o meio ambiente, expondo riscos à saúde da população e aos animais, o que corrobora com o descrito por Pereira et al. (2017). Em relação aos consultórios, pela quantidade de medicação descartada ser ínfima, a preocupação com riscos ambientais é valorizada, porém minimizada. A dentista do Consultório 3 demonstrou conhecimento sobre estudos onde a procriação de peixes é afetada pela presença de anticoncepcionais nas águas. Luo 
et al. (2014) mencionaram que o processo de tratamento de água não consegue eliminar completamente alguns medicamentos, como antibióticos e hormônios, afirmação confirmada pelo Gerente da Farmácia do Hospital 1 e pelo representante da empresa BHS.

O Laboratório 1, o Distribuidor 1 e a Farmácia 1 externaram uma preocupação com automedicação pela sobra de medicamentos ou o risco do consumo do medicamento diretamente do lixo. A Diretora Comercial da Farmácia 1 mencionou como consumidora, triturar medicamentos vencidos em sua casa antes de descartálos no lixo. A Coordenadora de EHS do Laboratório 2 enfatizou os riscos à saúde pública por desvios na cadeia de fornecimento para falsificação de medicamentos, em concordância com as pesquisas de Kongar et al. (2015) e Narayana, Elias e Pati (2014).

Luna e Viana (2017), ao entrevistar o representante da Sindusfarma concluíram que o conceito de LR ainda não é bem compreendido nos diversos segmentos o que ficou evidente na entrevista realizada no Hospital 1, quando a Coordenadora Ambiental afirmou que para medicamentos não aplica $L R$, sendo destinados diretamente para incineração.

\subsection{REGULAMENTOS GOVERNAMENTAIS}

Todos os entrevistados foram unânimes em citar a aplicação das normativas da ANVISA nos processos farmacêuticos. Os laboratórios farmacêuticos seguem basicamente a RDC n 222/2018 da ANVISA e o CONAMA n 358 sobre o descarte de resíduos. Para o transporte de medicamentos, seguem a RDC $n^{\circ} 304$ e quem lida com medicamentos controlados, segue a portaria 344 da ANVISA. O Laboratório 2 respalda a RDC $n^{\circ} 222$ e a CONAMA $n^{\circ} 358$ na PNRS, em contraste com o Laboratório 3 que não aplica a PNRS por não ser específica para o setor farmacêutico. Quanto a Decisão da Diretoria da CETESB No 114/2019/P/C, o Laboratório 1 não está aplicando, o Laboratório 2 se associou à Interfarma para contribuir com a LR de medicamentos domiciliares mesmo não sendo obrigados e o Laboratório 3 aderiu se associando ao conglomerado de indústrias através do SINDUSFARMA por seu volume de medicamentos nas farmácias ser insignificante e a legislação se aplicar de acordo com o volume vendido nas farmácias. 
O Distribuidor 1 utiliza a RDC $n^{\circ} 222$ e RDC n 304 para o transporte e distribuição de medicamentos, já a representante do Distribuidor 2 além dessas normas, mencionou CONAMA n 358 e a portaria CVS n 21 de 10/09/2008 que não foi citada por nenhum outro entrevistado. O decreto federal $n^{\circ} 10388$ de 5 de junho de 2020 que institui a LR de medicamentos domiciliares e suas embalagens após o descarte pelos consumidores foi mencionado apenas pelo Distribuidor 2 e Hospital 2 já que as entrevistas foram realizadas no $2^{\circ}$ semestre de 2020.

As farmácias salientaram seguir a RDC $n^{\circ} 44$ sobre as Boas Práticas Farmacêuticas, sendo que a Farmácia 1 também diz seguir a RDC $n^{\circ} 222$ para o descarte de resíduos.

O Hospital 1 mencionou a PNRS, RDC n²22, CONAMA n 358 e reporta ao IBAMA sobre a geração de resíduos e à SABESP sobre as condições do esgoto gerado, em contraste com o Hospital 2 público que mencionou seguir fundamentalmente a RDC $n^{\circ} 222$.

Jorgensen (2008), Glover et al. (2014) e Souza (2013) ressaltaram que a cadeia farmacêutica incorpora os requisitos ambientais em acordo à legislação vigente, mas há empresas como o Laboratório 2 que fazem mais do que a legislação exige.

Daughton (2003) destacou a falta de orientação e regulamentos conflitantes sobre o descarte de medicamentos, o que corrobora com a posição da Coordenadora Ambiental do Hospital 1 que ressaltou que um dos principais obstáculos da LR é o conflito gerado pelas legislações de diferentes órgãos ambientais. Tanto o Laboratório 2, Laboratório 3 quanto o Distribuidor 2 afirmaram haver falta de clareza na Decisão Diretora da CETESB No 114/2019/P/C, o que abriu precedente para que alguns laboratórios entrassem com uma liminar na justiça questionando o cumprimento da LR de medicamentos domiciliares.

\subsection{LR DE MEDICAMENTOS DOMICILIARES}

Autores como Luna e Viana (2019), Aquino et al. (2018), Bellan et al. (2012) e Stocher et al. (2018) compartilham a premissa de que não há uma legislação brasileira específica para o descarte de medicamentos pelo consumidor final. Estas afirmações vêm ao encontro dos dados coletados nas entrevistas, onde observamos que há um contraste muito grande em relação a este tema, não havendo uma 
uniformidade nas ações realizadas pelos diferentes atores da cadeia. Na pesquisa este achado fica evidente pois o Laboratório 1 não tem programa vigente de LR de medicamentos domiciliares, o Laboratório 2 possui dois coletores para descarte de medicamentos em farmácias mesmo não havendo necessidade de atender a essa legislação e o Laboratório 3 cumpre o requisito através da adesão ao conglomerado de empresas do SINDUSFARMA. Até o momento da realização das entrevistas, as normas vigentes relacionadas à LR de medicamentos domiciliares eram ABNT: NBR 16457 e a Decisão da Diretoria da CETESB N ${ }^{\circ}$ 114/2019/P/C, sendo esta de caráter estadual, somente vigente no Estado de São Paulo. Ainda o Gerente da Controladoria do Laboratório 3 explicou que não existia uma legislação específica para LR domiciliar até que a Decisão da CETESB fez com que as empresas tivessem que se adequar em um pouco tempo. A Coordenadora de EHS do Laboratório 2 comentou que muitos laboratórios que precisavam aderir à diretiva da CETESB, por risco de perda da licença de operação, entraram com uma liminar na justiça para suspensão do programa.

Os distribuidores entrevistados não aplicam qualquer programa de LR de medicamentos domiciliares, já as Farmácias e os Hospitais usam diferentes estratégias para o retorno de medicamentos. Tais posturas se alinham ao trabalho de Luna e Viana (2019), que afirmaram que não há uma legislação nacional que obrigue as farmácias a receberem medicamentos vencidos ou não utilizados pelo consumidor final, sendo esta uma por iniciativa de algumas farmácias. Nos consultórios médicos, a entrada de medicamentos se dá através dos propagandistas de laboratório farmacêuticos, mas não há prática de recolhimento de medicamentos de pacientes ou mesmo a retirada pelos propagandistas de medicamentos expirados.

\subsection{LR: MOTIVOS DE RETORNO / RECALL}

Luna e Viana (2017), Narayana, Elias e Pati (2014), Kabir (2013), Bravo e Carvalho (2015) ressaltaram que o retorno dos produtos (LR) na indústria farmacêutica ocorre principalmente quando: os produtos estão com a data de validade próxima ao vencimento ou vencidos; produtos ou embalagens danificados; recall ou por erros na entrega. Os Laboratórios Farmacêuticos, Distribuidores, Farmácias e Hospitais entrevistados destacaram os mesmos motivos descritos na 
literatura para ocorrência de LR. Nos Consultórios, os motivos são os mesmos, exceto erros nos pedidos, pois o ingresso de medicamentos ocorre via propagandistas. Bellan et al. (2012) destacaram a gestão inadequada do inventário de medicamentos pelas farmácias e outros estabelecimentos de saúde, e o Hospital 2 também citou como motivo de LR, a falha no processo logístico. $O$ autor também ressaltou as amostras grátis distribuídas pelos laboratórios farmacêuticos como publicidade, fato não mencionado nos consultórios entrevistados. O Consultório 2 prefere recusar amostras grátis de propagandistas se a quantidade não for suficiente para ofertar ao paciente.

O roubo de carga e falsificação de medicamentos mencionado por Kongar et al. (2015), foi também citado por Laboratório 1 e Laboratório 2 como uma preocupação, mas disseram que no passado as ocorrências eram mais frequentes. No caso de sobras de medicamentos originados da dispensação excessiva para o tratamento conforme mencionado por Bellan et al. (2012), o Hospital 1 concordou que deveria haver maior flexibilidade na indústria para venda da quantidade de acordo com a prescrição e a produção de embalagens maiores para medicamentos de uso contínuo. Campos et al. (2017) sugeriram sobre uso racional dos medicamentos conforme a quantidade prescrita e o Laboratório 1 relatou a impossibilidade de aplicar o fracionamento de medicamentos nas farmácias devido ao risco de contaminação cruzada.

\subsection{GESTÃO DO FLUXO DE DEVOLUÇÕES}

Kumar, Dieveney e Dieveney (2009) afirmaram que para uma gestão eficiente da LR, faz-se necessário um processo bem definido e consistente. De forma geral, todos os atores da cadeia entrevistados, administram de forma bem similar o fluxo da LR: os materiais devolvidos ficam em uma área segregada e bloqueados no sistema, é necessário a NF de origem e a geração de NF devolução, e os medicamentos a expirar são segregados em torno de 1 mês a 3 meses antes do vencimento. Apesar de os volumes de LR serem considerados insignificantes, são emitidos Certificado de Destinação de Final de Resíduos para incineração, onde medicamentos controlados devem ser lacrados e reportados em conformidade com a portaria 344 ANVISA. No caso de devolução pelo consumidor final, o SAC é envolvido. No Laboratório 3, quando uma devolução está dentro do prazo de 
validade, são realizados testes de validação e estabilidade a fim de averiguar se os princípios continuam ativos e o medicamento poderá ser reaproveitado.

Olorunniwo e Li (2010) mencionaram o uso de TI na gestão da LR, o que é feito por todas as empresas entrevistadas, exceto a Farmácia 3 que por ser muito pequena administra o estoque de forma manual. Todas as farmácias praticam a segregação conforme estabelecido pelas "Boas Práticas Farmacêuticas", preenchem o relatório da portaria $n^{\circ} 344 / 98$ em caso de medicamentos controlados, com o lacramento do lote pela Autoridade Sanitária e recolhimento pela prefeitura com pagamento da taxa compatível com a geração de resíduos.

Todas as empresas aderiram ao Plano de Gerenciamento de Resíduos de Saúde onde os relatórios de atividades pelos resíduos gerados na fabricação, formulação, distribuição e utilização de produtos farmacêuticos são emitidos em atendimento às normas: Conama $n^{\circ} 358$, ANVISA RDC $n^{\circ} 222 / 2018$ e RDC $n^{0}$ 44/2009, CETESB e IBAMA.

\subsection{DEFINIÇÃO DE RESPONSABILIDADES / CUSTO DA LR}

Kumar, Dieveney e Dieveney (2009), Campos et al. (2017), Luna e Viana (2017), Aquino et al. (2018) e Demajorovic, Augusto e Souza (2016) concordaram com a necessidade de que cada pessoa na cadeia de suprimentos esteja ciente de seu papel e responsabilidades, e que ainda existem muitos conflitos sobre a divisão dos custos e responsabilidades na LR. Todos os entrevistados compartilharam das afirmações dos autores citados e afirmam que a LR neste setor é vista como custo necessário. Quanto aos papéis e responsabilidades, todos concordaram que estão bem definidas pelo acordo comercial firmado. Cada ator em cada ponto da cadeia é responsável pelo seu estoque, exceto em casos de recall, onde a responsabilidade é do laboratório fabricante. O que ainda não está bem definido é a LR dos medicamentos do consumidor final em relação ao descarte de medicamentos domiciliar, principalmente em relação aos custos e aguarda-se um decreto do MMA para que se definam as responsabilidades, exatamente como defendem Aquino et al. (2018) que constataram que ainda não está estabelecido um acordo setorial entre as farmácias e os fabricantes sobre as responsabilidades pelos custos da LR e seleção dos destinos adequados. Na opinião do Laboratório 3, pela LR ser um custo para empresas, poucos laboratórios farmacêuticos têm um programa para recolher 
medicamentos expirados ou em desuso da população. Antes da legislação da CETESB, o Laboratório 1 implantou coletores em farmácias, mas o programa foi suspenso por não ter havido um acordo sobre o compartilhamento de responsabilidades e custos com outros laboratórios. Ainda no momento da entrevista, não haviam se adequado à legislação da CETESB. O Distribuidor 2 também acha que as responsabilidades estão bem definidas dentro da cadeia, mas salientou que com o Decreto Federal n 10388, haverá uma melhoria no que diz respeito ao consumidor final.

Outro ponto polêmico observado nas entrevistas é a responsabilidade pelo serviço terceirizado na LR para a destinação final dos medicamentos. Os entrevistados na cidade de São Paulo tem que utilizar a empresa da prefeitura para a coleta, armazenagem e incineração dos medicamentos em desuso. A maioria dos entrevistados diz que a responsabilidade é da empresa coletora do resíduo, mas pela CONAMA $n^{\circ} 358$, "Cabe aos geradores de resíduos de serviço de saúde e ao responsável legal, referidos no art. 10 desta Resolução, o gerenciamento dos resíduos desde a geração até a disposição final, de forma a atender aos requisitos ambientais e de saúde pública e saúde ocupacional, sem prejuízo de responsabilização solidária de todos aqueles, pessoas físicas e jurídicas que, direta ou indiretamente, causem ou possam causar degradação ambiental, em especial os transportadores e operadores das instalações de tratamento e disposição final, nos termos da Lei no 6.938, de 31 de agosto de 1981". O Hospital 1 relatou um episódio irregular ocorrido no armazenamento do resíduo pela empresa da prefeitura que gerou multa para o Hospital 1. Depois, eles conseguiram repassar para a prefeitura, mas no primeiro momento, quem responde é o gerador do resíduo.

\subsection{PL: UTILIZAÇÃO DE FORNECEDORES TERCEIROS NA LR}

Campos et al. (2017) recomendaram a inclusão de fornecedores de logística terceirizados (3PLs) e critérios específicos para selecioná-los e as certificações exigidas. Os dados observados apontam que todas as empresas entrevistadas utilizam transporte terceirizado certificado e monitorado, respeitando as exigências da ANVISA conforme RDC n 304/2019 na logística direta. Quando ocorre uma devolução (LR) por parte dos clientes, o transporte é o mesmo, seguindo os procedimentos de temperatura e armazenagem pertinentes. Como já comentado, o 
Laboratório 3, em casos de devoluções dentro do prazo de validade, pode aproveitar os medicamentos após comprovação de eficácia através dos testes de estabilidade e validação. As demais empresas, já segregam diretamente para descarte.

Kumar, Dieveney e Dieveney (2009) mencionaram que pela LR ser predominantemente realizada por fornecedores terceiros (3PL - Third-party logistic), falta uma melhor compreensão do processo como um todo. Este fato é observado na coleta das empresas dos resíduos destinados ao descarte, como explicado no tópico anterior 6.6. Ainda falta uma compreensão das responsabilidades, principalmente nas empresas da prefeitura.

\subsection{COMPARTILHAMENTO DE INFORMAÇÕES}

Narayana, Pati e Padhi (2019), Kainuma e Tawara (2006), Olorunniwo e Li (2010) são favoráveis a uma política de compartilhamento de informações para gerenciar o estoque e minimizar as devoluções. Isto se contrapõe ao observado durante as entrevistas que evidenciam não haver um compartilhamento de informações na cadeia que vise otimizar o estoque e evitar perdas de medicamentos. O Laboratório 3 acredita que um dos motivos para não haver esse compartilhamento seria o risco de compliance por divulgação de informações, porém acredita que existe uma tendência no surgimento de empresas como a BHS que prestam o serviço de LR, centralizando informações. Nas Farmácias 1 e 2, há um compartilhamento do estoque diretamente com alguns representantes de laboratórios farmacêuticos, mas o viés é puramente comercial. Já o Distribuidor 1 afirmou que não há necessidade de compartilhar informações no intuito de evitar perdas no estoque, pois para ele, quanto mais vender, melhor. $\mathrm{Na}$ opinião do Hospital 1, cada ator da cadeia vê seus próprios interesses econômicos.

\subsection{RASTREABILIDADE DOS MEDICAMENTOS}

Kongar et al. (2015) e Kumar, Dieveney e Dieveney (2009) salientaram a importância do uso de etiquetas de RFID no controle e rastreabilidade dos medicamentos, que tem como fator limitador o custo. Através das entrevistas percebemos que não há uso de RFID nem na logística direta como na reversa. A rastreabilidade é feita pela NF e número do lote. No caso dos Hospitais 1 e 2, há o 
MTR - Manifesto de Transporte que acompanha os resíduos e deve ser assinado em três vias (empresa geradora, transportadora e empresa responsável pelo descarte). No caso dos medicamentos controlados, o rigor é maior. Há necessidade da presença da Autoridade Sanitária para lacrar o lote, gerando um número de lacre que acompanha o lote para rastreabilidade.

Campos et al. (2017) afirmaram em seu artigo que falta um sistema para monitorar os retornos, em concordância com Luna e Viana (2017), que enfatizaram a importância da informatização e a rastreabilidade durante o processo de distribuição dos medicamentos, o que pode auxiliar na implantação de um processo de LR mais robusto. Todas as empresas entrevistadas utilizam TI para monitorar e bloquear os retornos no sistema, exceto a Farmácia 3 que ainda faz os controles manualmente.

\subsection{CLASSIFICAÇÃO DE MEDICAMENTOS PARA DESCARTE}

A Conama $n^{\circ} 358$ e a ANVISA RDC $n^{\circ} 222$ classificam os resíduos de serviços de saúde (RSS) em Grupo A - infectantes, Grupo B - químicos, Grupo C radioativos, Grupo D - lixo comum (reciclável ou orgânico) e Grupo E perfurocortantes para separação e descarte. Os medicamentos estão dentro do Grupo B - químicos, tóxicos. O entrevistado da empresa BHS confirmou que os medicamentos para descarte são classificados como resíduos perigosos do grupo B. Todas as empresas entrevistadas separam os medicamentos controlados dos demais medicamentos para o descarte. Os medicamentos controlados devem seguir a portaria 344 da ANVISA, permanecendo em área trancada aguardando a fiscalização da vigilância sanitária lacrá-los para posterior incineração.

Nos coletores dispostos em farmácias sob a responsabilidade da empresa BHS, há três separações para descartar os medicamentos: comprimidos e pomadas, líquidos e sprays e caixas e bulas. No Hospital 1, também separam os medicamentos líquidos dos sólidos para descarte. Luna e Viana (2017) citaram em seu artigo a possibilidade de descartar algum medicamento na pia ou lixo comum fato observado apenas pelo Hospital 1. A SABESP autoriza o descarte de alguns medicamentos na água e o esgoto do Hospital 1 é monitorado para averiguar se não há substâncias proibidas sendo descartadas irregularmente. Para o consumidor final, não há uma classificação de medicamentos na bula ou na caixa do medicamento para o correto descarte, gerando situações errôneas. O Laboratório 2 exemplificou 
que nos coletores das farmácias descarta-se até Rinosoro que entra no volume dos itens para LR sem a real necessidade. Esse dado corrobora com a pesquisa de Luna e Viana (2017), que também evidenciaram em suas entrevistas ao Sindusfarma e os fabricantes de medicamentos que nem todo medicamento é perigoso e causa problemas ambientais, recomendando uma classificação de periculosidade dos medicamentos e orientação adequada de descarte.

\subsection{MÉTODOS DE DESCARTE / DISPOSIÇÃO FINAL}

Bellan et al. (2012) e Luna e Viana (2017) compartilharam que não há uma legislação brasileira específica para o descarte de medicamentos pelo consumidor final, já sobre os resíduos sólidos de saúde (RSS), a regulamentação está mais bem definida.

Bellan et al. (2012) enumeraram que os principais métodos de descarte dos resíduos químicos, incluindo os medicamentos adotados pela PSC são: retornar à indústria; disposição em aterros, sempre que o resíduo for encapsulado ou desativado; em aterros com proteção aos sistemas aquífero e de esgoto; incineração em contentores fechados; incineração a temperaturas médias; e decomposição química. Outros autores como Luna e Viana (2017), Campos et al. (2017), Narayana, Elias e Pati (2014), Daughton (2003), Blankenstein e Junior (2018), Kongar et al. (2015) citaram que o método mais utilizado para descarte de medicamentos é a incineração que foi o método de disposição utilizado por todos os entrevistados da cadeia farmacêutica no Estado de São Paulo, exceto os Consultórios 1 e 2 que descartam no lixo comum. O representante da empresa BHS explicou que, em quase todo Brasil, o destino final dos medicamentos é a incineração exceto no Rio Grande do Sul, cujo destino são os aterros industriais classe 1, que impedem a contaminação do solo, conforme também descrito no artigo de Stocher et al. (2018).

Musson et al. (2007), Jones, Voulvoulis e Lester (2003), Tong, Peake e Braund (2011) e Aquino et al. (2018) indicaram que o descarte de medicamentos em lixo comum, pia ou esgoto é uma prática comum evidenciada nas entrevistas dos Consultórios 1 e 2. 


\subsection{REUTILIZAÇÃO DE MEDICAMENTOS DEVOLVIDOS NO PRAZO DE VALIDADE}

Daughton (2003) e Kongar et al. (2015) salientaram que muitas farmácias nos EUA recebem medicamentos vencidos, sendo que alguns estados dos EUA permitem a reutilização de medicamentos, mas ainda há limitações devido à garantia sobre a integridade dos medicamentos redistribuídos e as responsabilidades sobre os mesmos. Existem diferentes opiniões quanto à reutilização de medicamentos por não se conhecer as condições de temperatura e umidade em que o produto foi armazenado. Nas entrevistas evidenciamos que não existe a prática de reutilização de medicamentos devolvidos mesmo dentro do prazo de validade, devido a não se ter garantias quanto à forma como foram armazenados. Apenas o Laboratório 3 tem como prática, em lotes devolvidos dentro do prazo, verificar a integridade dos medicamentos através de testes de estabilidade e caso sejam aprovados, reaproveitá-los. Já os Consultórios 1, 2 e 3 adotam na informalidade a prática de doação aos mais carentes. O Consultório 1 mencionou a existência da farmácia dos pobres dentro de um Hospital referenciado na cidade de São Paulo, em consonância com citação de Narayana, Pati e Padhi (2019) que recomendaram mudanças nos processos de LR na Índia a fim de permitir a realocação de medicamentos sem uso dentro do prazo de validade para mercados carentes. Medeiros, Moreira e Lopes (2014) citaram em seu artigo um programa chamado de Devolução Segura de Medicamentos no Hospital das Clínicas, que recebe e avalia medicamentos que estando em perfeitas condições, são dispensados para pacientes carentes. O Hospital 1 lamentou que em nosso país se descarte medicamentos pela validade. Os consultórios 1, 2 e 3 afirmaram que muitos medicamentos, mesmo após a validade expirada continuam com seus princípios ativos, mas não recomendam o uso para qualquer paciente.

\subsection{DEVOLUÇÃO DE MEDICAMENTOS / PONTOS DE COLETA}

Daughton (2003) e Vollmer (2010) demonstraram que em alguns países desenvolvidos da Europa e em alguns estados dos EUA, a entrega de medicamentos vencidos e utilizados pelos consumidores no ponto de venda já é uma prática. Luna e Viana (2017) levantaram a questão sobre as possíveis soluções 
e pontos de coletas para os medicamentos vencidos, de modo que a indústria farmacêutica possa ter um canal reverso específico para a coleta, que poderia ser nas farmácias, facilitando ao consumidor final a entrega do medicamento e a coleta pelos outros elos da cadeia responsáveis pela entrega. Segundo a RDC $n^{\circ} 44$, fica permitido às farmácias e drogarias participar de programas de coleta de medicamentos a serem descartados pela comunidade, porém a situação observada nas Farmácias 1, 2 e 3 é bastante distinta. A Farmácia 1 não aceita devolução de sobras e/ou medicamentos expirado do consumidor final, tampouco possui coletores em suas unidades, a Farmácia 2 possui coletor da empresa BHS na unidade onde ocorreu a entrevista e a Farmácia 3 aceita do consumidor o descarte de medicamento, mas não há um programa formal de recolhimento de medicamentos na unidade. A empresa BHS Brasil Health Service operacionaliza LR com a participação dos pontos de coleta em farmácias dentro do Estado de São Paulo através da adesão ao programa da Interfarma. O Hospital 1 aceita na informalidade algum paciente que queria descartar medicamentos em desuso, mas não possui um programa ou coletor em suas unidades. O Hospital 2 não aceita medicamentos do consumidor final. Stocher et al. (2018) observaram em sua pesquisa no Rio Grande do Sul que farmácias que possuem coletores de medicamentos vencidos ou em desuso proporcionam uma imagem de sustentabilidade à organização, podendo gerar uma vantagem competitiva sobre as concorrentes.

Pela RDC n 44/2009, os produtos violados, vencidos, sob suspeita de falsificação, corrupção, adulteração ou alteração devem ser segregados em ambiente seguro e diverso da área de dispensação e identificados quanto a sua condição e destino, de modo a evitar sua entrega ao consumo. Todas as farmácias entrevistadas seguem esta prática da LR.

Guirguis (2010) sugeriu que os profissionais do ramo farmacêutico são a melhor opção para coletar medicamentos não utilizados e educar os clientes bem como Aquino et al. (2018) realizaram uma pesquisa diretamente em farmácias no município de São Paulo, com o objetivo de compreender o papel dos farmacêuticos responsáveis na LR de medicamentos, visando a conscientização da população no descarte adequado dos medicamentos expirados o que foi evidenciado na Farmácia 2 , onde existe a orientação ao consumidor final para os riscos do descarte incorreto de medicamentos e também o auxílio na utilização do coletor disponível na unidade, em contradição à Farmácia 1 que não se preocupa com a coleta de medicamentos 
do consumidor final. O Hospital 1 orienta a levar os medicamentos para um posto de coleta mais próximo de sua residência. O Consultório 3 procura orientar seus pacientes sobre o que fazer com sobras de medicamentos, inclusive verifica se as condições de armazenamento foram adequadas e pede aos seus pacientes para trazer ao consultório para que sejam encaminhados à doação, mas todas essas ações são realizadas na informalidade.

\subsection{CONSCIENTIZAÇÃO / CAMPANHAS DE DIVULGAÇÃO}

Pereira et al. (2017) citaram em sua pesquisa programas de conscientização no Brasil como: Programa Destino Certo; Programa Descarte Consciente; Programa Descarte Correto de Medicamentos, mas ainda não teria um programa nacional vigente. Stocher et al. (2018) em seu artigo salientaram que há pouca divulgação sobre o serviço de coleta oferecido pela rede de farmácias Panvel que está vinculado ao Programa Destino Certo. Todos os entrevistados foram unânimes em relatar que desconhecem campanhas de divulgação para orientar o consumidor final sobre o descarte correto de medicamentos. A própria empresa BHS confirmou que há orientações no site para os locais corretos de descarte de medicamentos, mas ainda não há campanhas de divulgação para conscientização do consumidor final. Xie e Breen (2012) salientaram a necessidade de aumentar a conscientização sobre o impacto da medicação no meio ambiente e métodos de disposição eficientes, como por exemplo, trazendo a medicação para um local de coleta. Em contrapartida, Kongar et al. (2015) citaram que em 2011, a União Europeia estabeleceu uma campanha para conscientizar a população sobre impactos ambientais e de saúde no descarte inadequado de produtos farmacêuticos, orientando sobre métodos de eliminação segura de medicamentos vencidos ou sobras. Daughton (2003) relatou que países como Canadá, Itália, França e Espanha conduziram programas sobre a LR de medicamentos para o correto descarte de produtos farmacêuticos e também na Austrália, em 1998, foi lançado um programa de coleta de medicamentos em parceria com o Governo e indústrias farmacêuticas.

As campanhas de conscientização são extremamente importantes, pois minimizam a possibilidade de envenenamento acidental de crianças por medicamentos vencidos, reduz custos com medicamentos, evita a auto-medicação inadequada e o dano potencial ao meio ambiente (DAUGHTON, 2003). 
As próprias normas como CETESB No 114/2019/P/C dizem que "o plano de LR deverá contemplar a realização de campanhas de divulgação sobre a importância da participação, bem como fornecer orientações sobre a forma e locais de descarte, tanto aos consumidores quanto a outros envolvidos na LR e a RDC $n^{\circ}$ 44/2009 menciona que "as farmácias e drogarias podem participar de campanhas e programas de promoção da saúde e educação sanitária promovidos pelo Poder Público", mas as evidências obtidas nas entrevistas contrariam as ideias levantadas pelos diversos autores estudados e as normas regulamentares vigentes, visto que, não existem efetivamente campanhas de conscientização.

\subsection{INCERTEZA: QUANTIDADE E QUALIDADE DOS PRODUTOS RETORNADOS}

Tibben-Lembke e Rogers (2002), Kumar, Dieveney e Dieveney (2009) e Ye e Zhenhua (2014) compararam as diferenças entre a logística direta e a LR, principalmente em relação às incertezas da quantidade e na qualidade dos produtos retornados, sendo a LR mais difícil de controlar e rastrear. Todos os entrevistados explicaram que os volumes retornados são insignificantes, o que faz com que as incertezas sobre a qualidade e quantidade retornadas não afetem. Já nos coletores disponibilizados em farmácias sob a gestão da BHS, por ser este um programa relativamente novo, eles ainda estão aprendendo a lidar com as incertezas da LR.

\subsection{PRÁTICA LR: COMPLEXIDADE E DESAFIO}

Segundo Bravo e Carvalho (2015), o retorno dos medicamentos também poderá ser muito complexo, principalmente em empresas multinacionais que operam em muitos países. Nos relatos, os Laboratórios não declararam sofrer esta dificuldade. O que o Laboratório 1 destacou foi a dificuldade dentro do próprio Brasil devido aos contrastes entre os estados e falta de incineradores homologados pela ANVISA em todas as regiões, o que se alinha aos achados na literatura do artigos de Bellan et al. (2012) e do artigo de Medeiros, Moreira e Lopes (2014), que salientaram a dificuldade da implantação de um sistema unificado de LR, devido à dimensão e características distintas das regiões do Brasil. Neste sentido, o Laboratório 3 também destacou a pesquisa da KPMG, que concluiu que os desafios 
da LR de medicamentos nas regiões Norte e Nordeste seriam maiores se comparado às regiões Sul e Sudeste.

No Brasil, o descarte correto de medicamentos ainda é um grande desafio (CAMPOS et al., 2017; LUNA; VIANA, 2017) e não há uma legislação nacional que obrigue a farmácia a receber o medicamento vencido ou não utilizado pelo consumidor final, somente por iniciativa de algumas farmácias. Este fato foi claramente observado nas entrevistas, mesmo após a Decisão da Diretoria da CETESB N $N^{\circ} 114 / 2019 / P / C$ onde fica claro a falta de preocupação em todos os níveis da cadeia farmacêutica com o problema ambiental do descarte incorreto pelo consumidor final.. Em contraste, o Hospital 1 salientou que o número elevado de legislações ambientais, nas diferentes esferas (federal, estadual e municipal) acaba gerando informações conflitantes. Outro obstáculo enfatizado pelo Laboratório 1, Distribuidor 2, Farmácia 1 e Farmácia 3 é o processo burocrático de emissão de NF para devoluções.

O entrevistado da BHS afirmou que facilitaria se os medicamentos não fossem classificados como resíduos perigosos e que houvesse um decreto federal para LR do consumidor final, o que deverá ocorrer por vigência do Decreto $\mathrm{n}^{\circ} 10388$ de junho de 2020.

\subsection{INDICADORES DA LR}

Skinner, Bryant e Richey (2008) escreveram que uma maior integração da logística direta e reversa pode gerar também oportunidades de redução de custos para empresa, onde a avaliação econômica é um importante indicador do desempenho logístico reverso da empresa. De uma forma geral, os indicadores monitorados pelas empresas entrevistadas estão relacionados à quantidade de produtos retornados e motivos do retorno, exceto a Farmácia 3 que somente monitora os créditos gerados por uma devolução ao distribuidor ou representante do laboratório farmacêutico. Os hospitais também agregam indicadores mais amplos ligados à geração de resíduos hospitalares. 


\section{CONCLUSÃO E PESQUISAS FUTURAS}

Após extensa revisão da literatura, levantamento e análise do material coletado, este estudo permite as seguintes conclusões:

- Apesar de todos os atores da cadeia de suprimentos reconhecerem a importância da LR e praticar os processos de retorno de medicamentos, exceção aos consultórios médicos, é imprescindível a implementação do sistema de LR em um sentido mais amplo, visando a redução da contaminação ambiental, dos volumes de resíduos gerados e dos efeitos nocivos sobre a saúde humana pelo consumo indevido de medicamentos nos domicílios, o descarte adequado de medicamentos com ampla conscientização de todos os elos da cadeia e adequação às regulamentações governamentais. A implementação do sistema de LR também aponta para o potencial de geração de novos negócios, como evidenciado na prestação de serviços logísticos da empresa entrevistada BHS, quando combinada com outros sistemas de LR e outras atividades relacionadas à gestão de resíduos que estão presentes no cotidiano das diversas instituições.

- O Brasil possui uma extensa regulamentação sobre gestão de resíduos, sendo ambígua e complexa. A legislação poderia ser simplificada e mais unificada, consolidando e absorvendo as diferenças entre as diversas regiões do país. Em relação ao consumidor final, o Estado de São Paulo assumiu um papel de liderança na aplicação do plano de LR da CETESB $N^{\circ}$ 076/2018/C em abril de 2018. Este procedimento gerou um aprendizado e a necessidade de adequação se alinhando à PNRS, acarretando uma nova revisão da CETESB N ${ }^{\circ}$ 114/2019/P/C em outubro de 2019.

- Todos os atores entrevistados entendem os riscos ambientais do descarte inadequado de medicamentos, mas as práticas sustentáveis são observadas nas empresas de maior estrutura, onde os princípios da sustentabilidade estão incorporados à cultura da empresa, através de sua missão e valores, Em relação ao consumidor final, existe o entendimento da importância de conscientização sobre o seu papel no processo de LR, porém a inexistência de facilitadores e de campanhas de conscientização 
leva a uma prática inadequada do consumidor em relação à destinação final de medicamentos expirados ou que sobraram de tratamentos. $O$ primeiro passo seria conscientizar a população sobre os riscos do descarte indevido; o segundo, oferecer a ela meios para que possa fazer isso corretamente e com segurança. Há muitas iniciativas em andamento no país, mas também ainda há muito a se fazer. A população precisaria receber nos pontos de vendas ou mesmo através das bulas e embalagens dos medicamentos a orientação para o correto descarte. Esta simples ação já mobilizaria certamente o consumidor final. Com a Decisão da Diretoria da CETESB N ${ }^{\circ}$ 114/2019/P/C, já ocorreram avanços no Estado de São Paulo, mas há necessidade de um maior número de pontos de coleta para receber o descarte adequado dos medicamentos e a divulgação ao consumidor final. Se um número maior de pontos de coleta estivesse disponível em farmácias e drogarias, seria um grande facilitador para o consumidor final e para a correta destinação dos medicamentos descartados.

- Muito recentemente, junho de 2020, entrou em vigor o decreto federal $10.388 / 20$, que instituiu o sistema de LR de medicamentos. A norma inclui produtos vencidos ou em desuso em poder dos consumidores, que deverão entregá-los nas farmácias, não abrangendo aqueles descartados por prestadores de serviços de saúde públicos e privados, como hospitais, laboratórios, unidades de saúde, consultórios, clínicas médicas e odontológicas. O sistema deverá ser implementado gradualmente conforme as fases estabelecidas na normativa e participarão do sistema fabricantes, importadores, distribuidores e comerciantes de medicamentos. Este decreto federal mostra um grande avanço no descarte adequado dos medicamentos pelo consumidor final, um avanço na definição dos papéis dos elos da cadeia de suprimentos, e deverá propiciar muito material para futuras pesquisas.

- Na gestão do fluxo de devoluções, as responsabilidades e custos estão bem definidos no nível fornecedor-cliente através do contrato comercial. Já o compartilhamento de informações na cadeia ocorre na maioria dos casos por interesses comerciais e não para minimizar os desperdícios. 
- A rastreabilidade dos medicamentos é efetuada pela NF ou pelo Manifesto de transporte - MTR, não havendo um sistema de etiquetas RFID. No caso da LR do consumidor final, com a portaria $n^{\circ} 280$ de 29 de junho de 2020, o Manifesto de Transporte se tornará online com intuito de agilizar o processo de descarte e incineração dos medicamentos. Pode ser uma pesquisa futura a prática de implantação do MTR online e quantificar os ganhos obtidos.

- Quanto à classificação de um medicamento para descarte, somente há separação dos medicamentos controlados. Nos hospitais entrevistados, mencionaram que há certos medicamentos liberados pela SABESP para serem descartados no esgoto, mas por não haver esta orientação na bula ou na caixa do medicamento, há o risco de fazer LR produtos inócuos ao meio ambiente, o que valida a necessidade de programas educacionais $\mathrm{e}$ de conscientização mais amplos.

- Identificando as oportunidades de melhoria que possam minimizar os desperdícios no processo e reduzir os danos ao meio ambiente, a indústria farmacêutica terá um melhor aproveitamento dos recursos, preservando o meio ambiente e saúde, podendo até obter uma vantagem competitiva para todos os parceiros da cadeia de suprimentos.

- A LR no Brasil ainda é um grande desafio devido às dimensões territoriais, à diversidade socioeconômica, entraves logísticos e a falta de incinerador homologado pela ANVISA em todas as regiões do país. Como sugestão para pesquisas futuras, saliento a necessidade de um estudo comparativo da LR entre os estados do Brasil com base no Decreto Federal no 10388 de 05 de junho de 2020.

O tema de LR é de extrema importância, e a legislação está em contínua evolução como foi observado durante a pesquisa, desta forma, faz-se necessário um estudo rotineiro e a análise dos resultados gerados pela implementação das normas regulatórias em todos os atores da cadeia de suprimentos farmacêuticos. 


\section{REFERÊNCIAS}

ABNT. Associação Brasileira de Normas Técnicas. ABNT NBR 16457:2016. 2016. Disponível em: http://www.abnt.org.br/normas-tecnicas/normas-abnt. Acesso em: 28 jul. 2019.

AQUINO, S.; ANTONIO SPINA, G.; LEITÃO ZAJAC, M.; LUIZ LOPES, E. Reverse Logistics of Postconsumer Medicines: The Roles and Knowledge of Pharmacists in the Municipality of São Paulo, Brazil. Sustainability, v. 10, n. 11, p. 4134, 2018.

BARDIN, L. Análise de Conteúdo. Edição revista e ampliada. Edições 70, 2011.

BELLAN, N.; PINTO, T. D. J. A., KANEKO, T. M., MORETTO, L. D., SANTOS JUNIOR, N. D. Critical analysis of the regulations regarding the disposal of medication waste. Brazilian Journal of Pharmaceutical Sciences, v. 48, n. 3, p. 507-518, 2012.

BLANKENSTEIN, G. M. P.; JUNIOR, A. P. O descarte de medicamentos e a Política Nacional de Resíduos Sólidos: uma motivação para a revisão das normas sanitárias. Revista de Direito Sanitário, v. 19, n. 1, p. 50-74, 2018.

BOUZON, M.; MIGUEL, P. A. C.; RODRIGUEZ, C. M. T. Managing end of life products: a review of the literature on reverse logistics in Brazil. Management of Environmental Quality: An International Journal, v. 25, n. 5, p. 564-584, 2014.

BRASIL Agência Nacional de Vigilância Sanitária. RDC n $^{\circ}$ 222, de 28 de março de 2018. Regulamenta as Boas Práticas de Gerenciamento dos Resíduos de Serviços de Saúde e dá outras providências. 2018. Disponível em:

http://portal.ANVISA.gov.br/documents/10181/3427425/RDC_222_2018_.pdf/c5d308 1d-b331-4626-8448-c9aa426ec410. Acesso em: 12 fev. 2019.

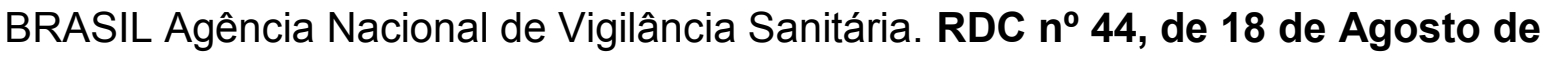
2009. Dispõe sobre Boas Práticas Farmacêuticas para o controle sanitário do funcionamento, da dispensação e da comercialização de produtos e da prestação de serviços farmacêuticos em farmácias e drogarias e dá outras providências. 2009.

Disponível em:

http://portal.anvisa.gov.br/documents/10181/2718376/rdc_44_2009_comp.pdf/2180c e5f-64bb-4062-a82f-4d9fa343c06e. Acesso em: 02 mar. $201 \overline{9}$.

BRASIL. Conselho Nacional do Meio Ambiente. CONAMA n 358 de 29 de abril de 2005. Dispõe sobre o tratamento e a disposição final dos resíduos dos serviços de saúde e dá outras providências, 2005. Disponível em:

http://www2.mma.gov.br/port/conama/res/res05/res35805.pdf. Acesso em: 12 fev. 2019. 
BRASIL. Decreto Federal $\mathbf{n}^{\circ} 10388$ de 5 de junho de 2020. Regulamenta o $\S 1^{\circ}$ do caput do art. 33 da Lei $n^{\circ} 12.305$, de 2 de agosto de 2010 , e institui o sistema de LR de medicamentos domiciliares vencidos ou em desuso, de uso humano, industrializados e manipulados, e de suas embalagens após o descarte pelos consumidores. 2020. Disponível em: http://www.planalto.gov.br/ccivil_03/_ato20192022/2020/decreto/D10388.htm. Acesso em: 19 nov. 2020.

BRASIL. Lei Federal No 12.305 de 2 de agosto de 2010. Institui a Política Nacional de Resíduos Sólidos; altera a Lei no 9.605, de 12 de fevereiro de 1998; e dá outras providências. 2010. Disponível em: http://www.planalto.gov.br/ccivil_03/_ato20072010/2010/lei//12305.htm. Acesso em: 02 mar. 2019.

BRASIL. Lei Federal № 7.735 de 22 de fevereiro de 1989. Dispõe sobre a extinção de órgão e de entidade autárquica, cria o Instituto Brasileiro do Meio Ambiente e dos Recursos Naturais Renováveis e dá outras providências, 2012. Disponível em: http://www.ibama.gov.br/sophia/cnia/legislacao/ibama/in0013-181212.pdf. Acesso em: 18 mai. 2019.

BRAVO, A. M. S.; CARVALHO, J. C. D. Challenging times to pharmaceutical supply chains towards sustainability: a case study application. International Journal of Procurement Management, v. 8, n. 1/2, p. 126-140, 2015.

CAMPOS, E. A. R.; PAULA, I. C.; PAGANI, R. N.; GUARNIERI, P. Reverse logistics for the end-of-life and end-of-use products in the pharmaceutical industry: a systematic literature review. Supply Chain Management: An International Journal, v. 22, n. 4, p. 375-392, 2017.

CENTRO DE VIGILÂNCIA SANITÁRIA. Portaria CVS n²1 de 10 de setembro de 2008. Centro de Vigilância Sanitária da Coordenadoria de Controle de Doenças da Secretaria de Estado da Saúde. Disponível em:

http://www.cvs.saude.sp.gov.br/pdf/08pcvs21.pdf. Acesso em: 19 nov. 2020.

CETESB. Decisão de Diretoria № 076/2018 de 03 de abril de 2018. Companhia Ambiental do Estado de Sâo Paulo. Estabelece Procedimento para a incorporação da LR no âmbito do licenciamento ambiental, em atendimento a Resolução SMA 45, de 23 de junho de 2015 e dá outras providências. 2018. Disponível em: https://cetesb.sp.gov.br/wp-content/uploads/2018/04/DD-076-2018-C.pdf. Acesso em: 26 fev. 2019.

CETESB. Decisão de Diretoria No 114/2019/P/C de 23 de outubro de 2019. Companhia Ambiental do Estado de Sâo Paulo. Estabelece Procedimento para a incorporação da LR no âmbito do licenciamento ambiental, em atendimento a Resolução SMA 45, de 23 de junho de 2015 e dá outras providências. 2019. Disponível em: https://cetesb.sp.gov.br/wpcontent/uploads/2019/10/DIVULGA\%C3\%87\%C3\%83O-DA-DD-114-2019-P-CProcedimento-pa-incorpora\%C3\%A7\%C3\%A3o-da-Logistica-Reversa-nolic.ambiental.pdf. Acesso em: 20 jun. 2020. 
CHOUINARD, M.; D'AMOURS, S.; AÏT-KADI, D. Integration of reverse logistics activities within a supply chain information system. Computers in Industry, v. 56, n. 1, p. 105-124, 2005

CLENDENIN, J. A. Closing the supply chain loop: Reengineering the returns channel process. The International Journal of Logistics Management, v. 8, n. 1, p. 75-86, 1997.

DAUGHTON, C. G. Cradle-to-cradle stewardship of drugs for minimizing their environmental disposition while promoting human health. II. Drug disposal, waste reduction, and future directions. Environmental Health Perspectives, v. 111, n. 5, p. 775-785, 2003.

DEMAJOROVIC, J.; AUGUSTO, E. E. F.; SOUZA, M. T. S. Reverse logistics of Ewaste in developing countries: challenges and prospects for the Brazilian model. Ambiente \& Sociedade, v. 19, n. 2, p. 117-136, 2016.

DOWLATSHAHI, S. Developing a theory of reverse logistics. Interfaces, v. 30, n. 3, p. $143-155,2000$

EISENHARDT, K. M. Building theories from case study research. Academy of management review, v. 14, n. 4, p. 532-550, 1989.

FARRADIA, Y.; BON, A. T. B.; MUHARAM, H. Internal vs External Green Supply Chain Management at Petrochemical Industry Economic Performance in Indonesia. Proceedings of the International Conference on Industrial Engineering and Operations Management Bangkok, Thailand, 5-7 mar. 2019.

FLEISCHMANN, M.; BEULLENS, P.; BLOEMHOF-RUWAARD J. M.; VAN WASSENHOVE, L. N. The impact of product recovery on logistics network design. Production and operations management, v. 10, n. 2, p. 156-173, 2001.

GLOVER, J. L.; CHAMPION, D.; DANIELS, K. J.; DAINTY, A. J. D. An Institutional Theory perspective on sustainable practices across the dairy supply chain. International Journal of Production Economics, v. 152, p. 102-111, 2014

GOVINDAN, K.; SOLEIMANI, H.; KANNAN, D. Reverse logistics and closed-loop supply chain: A comprehensive review to explore the future. European Journal of Operational Research, v. 240, n. 3, p. 603-626, 2015.

GUIDE JR, V. D. R.; WASSENHOVE, L. N. V. OR FORUM-The evolution of closedloop supply chain research. Operations research, v. 57, n. 1, p. 10-18, 2009.

GUIRGUIS, K. Medications collected for disposal by outreach pharmacists in Australia. Pharmacy world \& science, v. 32, n. 1, p. 52-58, 2010. 
INTERFARMA. Associação da Indústria Farmacêutica de Pesquisa. Logística reversa. 2020. Disponível em:

https://www.interfarma.org.br/sustentabilidade/logistica-reversa. Acesso em: 25 jun. 2020.

ISMAIL, L. B.; ALAWAMLEH, M.; ALADWAN, K.; ALRAGHEB, A. A. The relationship between green SCM practices and organisational performance: evidence from Jordanian pharmaceutical manufacturers. International Journal of Logistics Systems and Management, v. 34, n. 2, p. 172-192, 2019.

JAYARAM, J.; AVITTATHUR, B. Green supply chains: a perspective from an emerging economy. International Journal of Production Economics, v. 164, p. 234244, 2015.

JONES, O. A.; VOULVOULIS, N.; LESTER, J. N. Potential impact of pharmaceuticals on environmental health. Bulletin of the World Health Organization, v. 81, n. 10, p. 768-769, 2003.

JORGENSEN, T. H. Towards more sustainable management systems: through life cycle management and integration. Journal of cleaner production, v. 16, n. 10, p. 1071-1080, 2008.

KABIR, M. I. Reverse logistics in pharmaceutical industry. International journal of supply chain management, v. 2, n. 1, 2013.

KAINUMA, Y.; TAWARA, N. A multiple attribute utility theory approach to lean and green supply chain management. International Journal of Production Economics, v. 101, n. 1, p. 99-108, 2006.

KONGAR, E.; HAZNEDAROGLU, E.; ABDELGHANY, O.; BAHTIYAR, M. O. A novel IT infrastructure for reverse logistics operations of end-of-life pharmaceutical products. Information Technology and Management, v. 16, n. 1, p. 51-65, 2015.

KUMAR, S.; DIEVENEY, E.; DIEVENEY, A. Reverse logistic process control measures for the pharmaceutical industry supply chain. International Journal of Productivity and Performance Management, v. 58, n. 2, p. 188-204, 2009.

LEE, C. K. M.; LAM, J. S. L. Managing reverse logistics to enhance sustainability of industrial marketing. Industrial Marketing Management, v. 41, n. 4, p. 589-598, 2012.

LUNA, R. A.; VIANA, F. L. E. O papel da Política Nacional dos Resíduos Sólidos na LR em empresas farmacêuticas. Revista de Gestão Social e Ambiental, v. 13, n. 1, p. 40-56, 2019.

LUNA, R. A.; VIANA, F. L. E. Os desafios da indústria farmacêutica brasileira diante da Política Nacional de Resíduos Sólidos. Revista em Agronegócio e Meio Ambiente, v. 10, n. 1, p. 167, 2017. 
LUO, Y.; GUO, W.; NGO, H. H.; NGHIEM, L. D.; HAI, F. I.; ZHANG, J.; LIANG S.; WANG, X. C. A review on the occurrence of micropollutants in the aquatic environment and their fate and removal during wastewater treatment. Science of the total environment, v. 473, p. 619-641, 2014.

MEDEIROS, M. S. G.; MOREIRA, L. M. F.; LOPES, C. C. G. O. Descarte de medicamentos: programas de recolhimento e novos desafios. Revista de Ciências Farmacêuticas Básica e Aplicada, v. 35, n. 4, 2014.

MEREDITH, J. Building operations management theory through case and field research. Journal of operations management, v. 16, n. 4, p. 441-454, 1998.

MIGUEL, P. A. C. Estudo de caso na engenharia de produção: estruturação e recomendações para sua condução. Production, v. 17, n. 1, p. 216-229, 2007.

MISHRA, R.; NAPIER, R. Reverse logistics: Antecedents of successful implementation and firm performance effects. Journal of Supply Chain and Operations Management, v. 12, n. 2, p. 33-49, 2014.

MOORI, R. G., POPADIUK, S., MARCONDES, R. C., CARUSO, C. R. W. Alinhamento da Cadeia de Suprimentos entre a Indústria de Medicamentos e as Farmácias e Drogarias sob a Perspectiva das Dimensões da Informação. Anais Eletrônicos. Encontro Nacional de Programas de Pós-Graduação. Brasília: Enanpad, 2005.

MUSSON, S. E.; TOWNSEND, T.; SEABURG, K.; MOUSA, J. A continuous collection system for household pharmaceutical wastes: a pilot project. Journal of the Air \& Waste Management Association, v. 57, n. 7, p. 828-835, 2007.

NARAYANA, S. A.; ELIAS, A. A.; PATI, R. K. Reverse logistics in the pharmaceuticals industry: a systemic analysis. The International Journal of Logistics Management, v. 25, n. 2, p. 379-398, 2014.

NARAYANA, S. A.; PATI, R. K.; PADHI, S. S. Market dynamics and reverse logistics for sustainability in the Indian Pharmaceuticals industry. Journal of cleaner production, v. 208, p. 968-987, 2019.

OLORUNNIWO, F. O.; LI, X. Information sharing and collaboration practices in reverse logistics. Supply Chain Management: An International Journal, v. 15, n. 6, p. 454-462, 2010

PEREIRA, A. L.; BARROS, R. T. V.; PEREIRA, S. R. Pharmacopollution and Household Waste Medicine (HWM): how reverse logistics is environmentally important to Brazil. Environmental Science and Pollution Research, v. 24, n. 31, p. 24061-24075, 2017.

RAJAGOPAL, P.; SUNDRAM, V. P. K.; NAIDU, B. M. Future Directions of Reverse Logistics in Gaining Competitive advantages. A Review of Literature. International Journal of Supply Chain Management, v. 4, n. 1, 2015. 
ROGERS, D. S.; TIBBEN-LEMBKE, R. S. Going Backwards: Reverse Logistics Trends and Practices, Reverse Logistics Executive Council, Reno, NV, 1999

SHAH, N. Pharmaceutical supply chains: key issues and strategies for optimization. Computers \& chemical engineering, v. 28, n. 6, p. 929-941, 2004

SHOHAN, S.; ALI, S. M.; KABIR, G.; AHMED, S. K. K.; SUHI, S. A.; HAQUE, T. Green supply chain management in the chemical industry: structural framework of drivers. International Journal of Sustainable Development \& World Ecology, p. 1-17, 2019.

SKINNER, L. R.; BRYANT, P. T.; RICHEY, R. G. Examining the impact of reverse logistics disposition strategies. International Journal of Physical Distribution \& Logistics Management, v. 38, n. 7, p. 518-539, 2008.

SOUZA, G. C. Closed-loop supply chains: a critical review, and future research. Decision Sciences, v. 44, n. 1, p. 7-38, 2013

SRIVASTAVA, S. K. Green supply-chain management: a state-of-the-art literature review. International journal of management reviews, v. 9, n. 1, p. 53-80, 2007.

STOCHER, F. M.; SILVA, M. L.; CAPELLARI, G.; JUNIOR, P. V. C. A LR no setor farmacêutico: um estudo em Santana do Livramento. Revista Produção Online, v. 19, p. 1069-1093, 2018.

STOCK, J.; SPEH, T.; SHEAR, H. Many happy (product) returns. Harvard Business Review, v. 80, n. 7, p. 16-17, 2002

TALEB, K. N.; GUPTA, S. M. Disassembly of multiple product structures. Computers \& Industrial Engineering, v. 32, n. 4, p. 949-961, 1997.

THIERRY, M. An analysis of the impact of Product Recovery Management on Manufacturing Companies, PhD. Thesis, Erasmus University Rotterdam, The Netherlands, 1995.

TIBBEN-LEMBKE, R. S.; ROGERS, D. S. Differences between forward and reverse logistics in a retail environment. Supply Chain Management: An International Journal, v. 7, n. 5, p. 271-282, 2002.

TONANONT, A., YIMSIRI, S., JITPITAKLERT, W., ROGERS, K. J. Performance evaluation in reverse logistics with data envelopment analysis. In: IIE Annual Conference. Proceedings. Institute of Industrial and Systems Engineers (IISE), p. 764, 2008.

TONG, A. Y.; PEAKE, B. M.; BRAUND, R. Disposal practices for unused medications around the world. Environment international, v. 37, n. 1, p. 292-298, 2011 
TREBILCOCK, B. Why are returns so tough? Modern Materials Handling, v. 56, n. 11, p. 45-51, 2001.

TSAI, W.; HUNG, S.J. Treatment and recycling system optimisation with activitybased costing in WEEE reverse logistics management: an environmental supply chain perspective. International journal of production research, v. 47, n. 19, p. 5391-5420, 2009.

VIEGAS, C. V.; BOND, A.; VAZ, C. R.; BERTOLO, R. J. Reverse flows within the pharmaceutical supply chain: A classificatory review from the perspective of end-ofuse and end-of-life medicines. Journal of Cleaner Production, p. 117719, 2019.

VOLLMER, G. Disposal of pharmaceutical waste in households-a European survey. In: Green and Sustainable pharmacy. Springer Berlin Heidelberg, p. 165-178, 2010.

XIE, Y.; BREEN, L. Greening community pharmaceutical supply chain in UK: a cross boundary approach. Supply Chain Management: An International Journal, v. 17, n. 1, p. 40-53, 2012.

YE, T.; ZHENHUA, Y. Reverse logistics network: A literature review. Journal of Chemical and Pharmaceutical Research, v. 6, n. 7, p. 1916-1921, 2014

YIN, R. K. Estudo de caso: planejamento e métodos. $2^{a}$ edição trad. Daniel Grassi. Bookman, Porto Alegre, 2001.

ZHOU, L.Y.; ZHANG, Q. Research on Logistics Activity Cost Control Procedures Based on ABC in Manufacturing Enterprises. In: Applied Mechanics and Materials. Trans Tech Publications, p. 910-914, 2011. 